\title{
THE EFFECTS OF LEPTIN ON PLACENTAL DEVELOPMENT AND FUNCTION, AND OFFSPRING BEHAVIOR IN MICE
}

\author{
A Dissertation \\ presented to
}

the Faculty of the Graduate School

at the University of Missouri-Columbia

In Partial Fulfillment

of the Requirements for the Degree

Doctor of Philosophy

by

KELLY E POLLOCK

Dr. Laura Schulz, Dissertation Supervisor

MAY 2014 
The undersigned, appointed by the dean of the Graduate School, have examined the dissertation entitled

THE EFFECTS OF LEPTIN ON PLACENTAL DEVELOPMENT AND FUNCTION AND OFFSPRING BEHAVIOR IN MICE

presented by Kelly E Pollock,

candidate for the degree of doctor of philosophy

and hereby certify that, in their opinion, it is worthy of acceptance.

Dr. Laura Schulz

Dr. Kathy Timms

Dr. Rodney Geisert

Dr. Dennis Miller 


\section{DEDICATION}

This would not have been possible without the support of my family, so I dedicate this dissertation to them.

To my parents, Alan and Phyllis Ketring, who always love, support and encourage me. Thank you for believing in me, even when I did not believe in myself, and being there no matter what the outcome.

To my husband, Robert, for insisting that I relax and have fun occasionally, even though I resisted. I know it often seemed like my studies and work came first, but you were first in my heart. Thank you for sticking with me.

To my son, Raiden, for being the most amazing little boy a mother could have. You changed my life forever, and have made it is so much better. Thank you for bringing so much love and happiness into our lives.

To my grandparents, Grandma Moosie and Grandpa Dude, for sharing your wisdom, but most importantly your time and love. Thank you for so many wonderful memories and for believing that if I set my mind to something, I could do it.

I also dedicate this in the memory of my Grandma and Grandpa Spillars, Uncle Chris, Aunt Dawn and Aunt Max. Each of whom helped shape the person I am today. You are loved and missed. 


\section{ACKNOWLEDGEMENTS}

Support from all members of the Schulz lab, past and present, made this research possible: Kathleen Pennington, Jessa Schlitt, Gerialisa Caesar, and Omonseigho Esangbedo, and special thanks to Ashley Sigafoos, Jennifer Harper, Jenny Kaiser, and Matt Hruska, undergraduates who were indispensable during this study. Thanks also go to Dr. William Folk for providing support for the glucose tolerance tests for the DB/+ and WT dams at d18.5 and Dr. Kevin Fritsche for providing the diet. The University of Missouri Center for Translational Neuroscience has our greatest appreciation for helping conduct the behavioral tests. Thanks to Nick Madden, Emma Fullerton, AJ Backer and Jessica Judd for your time and dedication.

\section{Grants}

This research was supported by American Society for Reproductive Medicine, NIH HD055231 and Missouri Mission Enhancement 


\section{TABLE OF CONTENTS}

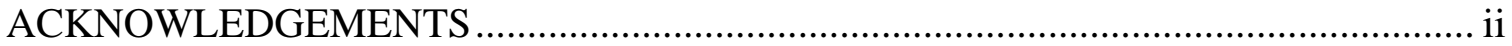

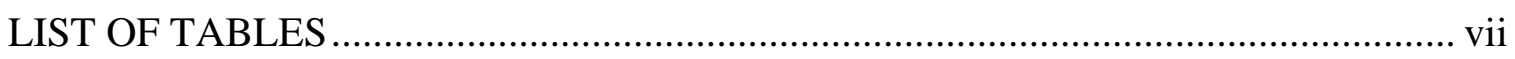

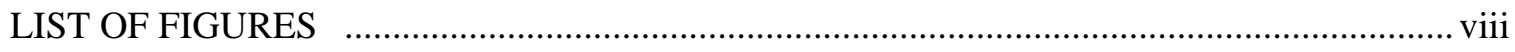

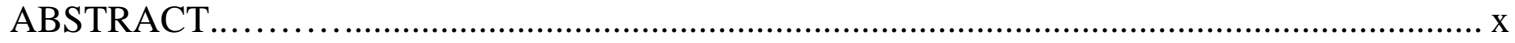

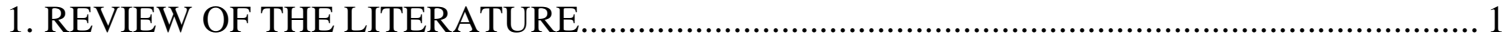

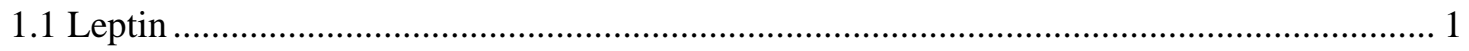

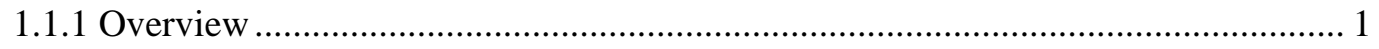

1.1.2 Structure of the Gene, mRNA and Protein of

Leptin and Its Receptors .................................................................

1.1.3 Expression of Leptin and Its Receptors...............................................

1.1.4 Regulation of Leptin............................................................................

1.1.5 Models for Leptin Research ..........................................................6

1.1.3 Leptin and Energy Homeostasis ..........................................................

1.2 Leptin and Reproduction.........................................................................

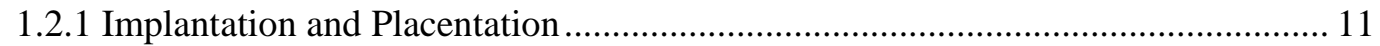

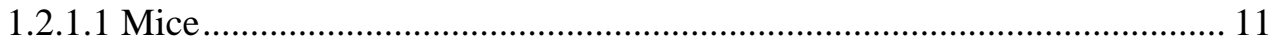

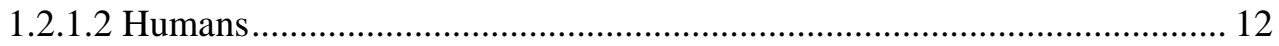

1.2.2 Leptin during Pregnancy ..................................................................13

1.2.2.1 Implantation.................................................................................. 13

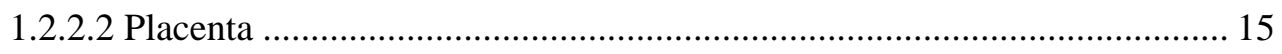

1.2.3 Leptin's Role in Pregnancy Related Disorders.. .....................................16 


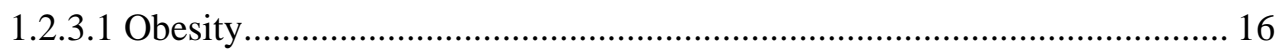

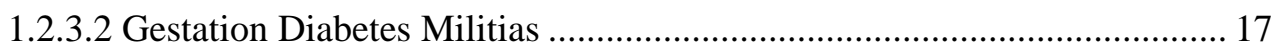

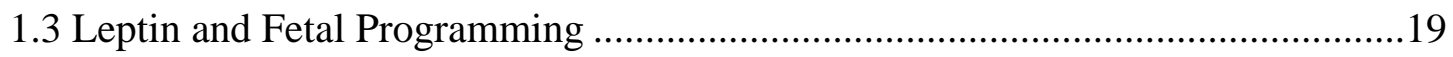

1.3.1 Developmental Origins of Health and Disease ................................................. 19

1.3.2 Leptin and Programming of Offspring Behaviors................................................ 21

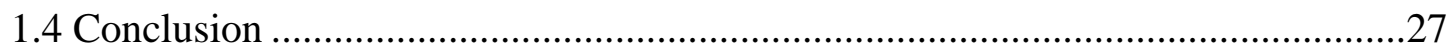

\section{EFFECTS OF LEPTIN RECEPTOR ON PLACENTAL}

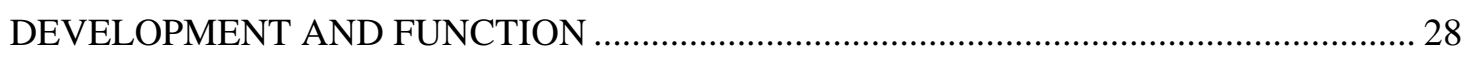

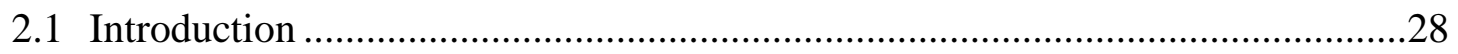

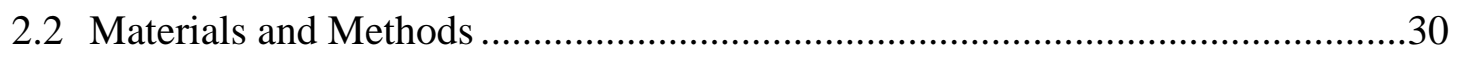

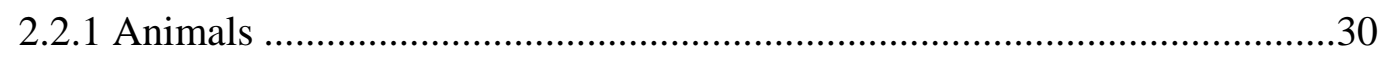

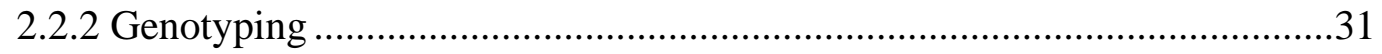

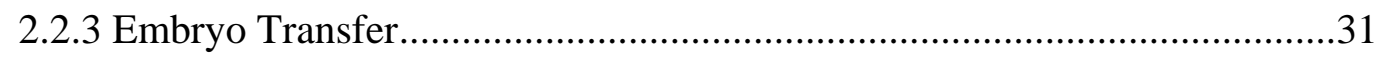

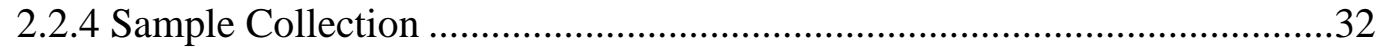

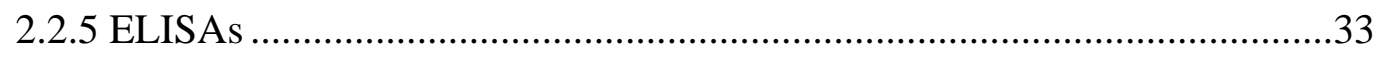

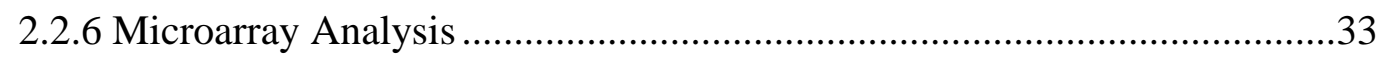

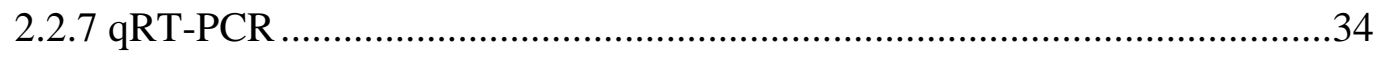

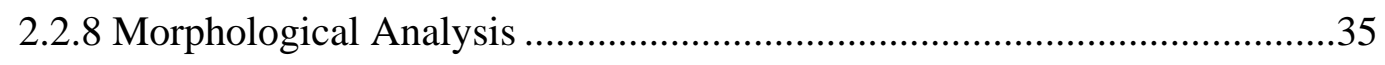

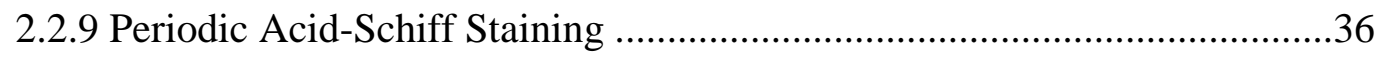

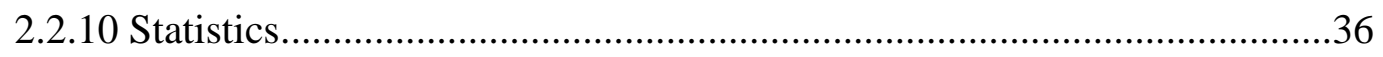

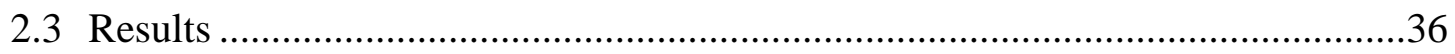

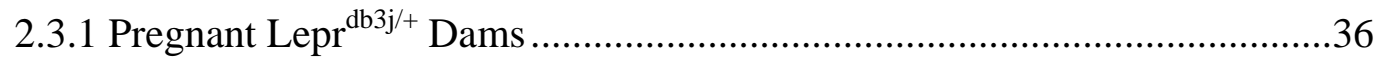

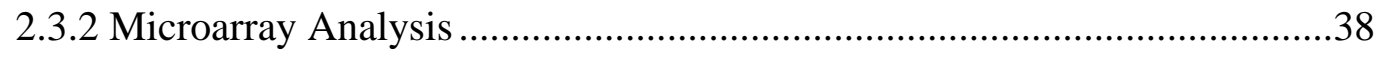




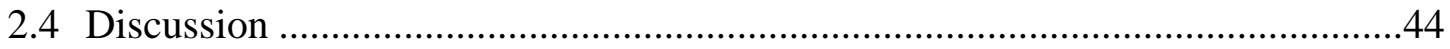

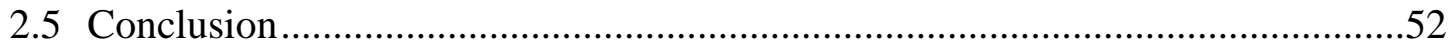

\section{HYPERLEPTINEMIA DURING PREGNANCY INCREASES}

OFFSPRING ACTIVITY AND PROTECTS OFFSPRING

FROM WEIGHT GAIN DURING ADULTHOOD ................................................................ 53

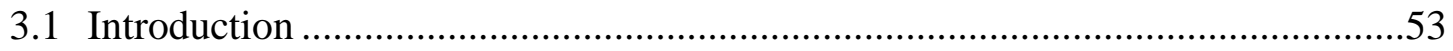

3.2 Materials and Methods ..................................................................................56

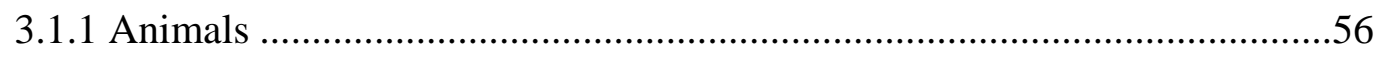

3.2.1 Experimental Design .........................................................................56

3.2.2 Lepr $^{\mathrm{db} /+}$ Model of Pregnancy Hyperleptinemia .............................................58

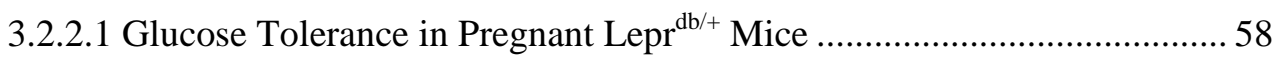

3.2..2 Developmental Programming by

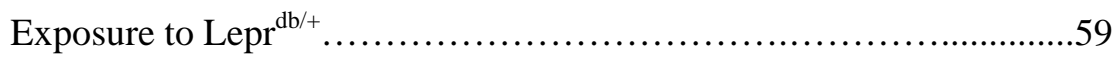

3.2.3 Leptin Infusion model of Pregnancy Hyperleptinemia ................................60

3.2.3.1 Developmental Programming by

Exposure to Leptin Infusion............................................60

3.2.4 Offspring Behavioral Tests .........................................................................61

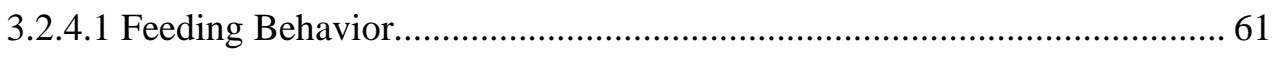

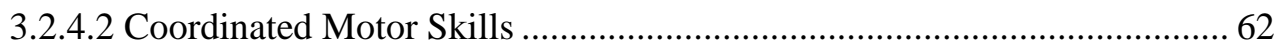

3.2.4.3 Locomotor Activity ……………………………………………………... 63

3.2.4.4 Anxiety-related Behaviors.......................................................................... 63 
3.2.5 Blood and Serum Assays..........................................................................64

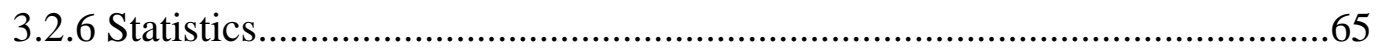

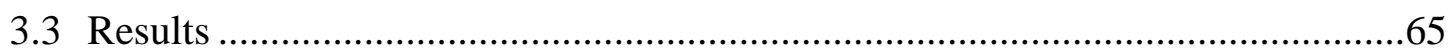

3.3.1 Maternal Glucose Tolerance, Insulin, Leptin and Weights..........................65

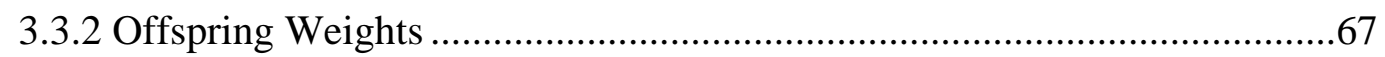

3.3.3 Offspring Feeding Behavior ......................................................................

3.3.3.1 Total Food Consumption .............................................................................. 70

3.3.3.2 Food Preference................................................................................................. 72

3.3.4 Offspring Locomotor Activity in Open Field................................................73

3.3.5 Offspring Coordinated Motor Skills..........................................................76

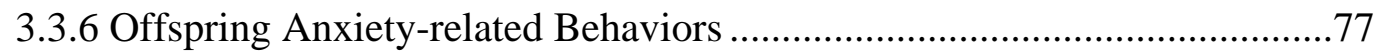

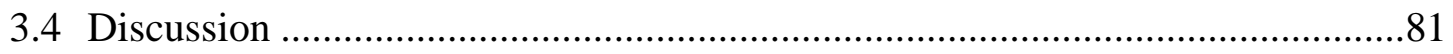

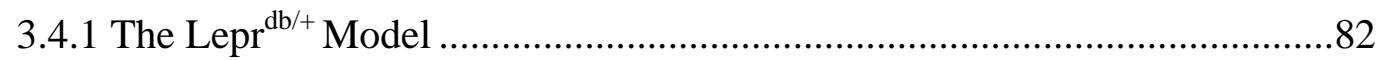

3.4.2 Hyperleptinemia Models ...............................................................................

3.4.3 Programming of Offspring Feeding Behavior and Locomotor Activity ............................................................................85

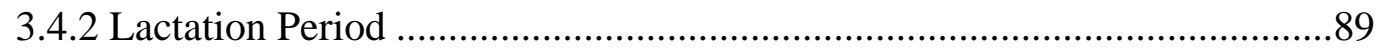

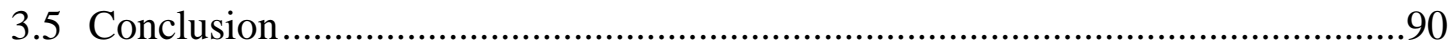

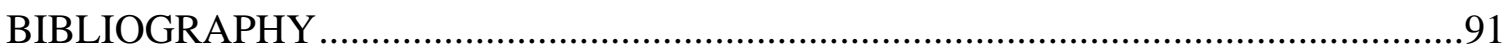

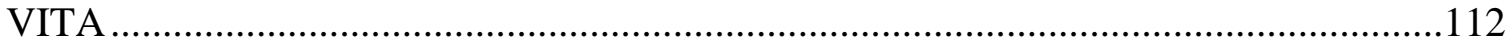




\section{LIST OF TABLES}

Table

Page

1. Embryo Transfer Data ...........................................................

2. DAVID Functional Annotation Cluster Analysis of

Differincially Expresssed Genes in Lepr $^{\mathrm{db3j} / \mathrm{db} 3 \mathrm{j}}$ Placenta.................................43

3. Solute Carrier Fold Changes from Lepr ${ }^{\mathrm{db3j} /+}$ vs. Lepr $^{+/+}$Microarray ...................................... 44

4. Selected Genes from Lepr ${ }^{\mathrm{db} 3 \mathrm{j} /+}$ vs. Lepr ${ }^{+/+}$Microarray

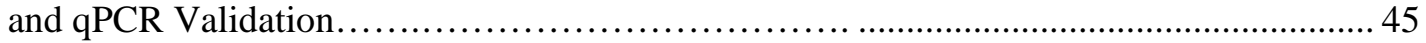

5. Average Maternal Weights and Litter Sizes of Hyperleptinemic Dams........................... 64

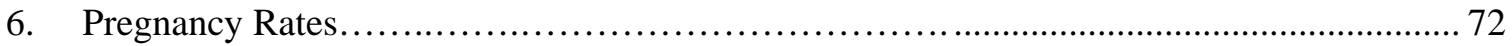

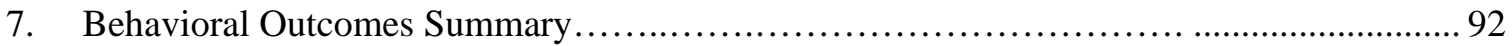




\section{LIST OF FIGURES}

Figure

Page

1. Leptin Receptor Knockout Model.................................................10

2. $\quad$ Lepr $^{\mathrm{db3j} /+}$ Maternal Leptin, Insulin and Glucose Tolerance ................................................. 41

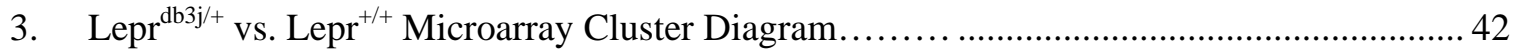

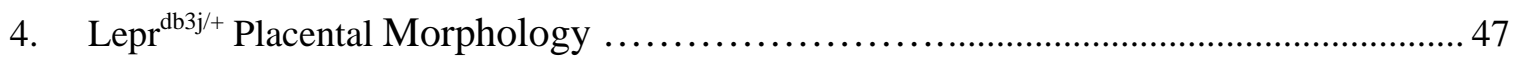

5. Maternal Hyperleptinemia Experimental Design Schematic................................................ 61

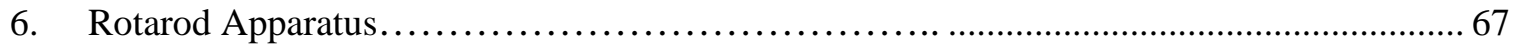

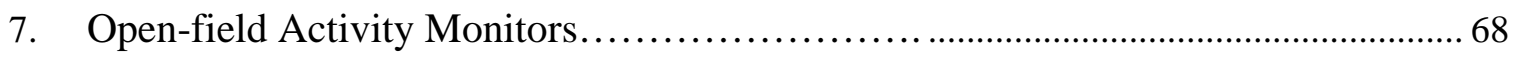

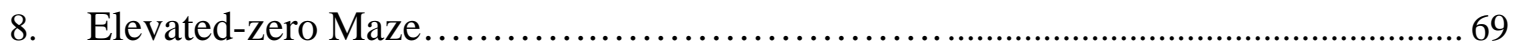

9. Hyperleptinemic Dams Glucose, Insulin and Leptin.............................73

10. Weights of Offspring from Hyperleptinemic Dams ................................................... 75

11. Food Consumption of Offspring from Hyperleptinemic Dams ..................................... 77

12. Food Preference of Offspring from Hyperleptinemic Dams ...................................... 79

13. Locomotor Activity in an Open Field of Offspring

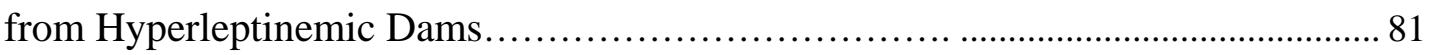

14. Coordinated Motor Skills of Offspring from Hyperleptinemic Dams ......................... 83

15. Anxiety-related Behaviors of Offspring from Hyperleptinemic Dams ........................... 85 
16. Exploratory Behaviors of Offspring from Hyperleptinemic Dams 
THE EFFECTS OF LEPTIN ON PLACENTAL DEVELOPMENT AND FUNCTION, AND OFFSPRING BEHAVIOR IN MICE

Kelly E Pollock

Dr. Laura Schulz, Dissertation Supervisor

\begin{abstract}
The nutritional and energy status of individuals is communicated throughout the body by means of leptin. This hormone also plays a role in implantation and placental development and function, as well as programming behavior via alteration of brain function. The current research provides insight into how leptin is involved in placental and fetal development. The goal of the first study was to determine the importance of the leptin receptors of the mouse conceptus in placental development and function. We utilized a leptin receptor knockout mouse model, and found significant alterations in gene expression in placentas lacking the receptor, suggesting that placental function may be altered. The goal of the second study was to determine the effect of maternal hyperleptinemia on offspring behavior. We compared wildtype offspring from two hyperleptinemic mouse models. Adult offspring from hyperleptinemic dams weighed less, and were more active than their controls. Female offspring from these dams consumed more food and had reduced preference for palatable food compared to their controls. Maternal hyperleptinemia during pregnancy protected offspring from weight gain by increasing activity. Overall, leptin affects placental gene expression, and possibly function, and offspring behaviors that influence energy homeostasis.
\end{abstract}




\section{CHAPTER 1}

\section{REVIEW OF THE LITERATURE}

\subsection{Leptin}

\subsubsection{Overview.}

Adipocytes produce a hormone referred to as leptin, which originated from the word leptós, meaning ‘thin’ in Greek (Halaas et al., 1995; Mustonen, 2003; Yang et al., 2006). It has numerous functions involving: energy homeostasis (i.e. fat storage and usage, energy expenditure, satiety, etc.) (Kowalski et al., 2001), reproduction (i.e. embryo implantation) (Yang et al., 2006), puberty and cyclicity (Ahima and Osei, 2004)) neuroendocrine pathways and brain development (Ahima and Osei, 2004), and immunity (Bernotiene et al., 2006).

Leptin (Lep), though not yet named, was found to circulate in the blood through parabiosis experiments conducted by Coleman (1973). In these experiments, a homozygous mouse with a mutation in either the $o b$ (obese; leptin) or the $d b$ (diabetes; leptin receptor (Lepr)) gene was joined to the circulatory system of a wildtype mouse. This was done by attaching the skin of the mice from the shoulder to the hip. The inflammation at the suture sites promotes microvascular formation, thus connecting the circulatory systems of the two mice (Kamran et al., 2013). The celiac arteries, which 
branch from the abdominal aorta, were also surgically connected (Coleman, 1973). The $\mathrm{Lep}^{\mathrm{ob} / \mathrm{ob}}$ and Lepr ${ }^{\mathrm{db} / \mathrm{db}}$ mice are diabetic and obese (Malik et al., 2001) due to hyperphagia, decreased energy expenditure, and increased conversion of calories into fat (Kowalski et al., 2001). They are also infertile and cold intolerant. When the circulatory systems of $\mathrm{Lep}^{\mathrm{ob} / \mathrm{bb}}$ mice were linked to wildtype mice, the Lep $\mathrm{p}^{\mathrm{ob} / \mathrm{ob}}$ mice ate less, lost weight and reversed all other symptoms. When the circulatory systems of Lepr ${ }^{\mathrm{db} / \mathrm{db}}$ mice were linked to Lep ${ }^{\mathrm{ob} / \mathrm{ob}}$ or wildtype mice, the Lepr ${ }^{\mathrm{db} / \mathrm{db}}$ mice remained the same, while the Lep ${ }^{\mathrm{ob} / \mathrm{ob}}$ and wildtype mice lost significant amounts of weight (Coleman, 1973). These results show that the $o b$ gene encodes a circulating factor, leptin, which is necessary to maintain the lean phenotype, since the Lep ${ }^{\mathrm{ob} / \mathrm{ob}}$ mice seem to lack a circulating element, but obesity is reverse when it is introduced. The $d b$ gene encodes a factor, leptin receptor, which responds to the circulating factor, since the Lepr ${ }^{\mathrm{db} / \mathrm{db}}$ mice seem to produce a circulating element but cannot respond to it (Ahima and Osei, 2004; Mustonen, 2003).

Another parabiosis study was conducted by Hervey using rats with lesions on the ventromedial nuclei of the hypothalamus (VMH) (Hervey, 1959). Rats with VMH lesions have obesity similar to the Lep ${ }^{\mathrm{ob} / \mathrm{ob}}$ and Lepr ${ }^{\mathrm{db} / \mathrm{db}}$ mice. When VMH-lesioned rats were linked to the circulatory systems of wildtype rats, the VMH-lesioned rats maintained the obese phenotype, while the wildtype rats lost weight (Hervey, 1959). This is similar to a Lepr ${ }^{\mathrm{db} / \mathrm{db}}$ mouse linked with a wildtype mouse. These results imply that a circulating factor from the $o b$ gene acts upon the $d b$ gene factor, which is located in the VMH (Ahima and Osei, 2004; Hervey, 1959). 


\subsubsection{Structure of the Gene, mRNA and Protein of Leptin and Its Receptors}

Positional cloning was the technique used to discover the gene that encodes leptin in mice (Ahima and Osei, 2004; Zhang et al., 1994). In mice this gene is located on chromosome 6. It is 13,656 base pairs in length and contains three exons (Bult et al., 2008). The mRNA is $4.5 \mathrm{~kb}$, which is transcribed into a 167 aa long polypeptide (Ahima and Osei, 2004). The N-terminus is cleaved, resulting in a 146aa circulating protein (Mustonen, 2003). The structure of the leptin protein is similar to those in the "long-chain helical cytokine family,” in that it has a group of four alpha-helices (Zhang et al., 1997).

The mouse ob gene was used to create leptin probes that were employed to discover the human homolog, which is located on chromosome 7 (Green et al., 1995). The protein coding region of the human OB gene is very similar to the mouse sequence, but only 30\% of the 3'-untranslated region is the same (Green et al., 1995). The human mRNA for leptin is similar in size and the protein is an $84 \%$ match to the mouse (Zhang et al., 1994).

The gene encoding the leptin receptor (Lepr) in the mouse is located on chromosome 4 and is 97,949bp in length (Bult et al., 2008). The LEPR gene is located on chromosome 1 in humans (Thompson et al., 1997). There are six known transcripts produced through alternative splicing from human, mouse and rat lepr genes denoted Lepr-a through $\mathrm{f}$ (Bernotiene et al., 2006). Lepr-a, Lepr-b and Lepr-c are the only transcripts that have been found in humans. However there is a soluble Lepr-e protein, which is produced by cleaving the other receptors (Maamra et al., 2001). Rats and mice have Lepr-a,b,c and e; Lepr-f has only been found in rats and Lepr-d only in mice (Bernotiene et al., 2006). 
The leptin receptor proteins are classified as part of the class I cytokine receptor family (Kowalski et al., 2001). All of the Lepr isoforms have identical ligand binding (extracellular) and transmembrane domains, except for Lepr-e, which lacks the transmembrane domain (Kowalski et al., 2001). Differences occur in the cytoplasmic (intracellular) domain. The longest isoform, Lepr-b, has both Janus kinase (JAK) and signal transducer and activator of transcription (STAT) binding motifs (Kowalski et al., 2001). The shorter isoforms only have the JAK binding motif, except Lepr-e, which lacks this domain (Kowalski et al., 2001).

Leptin binds to its receptor at the "cytokine receptor homology module 2 (CRH 2)" on the extracellular domain (Bernotiene et al., 2006). Once it is bound, a phosphorylation event activates the JAK2 pathway, which causes the phosphorylation of tyrosine-1138 (Bahrenberg et al., 2002). Then STAT transcription factors (i.e. STAT3 and STAT5) bind and become active by means of phosphorylation (Bahrenberg et al., 2002; Kowalski et al., 2001). Transcription at specific promoters is then stimulated in that cell/tissue (Bahrenberg et al., 2002). These events have only been observed with homodimers of the Lepr-b isoform (Bahrenberg et al., 2002). Lepr-a and Lepr-c isoforms may be involved in the transportation of leptin (McMinn, 2003).

\subsubsection{Expression of Leptin and Its Receptors.}

Leptin circulates through the blood and is removed by the kidneys in rats (Cumin et al., 1996). Adipose tissue is the main source of leptin production (Ahima and Osei, 2004), but other tissues have been found to produce the protein as well: stomach epithelium (rats) (Bado et al., 1998), brain and pituitary (rats) (Morash et al., 1999), placenta (in humans, but not rodents) (Masuzaki et al., 1997), fetal cartilage, bone and 
hair follicles (mice) (Hoggard et al., 1997), and skeletal muscle (mice) (Wang et al., 1998).

Leptin receptors Lepr-b and Lepr-a have both been found to be omnipresent, although Lepr-a is more highly expressed in most tissues (Kowalski et al., 2001), especially the kidneys and liver (McMinn, 2003). Brain microvessels contain high quantities of the Lepr-a and Lepr-c isoforms, which may indicate that they are involved in the transportation of leptin (McMinn, 2003). The soluble form of the leptin receptor, Lepr-e, circulates and can bind leptin. In organisms that are of normal body weight, the receptor binds around 50\% of leptin (McMinn, 2003). The Lepr-b isoform makes up 35\% of the leptin receptors produced in the hypothalamus (Kowalski et al., 2001). It is specifically expressed in the arcuate nucleus (ARC), which is associated energy with homeostasis (McMinn, 2003). Knowing the function and expression pattern of the leptin receptors may lead to therapies for human health concerns, such as obesity. Leptin could be a potential target for treatment during pregnancy for obese or diabetic women to help prevent or reduce their children's predisposition for obesity.

\subsubsection{Regulation of Leptin.}

The quantity of leptin, in organisms that are on an ad libitum diet, corresponds to the amount of adipose tissue present. This means that an increase or decrease in fat tissue results in a proportional increase or decrease in leptin production (Frederich et al., 1995).

Amount of fat is not the only regulator of leptin. Fasting results in decreased leptin levels that are disproportional to the amount of adipose tissue lost. On the other hand, eating results in a rise in leptin within hours (Saladin et al., 1995). Insulin has also been shown to regulate leptin; insulin stimulates leptin production in vitro, in mouse 
adipocyte cultures, and in vivo (Rentsch and Chiesi, 1996; Saladin et al., 1995). Steroids, such as glucocorticoids, and infections can also affect leptin production (Ahima and Osei, 2004).

In both mice and humans leptin levels are highest at night and wane during the day, and insulin may regulate this pattern (Ahima and Osei, 2004). Fasting prevents the leptin peak, and night fasting combined with daytime eating causes leptin to peak during the day in mice (Ahima and Osei, 2004). In humans, this diurnal rhythm is reduced in older adults, and is associated with increased fat accumulation and insulin resistance (Ahima and Osei, 2004). Leptin is released in a pattern of pulses throughout a 24-hour time period. The pattern is similar between males and females, but females have higher peaks (Ahima and Osei, 2004).

\subsubsection{Models for Leptin Research.}

The Lep ${ }^{\text {ob/ob }}$ mouse, mentioned above, is one of several mouse knockout models that have been used to study leptin and its receptors. They have a mutation that gives rise to a premature stop codon, thus creating a truncated protein that is degraded. This mouse model is often used in leptin research. Another knockout model is the Lepr ${ }^{\mathrm{db} / \mathrm{db}}$ mouse, also mentioned above, which has a mutation in the gene that encodes the leptin receptor (Figure 1). The mutation in the Lepr gene of Lepr ${ }^{\mathrm{db} / \mathrm{db}}$ mice causes a defect in mRNA splicing. The receptor isoform b has a segment added to it that has a stop codon at the end, causing it to be converted to isoform a, thus preventing the production of isoform b. All other isoforms are present (McMinn, 2003). These mice have the same characteristics as the Lep ${ }^{\mathrm{ob} / \mathrm{ob}}$ mice (Malik et al., 2001). This means that the long receptor isoform, Lepr-b, is very important in controlling the balance of energy (McMinn, 2003). 
A model that is similar to the Lepr ${ }^{\mathrm{db} / \mathrm{db}}$ mouse is the Lepr ${ }^{\mathrm{db} 3 \mathrm{j} / \mathrm{db} 3 \mathrm{j}}$ mouse knockout model, which has a mutation in the gene encoding the leptin receptor that causes a $17 \mathrm{bp}$ deletion in exon 11 (Figure 1). This causes the protein to become truncated 11 amino acids after the deletions, thus preventing the production of any known isoforms (Lee et al., 1997). These mice have the same characteristics as the $\mathrm{Lep}^{\mathrm{ob} / \mathrm{ob}}$ and $\mathrm{Lepr}^{\mathrm{db} / \mathrm{db}}$ mice (Kowalski et al., 2001).

Mice that are heterozygous for the leptin receptor have been used for studying leptin's role in reproduction and as a model for gestational diabetes militias (GDM). The Lepr $^{\mathrm{db} /+}$ mouse is not well defined as a model for gestational diabetes in women, even though it is considered one. Few studies have been conducted that look at gestational diabetes in these mice, and they have some conflicting findings. There may be multiple factors that contribute to the onset of gestational diabetes mellitus in the heterozygous Lepr $^{\mathrm{db} /+}$ mice, including the amount of fat in their diet during pregnancy, and number of previous pregnancies. In one study Lepr ${ }^{\mathrm{db} /+}$ females were mated at age 60 to 70 days old to Lepr ${ }^{\mathrm{db} /+}$ males. The percent fat in the diet during pregnancy was not reported. At day 18.5 of pregnancy the females underwent an overnight fast followed by a glucose tolerance test. Fasting glucose levels were higher in the Lepr ${ }^{\mathrm{db} /+}$ females and they had reduced glucose clearance compared to $\mathrm{Lepr}^{+/+}$females, which indicates that they are significantly more glucose intolerant (Ishizuka et al., 1999). Insulin levels were also measured, but weren’t significantly different. Leptin was measured and was significantly higher in Lepr ${ }^{\mathrm{db} /+}$ females before and during pregnancy compared to the $\operatorname{Lepr}^{+/+}$females (Ishizuka et al., 1999), which may indicate a predisposition for diabetes. Pups born to Lepr $^{\mathrm{db} /+}$ females were larger than their Lepr $^{+/+}$counterparts (Ishizuka et al., 1999). Two 
other studies from the same lab found similar differences using slightly different protocols. In both, females were mated at 60 to 80 days of age, and they were fasted for six hours. In the first study the percent fat in the diet was not indicated and $\mathrm{Lepr}^{+/+}$males were used for breeding (Yamashita et al., 2001), while the second used a 19\% kcal from fat diet (according to the diet data sheet) and Lepr ${ }^{\mathrm{db} / \mathrm{t}}$ males were used for breeding (Yamashita et al., 2003a). Another lab conducted studies in these mice and found no difference in glucose at gestational day 18 between Lepr $^{\mathrm{db} /+}$ and Lepr ${ }^{+/+}$females following an overnight fast. The females were at least 56 days old when mated to Lepr ${ }^{+/}$ males and they were on a three percent (by weight) fat diet (Lambin et al., 2007). The Lamping group found no differences in basal glucose levels or glucose tolerance of pregnant Lepr ${ }^{\mathrm{db} /+}$ females compared to controls when on a 13 to $18 \%$ kcal from fat diet. They put some females on a 45\% from kcal fat diet and the Lepr ${ }^{\mathrm{db} / /}$ females didn’t differ in their fasting glucose compared to the $\mathrm{Lepr}^{+/+}$females, but they had reduced glucose clearance (Harrod et al., 2011). This study also looked at glucose tolerance in multiparious and older females, but they saw no differences (Harrod et al., 2011). Taken together, it is unclear what conditions are necessary to induce GDM in the Lepr ${ }^{\mathrm{db} /+}$ mice. A controlled study looking at multiple parameters (percent fat diets, parity, age, etc) using the same procedures (fasting period, age at testing, amount of glucose, etc) is necessary to determine how to effectively use Lepr ${ }^{\mathrm{db} /+}$ as a model for GDM.

Another mouse model developed to study leptin is the Lepr ${ }^{\text {flox/flox }}$ mouse. Exon 17 of the leptin receptor gene in these mice is flanked by loxP sites, which can be used to remove this section of the gene by using Cre recombinase (Balthasar et al., 2004). When exposed to Cre, exon 17 is removed, causing a frame shift starting at the last nucleotide 
of exon 16 that creates a premature stop code in exon 18 (Figure1). The leptin receptor protein is no longer produced. Lepr ${ }^{\text {floxfllox }}$ mice not exposed to Cre have the same phenotype as wild type mice (Balthasar et al., 2004). These mice are used for conditional deletions of the leptin receptor. For example, a study was conducted using the Cre/loxP system for a tissue specific knockout. They used a POMC (neuron) promoter to control the expression of Cre recombinase, thus only POMC neurons lacked the leptin receptor, due to the exon 17 deletion (Balthasar et al., 2004). This resulted in mild obesity, increased leptin levels, and altered expression of hypothalamic neuropeptides (Balthasar et al., 2004).

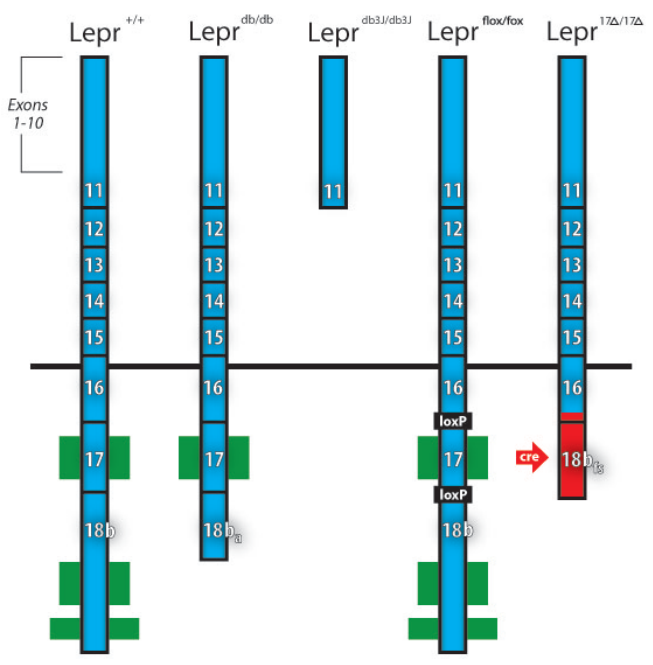

Figure 1 Leptin Receptor Knockout Models

\subsubsection{Leptin and Energy Homeostasis.}

As previously mentioned, one of the primary roles of leptin is to maintain energy homeostasis. It acts as a satiety factor through Lepr-b signaling in the hypothalamus. The arcuate nucleus (Arc) is a region of the hypothalamus that contains neurons that express orexigenic or anorexigenic factors that regulate food consumption. Neuropeptide Y (NPY) and Agoui-related protein (AgRP) are coexpressed in neurons in the Arc and 
stimulate food consumption. Conversely, Proopiomelanocortin (POMC) and cocaineand amphetamine-regulated transcript (CART), which are also coexpressed in neurons in the Arc, both inhibit food consumption (Elias et al., 1999). Both types of neurons also express leptin receptor b. Leptin levels increase with food consumption and/or increased body fat, which inhibits the orexigenic NPY/AgRP pathway and stimulates the anorexigenic POMC/CART pathway (Sahu, 2004). This effectively signals for the cessation of food consumption. Leptin also affects energy storage and expenditure; increased leptin levels signal for a decrease in energy storage and an increase in energy expenditure (Pelleymounter et al., 1995).

Less is known about the function of the short isoforms of the leptin receptor. A Lepr-a knockout mouse was developed to try to fill this knowledge gap. The Lepr-a knockout mice are slightly more glucose tolerant and have decreased fasting glucose, and when on a high fat diet they have slightly increased fat mass and body weight (Shichida and Yamashita, 2003). It is has previously been suggested that Lepr-a may act as a transporter of leptin across the blood-brain barrier. When Lepr-a knockout mice are challenged with a high fat diet, there is a reduction of leptin in the cerebrospinal fluid, which supports that hypothesis (Shichida and Yamashita, 2003). Lepr-b and c are upregulated in the Lepr-a knockouts and likely compensate for the loss, so it is difficult to make definite conclusions about its function (Bolton et al., 2003).

The soluble form of the leptin receptor, Lepr-e, acts as a binding protein for leptin. It can inhibit leptin action by preventing leptin from binding to its membrane bound receptors. On the other hand, it can decrease leptin's clearance time and increase its availability (Takahashi et al., 2003). 


\subsection{Leptin and Reproduction}

Leptin communicates the energy status of an individual to the body. When sufficient energy is not available (i.e. food supply, fat stores) leptin is low which signals the body to conserve energy. Reproductive processes, such as puberty, menstrual/estrus cycles, and pregnancy require a certain amount of energy. Females who have low body mass due to excessive exercise or insufficient food consumption often have delayed puberty, amenorrhea and fertility problems (Donato et al., 2011). Obesity, a state of excess energy, is associated with increased circulating leptin levels and reproductive complications such as infertility, but this is likely due to leptin resistance (Kitahara et al., 2003). Obese individuals also have reduced circulating Lepr-e and only $20 \%$ of leptin is bound, instead of 50\% (McMinn, 2003).

\subsubsection{Implantation and Placentation.}

To establish the vital communication between mother and fetus, implantation and placentation must occur successfully. Implantation provides the foundation for placental development. Therefore, if implantation does not occur properly, the subsequent placental development will be adversely affected. A properly functioning placenta is necessary to regulate the transfer of nutrients from the mother to the fetus, and leptin likely plays a role in that system of regulation.

1.2.1.1 Mice. Implantation in mice is invasive and similar to human implantation. After a blastocyst enters the uterus and hatches it becomes oriented on the antimesometrial side of the uterus with the inner cell mass (ICM) toward the mesometrial 
side (Bazer et al., 2009). After mating, maternal progesterone levels increase, which causes Muc-1, a mucin that lines the uterine epithelium, to be lost, allowing the blastocyst to attach (Bazer et al., 2009). The outer-layer of cells, the trophectoderm, of the embryo invades into the endometrium of the uterus (Hoegh et al., 2010). The uterus folds around the embryo, encapsulating it. Decidualization then occurs, and trophoblast giant cells invade in to the decidua and maternal vasculature (Bazer et al., 2009). This interferes with the musculature and elasticity around them (Hoegh et al., 2010). The vessels become dilated and less resistant to blood flow, due to their inability to constrict, thus supplying a sufficient amount of blood to the placenta (Hoegh et al., 2010).An ectoplacental cone is formed by the rapid proliferation of trophoblast cells. Stem cells, contained within the ectoplacental cone, engender the other trophoblast lineages; syncytiotrophoblasts and giant cells (Hoegh et al., 2010). Around day 9.5 of pregnancy, the allantois fuses with the chorion and the labyrinth layer develops. This layer is where fetal blood vessels come in contact with maternal blood (Cross et al., 1994) and is the site of nutrient, gas and waste exchange. There is also a junctional zone that is between the decidua and labyrinth, which has endocrine functions (Cross et al., 1994).

1.2.1.2 Humans. The human conceptus is even more invasive than the mouse conceptus. The ICM is oriented toward the uterine wall unlike the mouse. The embryo attaches to the uterine epithelium, syncytialization of the trophoblast cells occurs, and the embryo migrates into the uterine wall. By gestational day 21 chorionic villi are formed. They anchor the placenta and are within in the intervillous space where they are bathed in maternal blood; this is the site for the exchange of nutrients, gas and waste (Malassine et al., 2003). Stem cells, contained within the villi, engender the other trophoblast lineages; 
syncytiotrophoblasts and extravillous cytotrophoblasts (Hoegh et al., 2010).

Syncytiotrophoblasts fuse and cover the surface of the villi (Malassine et al., 2003).

Extravillous trophoblasts invade into the decidua, maternal blood vessels and

myometrium (more invasive than in mice). This prevents the blood vessels from

constricting, which allows for unrestricted blood flow (Malassine et al., 2003).

\subsubsection{Leptin during Pregnancy.}

During pregnancy plasma leptin levels increase in both mice and humans. In mice the levels begin to increase significantly at gestational day 11 and peak at day 17 (Tomimatsu et al., 1997). In humans leptin levels increase during the first two trimesters and plateau at the end of the second or beginning of the third trimester, and are two to three-fold higher than in the nonpregnant condition (Kitahara et al., 2003; Miehle et al., 2012). After delivery of the offspring, leptin returns to pre-pregnancy levels in mice and humans (Kitahara et al., 2003; Tomimatsu et al., 1997). It has been shown in the rat that the high leptin levels lead to down regulation of Lepr-b in the hypothalamus, where appetite is controlled by leptin, and increased Lepr-e, which binds leptin. This results in central leptin resistance, which may be necessary to insure adequate energy availability for fetal growth and development (Kitahara et al., 2003).

1.2.2.1 Implantation. Malik and others (2001) conducted a key experiment that demonstrated leptin as a crucial element involved in implantation. The Lep ${ }^{\mathrm{ob} / \mathrm{ob}}$ mouse was used in the study because it completely lacks circulating leptin, but retains the receptors. These mice are obese and infertile, but the phenotype can be reversed with exogenous leptin injections. In the study, these mice were supplemented with leptin, mated, and then leptin supplementation was removed at gestational day 0.5, 3.5, 6.5, 14.5 
or continued through parturition. Females that were taken off leptin at day 0.5 or 3.5 failed to remain pregnant. When leptin was removed after this point, the pregnancy went to term; however the offspring died postnatally, due to lack of mammary gland development in the dams, unless leptin administration was continued throughout pregnancy. Implantation in mice occurs between day 4.5 and 5.5 (Yoon et al., 2005); thus the results indicate that leptin is essential for pre-implantation and/or implantation itself (Malik et al., 2001). A more recent study similarly implicated leptin as a significant part of implantation. Leptin peptide antagonists, which block leptin activity, were directly injected into the uterus of pregnant mice on day 3 and this inhibited implantation (Ramos et al., 2005). These two studies show that leptin plays an important role in the implantation process.

The leptin receptor is expressed in the endometrium and embryo, the two key components involved in implantation. There is a pattern of leptin receptor expression throughout the menstrual cycle of women, but there is discrepancy over what that pattern is (Cervero et al., 2005). One research group published evidence demonstrating leptin receptor expression peaking during the early secretory phase (Kitawaki et al., 2000). In contrast, other groups indicated that leptin receptor expression was low during the early secretory phase and elevated during the proliferative and/or late secretory phases (Alfer et al., 2000; Cervero et al., 2004). All of the studies show expression of the receptor in the endometrium during the window of implantation (Cervero et al., 2005). One study found that in mice the leptin receptor is down regulated at implantation sites when compared to interimplantation sites (uterine area between implantation sites), and that it is more highly expressed in stromal tissue versus luminal epithelium (Yoon et al., 2005). In conjunction 
with other embryonic factors, it has been suggested that embryonic estrogen may be involved in the regulation of leptin receptor expression (Yoon et al., 2005). The leptin receptor is found in pre-implantation embryos, including the trophectoderm of the blastocyst (Cervero et al., 2005), although embryos lacking leptin receptor (Lep ${ }^{\mathrm{db} / \mathrm{db}}$ ) are viable.

1.2.2.2 Placenta. In humans, but not mice, the placenta produces leptin and is a major contributor to the high levels of leptin during pregnancy (Kitahara et al., 2003). Placental leptin production has been shown to be increased by human chorionic gonadotropin (hCG), which is secreted by synciotrophoblasts, and estradiol-17ß (E2) (Kitahara et al., 2003).

Leptin has been shown to affect nutrient transport in the placenta. It stimulates System A sodium dependent neutral amino acid transport (SNAT) activity in human placental explants (Jansson et al., 2003). Activity of SNAT is decreased in the syncytiotrophoblasts of pregnancies complicated by intrauterine growth restriction, and increased in pregnancies complicated by diabetes, which have high leptin levels, and result in large for gestational age fetuses (Jansson et al., 2003; Jansson et al., 2002). SNAT activity in pregnancies complicated by obesity, which also have high leptin levels, is decreased (Farley et al., 2010). Although it is still unclear what regulates SNAT activity, leptin may play a role, since altered placental SNAT activity and leptin activity seem to be associated.

Angiogenesis has been shown to be stimulated (Sierra-Honigmann et al., 1998) or blocked by leptin (Islami et al., 2003). The angiogenic factor C1qtnf6 is upregulated in food restricted mice treated with leptin (Schulz et al., 2012). Vascular endothelial growth 
factor (VEGF) secretions, which promote vascularization, are decreased by leptin (Islami et al., 2003). Arterial vascular smooth muscle cell growth is reduced by leptin in vitro (Bohlen et al., 2007). Impaired placental vascularization was found with decreased levels of fetal leptin (Huppertz et al., 2007), while another study showed no difference in placental vascularization in women with type 1 diabetes and increased fetal leptin levels (Nelson et al., 2009). The latter study is supported by another study that found no correlation between leptin and placental vascularization in sheep (Forhead et al., 2008). The precise function of leptin in angiogenesis is still unclear.

Leptin's affect on cell growth and survival is not excusive to vascular tissue. Trophoblast cell proliferation is stimulated by leptin in vitro and apoptosis is inhibited (Magarinos et al., 2007). Synthesis of DNA and protein in cultured trophoblast cells is also stimulated by leptin (Perez-Perez et al., 2010). Leptin, therefore, is important for placental growth in general.

\subsubsection{Leptin's role in Pregnancy Related Disorders}

Maternal obesity, Gestational Diabetes Mellitus (GDM) and pre-eclampsia are all associated with high levels of leptin in the maternal circulation (Cervero et al., 2006; Kautzky-Willer et al., 2001; Matsumoto et al., 2003).

\subsubsection{Obesity. Obesity is a major problem in developed and developing} countries. Metabolic syndrome, which causes six to seven percent of all deaths (Ford et al., 2010; Ono et al., 2005; Rinaudo and Wang, 2011), is associated with obesity and includes health issues such as diabetes, cardiovascular disease and non-alcoholic fatty liver disease (Ahima and Lazar, 2013). Despite having high leptin levels, obese individuals do not have reduced food intake or increased energy expenditure, suggesting 
that they are leptin resistant (Myers et al., 2010). In the United States over one-third of men and women were reported to be obese in 2011 to 2012 by the CDC (Ogden et al., 2013). Obesity is also a risk factor for reproductive dysfunction. Obese women of reproductive age have a higher incidence of polycystic ovary syndrome, and miscarriage (Guelinckx et al., 2008). Maternal obesity increases the risk of still birth and perinatal death, as well as macrosomia, which can lead to dystocia. Macrosomic offspring are more likely to become obese and/or diabetic (Guelinckx et al., 2008). Women who are obese during pregnancy have increased risk for hypertension, GDM and preeclampsia (PE) (Guelinckx et al., 2008).

In a normal pregnancy, leptin and Lepr-e levels increase, resulting in more bound leptin, which may be the cause of central leptin resistance (Kitahara et al., 2003). Pregnancies complicated by obesity are associated with higher levels of leptin and lower levels of Lepr-e compared to normal pregnancies, resulting in mostly unbound leptin (Ogier et al., 2002). The high levels of unbound leptin may cause the down regulation of Lepr-b in the placenta, due to negative feedback, resulting in placental leptin resistance (Farley et al., 2010; Tessier et al., 2013). Suppressor of cytokine signaling 3 (SOCS3), in addition to leptin, negatively regulates leptin receptor signaling. When leptin binds to its receptor it results in STAT3 triggering SOCS3 transcription, and SOCS3 is part of a negative feedback loop for leptin (Bjorbaek et al., 1999).

\subsubsection{Gestational Diabetes Militias. Two to five percent of pregnancies are} affected by GDM, glucose intolerance due to insulin resistance (Gilmartin et al., 2008). Gestational diabetes increases the risk of complications for the fetus, including: macrosomia, respiratory distress syndrome, and hypoglycemia. Long-term effects on the 
offspring consist of increased risk of obesity, childhood diabetes, impaired motor function, and attention deficit hyperactivity disorder (Gilmartin et al., 2008; Ornoy et al., 1998). Women with GDM are at higher risk for urinary tract and kidney infections, preterm labor, postpartum type 2 diabetes and preeclampsia (Gilmartin et al., 2008).

Gestational diabetes is associated with increased circulating leptin and Lepr-e compared to normal pregnancies (Kautzky-Willer et al., 2001; Lewandowski et al., 1999). High maternal and amnionic fluid leptin levels during early/mid pregnancy may predict an increased risk for developing GDM (Miehle et al., 2012). Inflammation is also associated with GDM, indicated by an increase in tumor necrosis factor alpha (TNF $\alpha$ ) and interleukin 6 (IL-6), both of which stimulate and are stimulated by leptin, creating a vicious cycle. Tumor necrosis factor alpha may be related to insulin resistance, contributing further to the diabetic condition (Miehle et al., 2012). Insulin is usually administered to women with GDM to control glucose levels, which may exacerbate the hyperleptinemia, because leptin is stimulated by insulin (Miehle et al., 2012).

The fact that leptin is elevated with maternal obesity and GDM suggests that it plays a role in either the etiologies of the disorders or perhaps as a compensatory or protective mechanism. Offspring from mothers with these disorders are predisposed to obesity and/or diabetes (Gilmartin et al., 2008; Guelinckx et al., 2008). Because of leptin’s function in energy homeostasis, it is reasonable to propose that leptin could contribute to that predisposition. 


\subsection{Leptin and Fetal Programming}

\subsubsection{Developmental Origins of Health and Disease}

Developmental Origins of Health and Disease (DOHaD) and fetal programming are the current terms for the hypothesis put forth by Barker et. al (1986), stating that conditions during prenatal life affect adult health. This idea came about when Barker and his colleagues observed a paradox concerning the rates of ischemic heart disease in England and Wales. As people became more affluent, rates of the disease increased, but the highest incidences occurred in the low income areas (Barker and Osmond, 1986). To further investigate this hypothesis, Barker and colleagues conducted a retrospective study looking at the birth and one-year weights of males born between 1911 and 1930 in a section of Hertfordshire, England. They found that males with a lower than average birth and one-year weights had high incidences of ischemic heart disease as the cause of death (Barker et al., 1989). Many more studies were done supporting the "Barker Hypothesis,” but it still received criticisms. One of the major concerns was the use of birth and oneyear weights as measures of prenatal and postnatal nourishment. Other factors can influence these weights, such as maternal health, smoking habits, and social class (Paneth and Susser, 1995).

One particular cohort of births lent itself to effectively test whether prenatal nutrition increases the risk of adult disease: the Dutch Hunger Winter cohort. In the winter and spring of 1944 to 1945 in the western region of the Netherlands, food was rationed by the German occupation due to a railway strike. All of the people in the region, regardless of social class, were restricted to 400 to 800 calories per day, including 
pregnant women (Schulz, 2010). When the war and famine ended prosperity followed. The children born around this famine have provided crucial data for testing and supporting the "Barker Hypothesis" and providing a foundation for DOHaD research (Schulz, 2010).

One study of this cohort traced a group of individuals born between November 1943 and February 1947 in Amsterdam (Roseboom et al., 2006). They were grouped according to when they were exposed to the 13 weeks of famine. There were those exposed during early, mid or late gestation or unexposed. Those considered unexposed were born before or conceived after the famine. During the famine the rations for children were never below recommended amounts (Roseboom et al., 2006). They evaluated individuals at ages 50 and 58 and found all who were exposed, no matter the stage pregnancy, had higher glucose and insulin levels compared to those who were unexposed. Birth weights were reduced in those exposed during mid and late gestation, but were normal in those exposed during early gestation. Undernutrition during mid gestation affected kidney function and bronchial development, while the ratio of carbohydrates and protein during late gestation affected adult blood pressure. Exposure to the famine during early gestation was correlated with a more atherogenic plasma lipid profile, increased fibrinogen levels and higher incidence of coronary heart disease (CHD) (Roseboom et al., 2006). Females who were conceived during the famine had higher BMIs compared to the other groups, and a high incidence of breast cancer. The fact that early gestational exposure to restricted nutrition resulted in increased adult health problems, but normal birth weights, shows that birth weight is not a good measure of prenatal nutrition or predictor of adult disease. Taken together, these findings indicate 
that maternal undernutrition during pregnancy can affect the adult health of their children and the exposures during different developmental periods have different effects (Roseboom et al., 2006).

\subsubsection{Leptin and Programming of Offspring Behaviors}

Fetal programming is not limited to maternal undernutrition. As previously discussed, maternal obesity and GDM have been found to predispose offspring to obesity and diabetes (Dabelea et al., 2000b; Drake and Reynolds, 2010). A study of nearly 3,200 mother-child pairs in Amsterdam found that maternal pre-pregnancy BMI was a major independent determinant of child weight and BMI at 14 months of age (Mesman et al., 2009). Another study of nearly 8,500 low-income mother-child pairs in the U.S. showed that maternal obesity increased the risk of children at ages 2 to 4 years of becoming obese (Whitaker, 2004). Approximately 10,000 mother-child pairs in the U.K. and Western U.S. were studied, demonstrating that children born to mothers with GDM had an increased risk for childhood obesity (Hillier et al., 2007; Lawlor et al., 2010). Studies of the Pima Indian population show that diabetes during pregnancy is a major risk factor of childhood obesity, which is clearly shown in sibling comparisons when one is born before maternal diabetes and the other born after (Dabelea et al., 2000a; Dabelea et al., 2000b). The uterine environment also affects offspring behaviors, which may contribute to the development of childhood and adult obesity.

Food consumption and preference can be altered in offspring who were affected by maternal obesity, over nutrition or diabetes (Brion et al., 2010; Kirk et al., 2009; Ong and Muhlhausler, 2011; Vucetic et al., 2010; Walker et al., 2008). A prospective study of more than 5,500 mother-child pairs and >3,000 father-child pairs demonstrated a strong 
association of maternal prenatal diet to the child's diet at age 10 compared to maternal postnatal diet and paternal diet. Maternal prenatal consumption of fats, proteins and carbohydrates was positively correlated to child consumption of the same macronutrients (Brion et al., 2010). In other words, mothers who consumed more fat during pregnancy had children who consumed more fat at age 10 , which suggests that offspring feeding behaviors may be affected by maternal prenatal nutrition and could increase their risk of obesity. Similar results have been seen in animal studies. One study in rats found that offspring from dams fed an obesogenic diet before conception, during pregnancy and lactation were hyperphagic and obese (Kirk et al., 2009). Another rat study observed an increase in food intake and a preference for high fat foods in offspring exposed to a maternal high fat diet from the last week of gestation through lactation (Walker et al., 2008). Ong and Muhlhausler (2011) investigated the effect of maternal 'junk-food' diet on offspring food preference and neurological alterations to the central reward pathways. They found that rat offspring from mothers on a 'junk-food' diet (preconception through lactation) consumed more fat as juveniles and adults. The mesolimbic reward pathway is also altered in the offspring. Juveniles from dams fed a 'junk-food' diet had increased opioid and dopamine sensitivity which increases their preference for high-fat foods. When the juveniles became adults, the reward pathway became desensitized, due to continued fat consumption, and augmented their preference for high-fat foods (Ong and Muhlhausler, 2011). Vucetic et al. (2010) also found alterations in the mesolimbic reward pathway, which increased preference for palatable foods, of offspring exposed to maternal high-fat diet during gestation and lactation, and that the alterations were due to hypomethylation of related promoters in the brain. 
Complimentary to energy intake, energy expenditure is an important component when looking at predisposition to obesity. Energy is expended in many ways including reproduction, basal metabolic rate, digestion and food processing, and thermoregulation (Garland et al., 2011).Two other ways to expend energy are voluntary/volitional exercise and spontaneous physical activity (SPA). Voluntary exercise can be defined as "locomotor activity that is not directly required for survival or homeostasis and not directly motivated by any external factor" (Garland et al., 2011). Volitional exercise can include sports, working out at a gym, and other related human activities, and possibly wheel running in rodents, although this is somewhat controversial (Garland et al., 2011). Spontaneous physical activity comprises activities related to daily life and survival. Obligatory activities encompass the acquisition of food, shelter and mates, as well as avoidance of predators and competing with rivals (Garland et al., 2011). This category may also include non-specific ambulatory behavior, grooming, rearing, fidgeting, maintaining posture, spontaneous muscle contraction, and other related behaviors. Spontaneous physical activity results in nonexercise activity thermogenesis (NEAT), which is the expenditure of energy. There is some overlap between the types of activity and the definitions vary within the field, making it difficult to compare studies (Garland et al., 2011).

There is a balance between daily energy intake and daily energy expenditure and if that balance is tipped one way or another it results in underweight or overweight individuals. Voluntary exercise and SPA can both play important roles in maintaining that balance (Garland et al., 2011). Humans in developed countries generally do not engage in much voluntary exercise, but this could potentially be offset by an increase in 
SPA, and therefore NEAT, if sedentary behaviors are reduced (Garland et al., 2011). However, many people do not need to perform spontaneous physical activities in their daily lives. Much time is now spent in front of a computer or television, or in a vehicle. Social and societal environments have significant influence on SPA, but there are also important biological components to consider. Studies have shown that SPA, and in turn NEAT, is affected by stimulation and lesioning of the brain (Garland et al., 2011; Kotz, 2008). Dopaminergenic pathways have been associated with SPA, as well as many neuropeptides that may be involved in these pathways including NPY, AgRP, leptin and orexins (Garland et al., 2011).

Many studies have shown that orexins, in particular, are central components in SPA and NEAT. Two forms of this peptide, orexin A and B, are produced in the hypothalamus. There are also two receptors. Orexin A has a higher binding affinity for both receptors and is more studied than orexin B (Sakurai et al., 1998). SPA is increased in rats when orexin A in injected into specific areas of the brain, and this effect is reversed when an antagonist for orexin receptor 1 in injected prior to orexin A (Kotz et al., 2006). Obesity resistant rats display an increase in SPA behavior compared to wildtype rats and this is associated with reduced fat mass gain (Teske et al., 2012) and increased expression of orexin (Teske et al., 2006). Despite decreased food consumption, orexin knockout mice become obese, which is likely due to a significant decrease in SPA (Hara et al., 2001). Narcolepsy in humans is associated with orexin deficiency as well as an increase in body weight (Dahmen et al., 2001; Kotagal et al., 2004), which may possibly be due to reduced SPA. 
Activity level in offspring has been shown to be altered by maternal diabetes. Children born to diabetic mothers have been found to have increased hyperactive behavior (Ornoy et al., 1998). A series of behavioral tests were given to children ages 5 to 12 from mothers with well controlled diabetes and mothers without diabetes. Children of diabetic mothers had scores on the Pollack tapper test and the Conners abbreviated parent-teacher questionnaire that indicated an increase in hyperactivity (Ornoy et al., 1998). A rat model of type I diabetes was used to study the effect of maternal arachidonic acid supplementation on offspring behavioral outcomes. Female rats were injected with streptozotocin, which is selectively toxic to the insulin producing beta islet cells in the pancreas, to artificially induce diabetes, which was either well or poorly controlled (Zhao et al., 2009). These mice were mated and fed either a control diet or a diet supplemented with arachidonic acid (AA). They found that offspring from dams with poorly controlled diabetes and/or dams supplemented with AA had increased activity in an open field maze at 8 and 12 weeks of age (Zhao et al., 2011). They also found that offspring from dams supplemented with AA, regardless of diabetic condition, performed better on a rotarod test, which tests coordinated motor skills (Zhao et al., 2011).

Other rodent studies have also shown that activity can be affected by maternal nutrition. In one study, mice dams were given a diet high in polyunsaturated fatty acids (PUFA), which can have negative effects in high amounts (Sultana et al., 2003), beginning 1 week before conception and ending after giving birth. They were placed on a regular chow diet throughout lactation. At 2, 3 and 12 months of age, offspring from dams on the high-PUFA diet were found to be more active in an open field maze (Raygada et al., 1998). Vickers and others (2000) found that adult offspring from 
undernourished rat dams became obese, which was associated with increased food intake that preceded increased weight gain. They then looked at activity and observed decreased locomotor behavior in offspring from undernourished dams (Vickers et al., 2003), which could also contribute to the development of adulthood obesity. These studies show that maternal nutritional state can program offspring activity behavior, which, in turn, affects their risk of obesity. Since leptin has is associated with maternal obesity, nutrition and diabetes, as well as SPA, it is possible the maternal leptin levels may program offspring SPA in childhood and adulthood.

Anxiety in offspring has also been shown to be affected by the in utero environment (Bilbo and Tsang, 2010; Rizzo et al., 1997a; Rizzo et al., 1997b; Walker, 2010) and is associated with inactivity and obesity (Strine et al., 2008). Children born to mothers with diabetes during pregnancy scored lower on a Sequential ability test, which shows sequential processing abilities as well as testing for disruptive anxiety (Rizzo et al., 1997a). In another study by the same group, children from diabetic mothers were more likely to be obese and that obesity was associated with an increase in anxiety (Rizzo et al., 1997b). A study in rats looked at the effect of a maternal high-saturated fat diet or high-trans fat diet versus a low-fat control diet on learning, anxiety and neurological development in offspring. Male offspring of dams from both of the high fat diet groups had increased anxiety compared to the controls (Bilbo and Tsang, 2010). Walker (2010) found that offspring from high-fat fed mothers had reduced stress response and that offspring chronically treated with leptin, for 10 days after birth, had a similar reduction in stress response. This suggests that leptin could play a role in programming offspring anxiety. 


\subsection{Conclusions}

Leptin is an essential component of reproduction, although knowledge of its functions in this complex biological process is still incomplete. Further research is required to understand the role it plays in placental and fetal development, and its relationship to obstetric disorders that have short-term and/or long-term effects on the health of the mother and fetus. Understanding more about leptin and its functions could lead to therapies for human disorders, such as obesity and gestational diabetes, for example, leptin sensitization, to overcome leptin resistance. Leptin resistance is associated with both maternal obesity and gestational diabetes and may be involved in predisposing offspring to obesity. 


\section{CHAPER 2}

\section{EFFECTS OF LEPTIN RECEPTOR ON PLACENTAL DEVELOPMENT AND FUNCTION}

\subsection{Introduction}

Leptin is a multifunctional hormone produced in adipose tissue for which serum concentrations are in proportion to fat mass (Hickey et al., 1996). It is a major regulator of energy homeostasis (Kowalski et al., 2001), and is required for successful reproduction (Malik et al., 2001). Food restriction lowers leptin levels in pregnant mice (Schlitt and Schulz, 2011) and affects placental and fetal growth (Clarke et al., 1998; Schlitt and Schulz, 2011). Leptin communicates nutritional and energy status of the body to the reproductive system, so it may also be partially responsible for the placental alterations caused by food restriction. We have recently shown that food restriction with leptin treatment alters the adaptive changes caused by the restriction (Schulz et al., 2012). Leptin in necessary for implantation (Malik et al., 2001) and stimulates trophoblast invasion, metalloproteinase activity, and blastocyst adhesion and outgrowth in vitro (Castellucci et al., 2000; Schulz and Widmaier, 2004; Yang et al., 2006). It has also been found to affect angiogenesis (Sierra-Honigmann et al., 1998), and to stimulate aminoacid transport (Jansson et al., 2003) in cultured human placental cells. The placenta is essential to the health and survival of the fetus. It is the site for the exchange of nutrients, 
gas and waste between the mother and fetus. From implantation to birth the placenta is developing to help regulate fetal growth and development and leptin plays a role in that process, but its precise functions are still unclear.

The current study investigates the effect of leptin receptor on placental gene expression and morphology. To our knowledge, there have been no in vivo studies utilizing leptin receptor knockouts to look at placental morphology and global and specific gene expression. Studying the leptin receptor in vivo allows us to observe biologically relevant data on the entire placenta, not just one cell type that is artificially cultured. This novel in vivo study utilizes a leptin receptor null mouse model (Lepr ${ }^{\mathrm{db} 3 j}$ ), which has a mutation in the gene encoding the leptin receptor that causes a 17bp deletion in exon 11. This 17bp deletion in exon 11 causes the protein to become truncated 11 amino acids after the deletion, and thus prevents the production of any known isoforms (Lee et al., 1997). In the homozygous state, Lepr $^{\mathrm{db3j}}$ mice are diabetic and obese due to hyperphagia, decreased energy expenditure, and increased conversion of calories into fat. They are also infertile and cold intolerant (Kowalski et al., 2001). A model similar to Lepr $^{\mathrm{db} 3 \mathrm{j}}$ is the Lepr ${ }^{\mathrm{db}}$ mouse, which lacks only the long form of the leptin receptor. In the heterozygous state, the Lepr ${ }^{\mathrm{db} /+}$ mice have normal a phenotype, but when pregnant they can develop gestational diabetes, and hyperleptinemia (Yamashita et al., 2001), which likely affects fetal development. Here, we mated reciprocal crosses of $\operatorname{Lepr}^{+/+}$and $\operatorname{Lepr}^{\mathrm{db} 3 \mathrm{j} /+}$ mice to measure glucose tolerance, insulin and leptin. We found no difference in glucose tolerance or insulin levels between $\mathrm{Lepr}^{+/+}$and Lepr ${ }^{\mathrm{db} 3 \mathrm{j} /+}$ dams, but Lepr ${ }^{\mathrm{db} 3 \mathrm{j} /+}$ dams do have hyperleptinemia. Therefore, in the current study, embryos were transferred from heterozygous Lepr ${ }^{\mathrm{db} 3 \mathrm{j} /+} \times$ Lepr $^{\mathrm{db} 3 \mathrm{j} /+}$ matings into wildtype recipients to examine the 
effects of embryonic and placental leptin receptor deficiency while controlling for any maternal effects. We hypothesized that lack of leptin receptors in the conceptus will alter placental gene expression and morphology.

\subsection{Materials and Methods}

\subsubsection{Animals}

All animal procedures were approved by the University of Missouri-Columbia institutional animal care and use committee and performed in accordance with the National Institutes of Health Guide for the Care and Use of Laboratory Animals. Two heterozygous Lepr ${ }^{\mathrm{db} 3 \mathrm{j} /+}$ male mice were obtained from Dr. Streamson Chua at the New York Obesity Nutrition Research Center (New York, New York). They were mated to 6 C57Bl/6 wild-type females received from Jackson Laboratory (Bar Harbor, Maine) to establish the colony. Reciprocal crosses of Lepr ${ }^{+/+}$and Lepr ${ }^{\mathrm{db} 3 \mathrm{j} /+}$ mice were made, and glucose tolerance tests were performed on pregnant wildtype and heterozygous females on day 18.5, and then they were sacrificed to collect blood for measurement of serum leptin and insulin. Lepr ${ }^{\mathrm{db} 3 j /+}$ males and females were mated to produce embryos to transfer into in C57Bl/6 wildtype recipient females (Harlan, Indianapolis, IN). Vasectomized CD1 wildtype males (Harlan, Indianapolis, IN) were used to induce pseudopregnancy in wildtype recipients. All animals were group housed, or housed in pairs after surgery, in a $12 / 12$ light/dark cycle at $68^{\circ} \mathrm{F}$ to $79^{\circ} \mathrm{F}$ with $30 \%$ to $70 \%$ humidity. 


\subsubsection{Genotyping}

Tail clips were taken from weanlings (three weeks old) or fetuses (d 18.5) for genotyping. The clips, approximately two mm in length, were placed in $200 \mu \mathrm{l}$ of lysis buffer (50 mM KCl, $10 \mathrm{mM}$ Tris-HCl (pH 8.3), two mM MgCl2, 0.1mg/ml gelatin, 0.45\% Nonidet p $40,0.45 \%$ Tween 20 ) containing $0.5 \mathrm{mg} / \mathrm{ml}$ proteinase $\mathrm{K}$, incubated at $55^{\circ} \mathrm{C}$ for three hours to overnight, then incubated at $95^{\circ} \mathrm{C}$ for 10 minutes to inactivate the proteinase K. PCR Master Mix (2x) (Fermentas.) Primers published by Lee et al. (1997), with 400ng of gDNA template, were used under the following conditions: $95^{\circ} \mathrm{C}$ for four minutes, 40 cycles of $\left(95^{\circ} \mathrm{C}\right.$ for 30 seconds, $57^{\circ} \mathrm{C}$ for 30 seconds, $72^{\circ} \mathrm{C}$ for 30 seconds). Products were visualized on a $2 \%$ agarose gel in a $5 \mathrm{mM}$ borax buffer (pH8.3) at 70 volts. The Lepr ${ }^{+/+}$mice produce a band that is 180 base pairs long; the Lepr ${ }^{\mathrm{db3j} / \mathrm{db} 3 \mathrm{j}}$ band is 163 base pairs and Lepr ${ }^{\mathrm{db} 3 j / t}$ have both bands.

\subsubsection{Embryo Transfer}

Embryos, of all three genotypes (Lepr $\left.{ }^{\mathrm{db} 33 / \mathrm{db} 3 j}, \operatorname{Lepr}^{\mathrm{db} 3 j /+}, \operatorname{Lepr}^{+/+}\right)$, from Lepr ${ }^{\mathrm{db} 3 j /+} \mathrm{X}$ Lepr $^{\mathrm{db} 3 j /+}$ crosses were flushed from the uteri of donor females on gd3.5 and placed in warmed $\left(37^{\circ} \mathrm{C}\right) \mathrm{CZBH}($ EmbryoMax CZB Medium with Phenol Red (Millipore) with 22mM HEPES) (Life Technologies, place) until they were transferred. Isoflurane gas was used to anesthetize gd2.5 pseudopregnant recipient females. The recipient ovary was exteriorized through a small incision parallel to the spinal column just enough to have access to the uterotubal junction, and a Dieffenbach vessel clip was attached to the fat pad to hold the tissue in place. A Stripper pipette tip (Origio MidAtlantic Devices, Mount Laurel, New Jersey) was then inserted into the uterus via an incision in the oviduct, and the embryos were expelled into the lumen. The ovary and uterus were placed back into 
the body cavity and the incision closed. For analgesia, 0.05 mg of Prevail (flunixin meglumine) (VetOne) was given via subcutaneous injection. Thirty-four transfer surgeries were performed with 13 successful pregnancies (38\% success rate). Refer to Table 1 for the number of embryos transferred, number of fetuses and fetal genotypes.

Table 1 Embryo Transfer Data

\begin{tabular}{cccccc}
\hline & & & \multicolumn{2}{c}{$\begin{array}{c}\text { \# of fetuses of each } \\
\text { genotype }\end{array}$} \\
\cline { 3 - 6 } $\begin{array}{c}\text { Recipient } \\
\text { Dam ID }\end{array}$ & $\begin{array}{c}\text { \# embryos } \\
\text { transferred }\end{array}$ & $\begin{array}{c}\text { \# of } \\
\text { fetuses }\end{array}$ & WT & $3 \mathbf{3 j} / 3 \mathrm{j}$ & $\mathbf{3 j / +}$ \\
\hline 33 & 12 & 7 & 2 & 1 & 4 \\
40 & 4 & 2 & 0 & 0 & 2 \\
42 & 8 & 1 & 0 & 1 & 0 \\
72 & 13 & 4 & 1 & 1 & 2 \\
100 & 7 & 3 & 2 & 1 & 0 \\
123 & 8 & 3 & 2 & 0 & 1 \\
145 & 9 & 4 & 0 & 1 & 3 \\
169 & 12 & 4 & 1 & 1 & 2 \\
173 & 8 & 7 & 1 & 4 & 2 \\
176 & 9 & 3 & 1 & 0 & 2 \\
185 & 10 & 3 & 1 & 0 & 2 \\
569 & 8 & 6 & 1 & 1 & 4 \\
588 & 8 & 1 & 0 & 0 & 1 \\
\hline & & & & &
\end{tabular}

\subsubsection{Sample Collection}

At day 18.5 of gestation, pregnant females from reciprocal crosses were fasted for six hours and then given $1 \mathrm{mg} / \mathrm{g}$ body weight of glucose via intraperitoneal injection. Blood glucose levels were measured at 0, 15, 20, 30, 60, and 120 minutes following glucose administration using a OneTouch Ultra Glucose Meter and test strips (Life Scan, Inc.). Females were then euthanized via $\mathrm{CO}_{2}$ and cervical dislocation for sample 
collection. Maternal blood was collected via cardiac puncture for serum, placed in $1.5 \mathrm{ml}$ microcentrifuge tubes and centrifuged at $1 \mathrm{xg}$ for 12 minutes at $4^{\circ} \mathrm{C}$. Serum was siphoned off and placed in new tubes, then stored at $-20^{\circ} \mathrm{C}$ until analysis.

Pregnant recipients from the embryo transfers were also euthanized at day 18.5 of gestation. The uterus was removed, leaving some decidua, and each conceptus was separated after noting its location. The placentas were carefully detached from the umbilical cords and uterus. Placental and fetal weights were recorded. Each placenta was cut in half. One half was fixed in $4 \%$ paraformaldehyde for morphological analysis. The other half was placed in TriReagent (Sigma, St. Louis, MO) and stored at $-80^{\circ} \mathrm{C}$ until RNA isolation was performed. Fetal tails were placed in lysis buffer for genotyping, as described above.

\subsubsection{ELISAs}

A rat/mouse insulin ELISA (Millipore, St. Charles, MO) was used to determine maternal serum insulin concentrations in pregnant wildtype and $\mathrm{Lepr}^{\mathrm{db} 3 \mathrm{j} /+}$ females from reciprocal crosses. The manufacturer's assay procedure was followed, with the primary antibody incubation period extended to overnight (intrassay variation: 5.9\%). A mouse leptin ELISA kit (Millipore, St. Charles, MO) was used to determine maternal leptin concentrations according to manufacturer's instructions, with the primary antibody incubation period extended to overnight (intrassay coefficient of variation: 9\%).

\subsubsection{Microarray Analysis}

There were five litters that had at least one wildtype and one Lepr ${ }^{\mathrm{db} 3 \mathrm{~J} / \mathrm{db} 3 \mathrm{~J}}$ placenta, and only these were used to control for any maternal effect. Two placentas, one of each genotype, from each of the five litters were used for microarray analysis. Placental samples stored in TriReagent (Sigma, St.Louis, MO) were thawed, then homogenized 
and phases separated according to manufacturer's instructions. The RNA was then purified by using the RNEasy Mini Kit (Qiagen, Valencia, CA) per manufacturer's instructions. RNA was sent to GenUs Biosystems (Northbrook, IL) for microarray analysis. Mouse whole-genome arrays (design ID 026655; Agilent) containing >39,000 probes were scanned on an Agilent G2565 Microarray Scanner. Data were analyzed with Agilent Feature Extraction and GeneSpring GX v7.3.1 software. Expression was considered to be different between wildtype and leptin receptor null placentas if expression was $>150 \%$ or $<66.7 \%, \mathrm{P}<0.05$. Gene expression in both placentas from one dam was divergent from the placentas from the other 4 dams. As this dam had been observed to be in labor at the time of collection, results from these placentas were excluded from all analyses.

The functional annotation clustering feature of the DAVID Bioinformatics Resource (Dennis et al., 2003) was used to categorize genes to determine what biological pathways may be affected by altered gene expression.

\subsection{7 $q R T-P C R$}

Real-time RT-PCR analysis was used to validate selected array results, by using the same RNA samples analyzed by microarray. Reverse transcription was carried out with Superscript III (Invitrogen, Carlsbad, CA) with random hexamer primers via manufacturer instructions. Quantitative PCR on selected genes was performed with $\mathrm{RT}^{2}$ SYBR Green ROX qPCR Mastermix (Qiagen, Valencia, CA) on an Applied Biosystems 7500 real-time PCR system using validated primers from Integrated DNA Technologies (Coralville, IA). Primers for Pcdh12, Grb10, Gcm1, Cpt1b and Acacb were designed using Primer Express software (Applied Biosystems/Life Technologies), except 
Esx1(Schaiff et al., 2007), Hprt (Pattyn et al., 2006), which have been previously published.

\subsubsection{Morphological Analysis}

Morphological analysis was conducted on placentas from litters containing at

least one wildtype and one Lepr ${ }^{\mathrm{db} 3 J / \mathrm{db} 3 \mathrm{~J}}$ placenta. Fixed placental halves were embedded in paraffin with the cut-face down (RADIL, Columbia, MO). Three pairs of serial 5- $\mu \mathrm{m}$ sections were cut at 50- $\mu \mathrm{m}$ intervals from each placenta and were either stained with hematoxylin and eosin (H\&E) (RADIL, Columbia, MO) or Periodic Acid-Schiff (PAS). Placentas stained with H\&E were used for measuring total placental, junctional zone and labyrinth zone areas. Images of overlapping sections of each placenta were taken with a 4X objective lens on an Olympus IX81 microscope, then arranged and aligned into a single image of the entire placental cross section.

Placentas from recipients carrying any combination of embryonic genotypes were included in the analyses of the placental areas, because statistical analysis of placentas coming only from dams carrying both genotypes indicated that the dam did not have an effect. Placental sections stained with PAS were used to identify glycogen cell (GC) areas in the junctional zone, and maternal and fetal blood space areas in the labyrinth zone. Three different placental sections from each mother were used to determine the average combined GC areas. Overlapping pictures of the junctional zone were taken with a 20X objective lens, then arranged and merged by using Adobe ${ }^{\circledR}$ Photoshop ${ }^{\circledR}$ CS4 Photomerge.

To measure maternal and fetal blood space areas, five sections of the labyrinth zone from one PAS stained placenta from each mother were photographed with a 40X 
objective lens. Fetal blood spaces were identified by the staining of the basement membrane which outlines them and the presence of nucleated red blood cells. Areas were measured by using the freehand selection tool and area calculation feature of ImageJ software (NIH).

\subsubsection{Periodic Acid-Schiff Staining}

Unstained placental sections mounted on slides were deparaffinized and hydrated using xylene substitute followed by decreasing ethanol washes and ending in deionized water. The Periodic Acid-Schiff (PAS) Staining System (Sigma-Aldrich) was used to stain placental sections per manufacturer's instructions. Tissues were counterstained with hematoxylin, then dehydrated. Permount (Fisher Scientific) and coverslips were then applied to mount and preserve the tissue staining.

\subsubsection{Statistics}

Paired t-test was used to analyze the microarray data. All other comparisons were analyzed by the Student's t-test.

\subsection{Results}

\subsubsection{Pregnant Lepr ${ }^{d b 3 j /+}$ Dams}

Pregnant heterozygous Lepr ${ }^{\mathrm{db} 3 j /+}$ females had significantly higher leptin than $\mathrm{Lepr}^{+/+}$controls at day 18.5, but their insulin levels and response to glucose were not significantly different (Figure 2). 
A

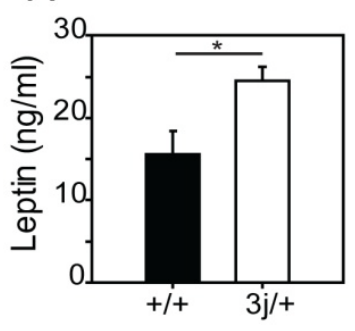

$\mathrm{B}$

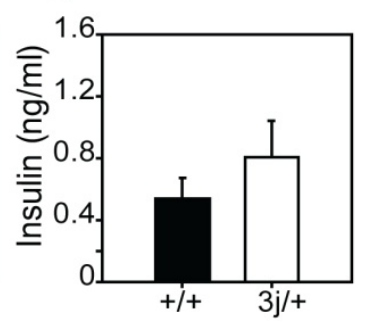

C

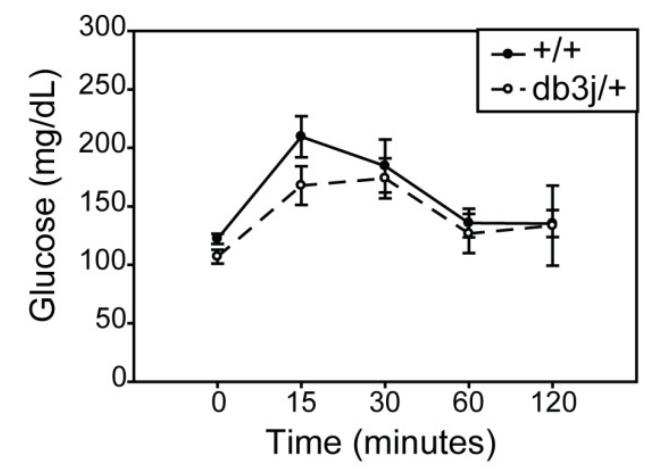

Figure 2. Lepr $^{\mathrm{db} 3 \mathrm{j} /+}$ Maternal Leptin, Insulin and Glucose Tolerance. Day 18.5 maternal serum (A) leptin and (B) insulin concentrations. (C) Maternal glucose tolerance test. (wt, n=3; 3j/+, n=4) (t-test, * $\left.{ }^{*}<0.05\right)+/+$, Lepr $^{+/+} ; 3 \mathrm{j} /+$, Lepr $^{\mathrm{db} 3 \mathrm{j} /+}$ 


\subsubsection{Microarray Analysis}

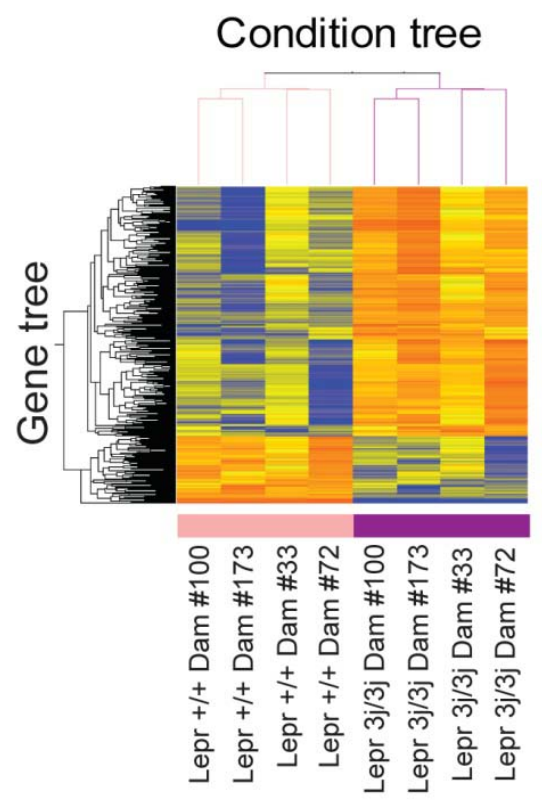

Figure 3. Lepr $^{\mathrm{db3j/t}}$ vs. Lepr ${ }^{+/+}$Microarray Cluster Diagram. Differentially expressed genes ( $>1.5$ fold, Paired T-test p-value $<0.05,413$ probes) in Lepr ${ }^{\mathrm{db3} 3 / \mathrm{db} 3 \mathrm{j}}$ vs. Lepr ${ }^{++}$are displayed as normalized to the $75^{\text {th }}$ percentile intensity of each array and further normalized to the median gene expression across eight samples. Red=High expression, Yellow=Medium expression, Blue=Low expression

Gene expression in wildtype and leptin receptor null placentas from the embryo transfer surgeries were analyzed via whole-genome microarray (GEO accession no. GSE38095). There were 413 differentially expressed genes detected by microarray analysis and the four placentas in each genotype clustered tightly (Figure 3). DAVID functional annotation clustering was used to categorize genes to determine which biological pathways were affected by ablation of placental leptin receptor (Table 3). The most overrepresented functional clusters (one and two) identified by the DAVID analysis of the 325 upregulated genes in the lepr-null placentas were related to transport, such as hydrogen and cation symporter activity, and carboxylic acid, organic acid, amine and amino acid transport. There were seven solute carrier (Slc) family genes listed in those 
two clusters of the 14 genes that were altered on the microarray. Twelve of the Slc genes were upregulated in the lepr-null placentas (Table 3). The $3^{\text {rd }}$ cluster in the list of upregulated genes is associated with membrane coat, which is also involved in transport activity and transport of cations, hydrogen, sugar and carbohydrates (Table 2). There were 5 other clusters of genes that had significant enrichment scores (See Table 2). There were only 2 clusters with significant enrichment scores in the DAVID analysis using the list of 88 genes down-regulated in the lepr-null placentas (Table 2). The first set of genes was categorized into signal, secreted, extracellular or disulfide bond. The second cluster contains genes associated with the enzymes and enzyme activity involving the breakdown of proteins.

Table 2. TheDAVID Functional Annotation Cluster Analysis of Differincially Expresssed Genes in Lepr ${ }^{\mathrm{db} 3 \mathrm{j} / \mathrm{db} 3 \mathrm{j}}$ Placentas

\begin{tabular}{|c|c|c|c|c|}
\hline Cluster & Categories & $\begin{array}{l}\text { Enrichment } \\
\text { Score }\end{array}$ & $\begin{array}{l}\text { \# of } \\
\text { Genes }\end{array}$ & Selected Genes \\
\hline \multicolumn{5}{|c|}{ Up regulated in lepr-null placentas } \\
\hline 1 & transport & 1.85 & 7 & Slc36a2, Slc35a5, Slc2a4, Slc12a8, Slc5a11, Slc1a5, Slc16a3 \\
\hline 2 & transport & 1.52 & 7 & Slc36a2, Slc35a5, Slc2a4, Slc12a8, Slc5a11, Slc1a5, Slc16a3 \\
\hline 3 & membrane coat & 1.3 & 9 & Tfre, Clen5 \\
\hline 4 & $\begin{array}{l}\text { Cyotoskeleton and non- } \\
\text { membrane bound orgnaelles }\end{array}$ & 1.28 & 30 & Plk4,Rps6kb1 \\
\hline 5 & $\begin{array}{l}\text { enzyme activity and } \\
\text { signaling }\end{array}$ & 1.23 & 22 & Grb10, Grpel1 \\
\hline 6 & $\begin{array}{l}\text { membrane, cell, vasicular } \\
\text { and insoluble fractions }\end{array}$ & 1.2 & 17 & Cpt1b, Slc2a4 \\
\hline 7 & ion binding & 1.14 & 54 & Slc12a8, Slc5a11, Scl26a4, Trp63 \\
\hline 8 & biosynthetic prcesses & 1.14 & 8 & Mthfr, Dhfr, Acacb \\
\hline \multicolumn{5}{|c|}{ Down regulated in lepr-null placentas } \\
\hline 1 & $\begin{array}{l}\text { signal, secteted, } \\
\text { extracellular, disulfide bond }\end{array}$ & 2.47 & 22 & Prl3d1, Htr1d \\
\hline 2 & enzymes, enzyme acitivity & 1.33 & 12 & Ggt1, Pgc \\
\hline
\end{tabular}


Table 3. Solute Carrier Fold Changes from Lepr ${ }^{\mathrm{db} 3 \mathrm{j} /+}$ vs. Lepr ${ }^{+/+}$Microarray

\begin{tabular}{lcc}
\hline Gene & Fold Change & P-Value \\
\hline SIc36a2 & 2.44 & 0.02 \\
SIc35a5 & 2.35 & 0.02 \\
SIc2a4 & 2.15 & 0.03 \\
SIc22a3 & 1.96 & 0.03 \\
SIc12a8 & 1.94 & 0.01 \\
SIc38a9 & 1.85 & 0.05 \\
SIc26a4 & 1.69 & 0.05 \\
SIc13a4 & 1.60 & 0.03 \\
SIc5a11 & 1.59 & 0.04 \\
SIc27a3 & 1.58 & 0.03 \\
SIc1a5 & 1.56 & 0.03 \\
SIc16a3 & 1.52 & 0.02 \\
SIc6a4 & 0.64 & 0.02 \\
\hline
\end{tabular}

Several of the genes from the microarray were of interest due to their involvement in placental invasion or morphological development. Stathmin 1 (Stmn1), Storkhead box 1 (Stox1), Prolactin family 3, subfamily d, member 1 (Prl3d1; formerly placental lactogen 1 (Pl-1) ) and Autophagy related 4C, cysteine peptidase (Atg4c) have all been associated with placental invasion and were down regulated in the Lepr-null placentas (Table 4). Histone deacetylace 1 (Hdac1) was down regulated in the lepr-null placentas, while DNA methyltransferase 3 cofactor (Dnmt3l) was upregulated (Table 4), but both are involved in placental morphological development. Scl6a4, which transports serotonin across the placenta, and Scl22a3, which is involved in serotonin degradation, were down regulated and up regulated respectively (Table 4). 
Table 4. Selected Genes from Lepr ${ }^{\mathrm{db} 3 j /+}$ vs. Lepr ${ }^{+/+}$Microarray and qPCR Validation

\begin{tabular}{lcccc}
\hline & \multicolumn{2}{c}{ Microarray } & \multicolumn{3}{c}{$\mathrm{qPCR}$} \\
${ } }$ & Fold Change P-Value & Fold Change P-Value \\
Gcm1 & 4.09 & 0.04 & 1.78 & 0.34 \\
Acacb & 1.76 & 0.02 & 0.89 & 0.47 \\
Grb10 & 1.69 & 0.03 & 1.10 & 0.43 \\
Cpt1b & 1.67 & 0.03 & 1.47 & 0.17 \\
Dnmt31 & 1.56 & 0.03 & - & \\
Prl3d1 & 0.58 & 0.05 & - & \\
Hdac1 & 0.57 & 0.003 & - & \\
Stox1 & 0.52 & 0.01 & - & \\
Stmn1 & 0.41 & 0.02 & - & \\
Htr1d & 0.41 & 0.01 & - & \\
Atg4c & 0.21 & 0.001 & - & \\
Esx1 & - & & 1.18 & 0.31 \\
Pcdh12 & - & & 0.99 & 0.41 \\
\hline
\end{tabular}

Genes of interest from the microarray were selected for verification by quantitative Polymerase Chain Reaction (qPCR). Glial cells missing 1 (Gcm1), Acetylcoenzyme A carboxylase beta (Acacb), Carnitine palmitoyltransferase 1b (Cpt1b), Growth factor receptor bound substrate 10 (Grb10) were all up-regulated in lepr-null placentas on the microarray (Table 4). Protocahherin-12 (Pcdh12) and Esx Homeobox 1 (Esx1), markers of the glycogen cell and syncytiotrophoblast lineages, respectively, were unchanged in the microarray, and PCR (Table 4). Gcm1, Grb10 and Cpt1b showed fold-differences in the qPCR analysis between Lepr null and wildtype placentas similar to those observed by microarray (Table 4); however there were no significant differences. 


\subsubsection{Placental and Fetal Weights and Morphology}

Litter sizes of one to seven, averaging at four, were observed following 13 successful embryo transfers (Table 1). After exclusion of one dam that was in labor at the time of collection, data were collected from 10 litters had at least one wildtype or Lepr $^{\mathrm{db} 3 J / d \mathrm{~b} 3 \mathrm{~J}}$ conceptus. There were no statistically significant differences in fetal or placental weights, but the latter trended lower in leptin receptor nulls $(\mathrm{p}=0.28$ and 0.051 , respectively) (Figure 4). The ratio of fetal to placental weight was not different either

\section{(Figure 4).}

We assessed placental development by examining several morphological parameters:junctional zone, labyrinth zone and total placental surface areas, which were traced by hand and measured in ImageJ. The junctional zone/labyrinth zone ratio was then calculated. The glycogen cell size, and maternal and fetal blood space surface areas, were also traced by hand and calculated in ImageJ (Figure 4). There were no significant differences, though the junctional zone/labyrinth zone ratio trended lower in the lepr-null placentas $(\mathrm{p}=0.16)$. 

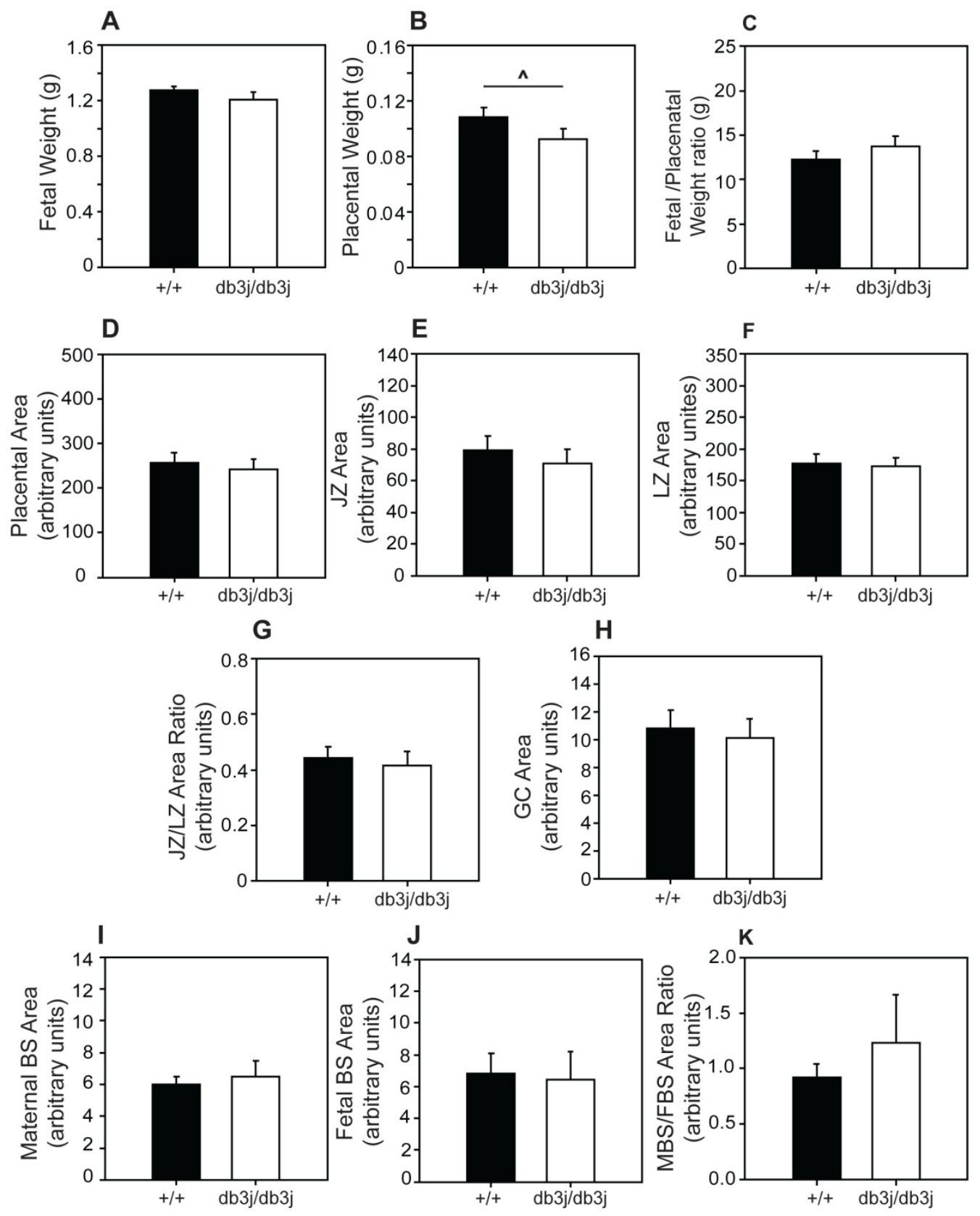

Figure 4. Lepr $^{\mathrm{db} 3 \mathrm{j} /+}$ Placental Morphology. (A) Average fetal wet weights. (B) Averange placental wet weights. (C) Fetal/placental weight ratio (D) Total placental area (junctional zone plus labyrinth zone areas). (E) Cross-sectional area of the junctional zone and (F) labyrinth zone. (G) Junctional Zone/Labyrinth zone ratio. (A-G: Lepr $^{+/+}$, $\mathrm{n}=10$; Lepr $\left.{ }^{\mathrm{db3j} / \mathrm{db3j}}, \mathrm{n}=9\right)(\mathbf{H})$ Glycogen cell areas $\left(\operatorname{Lepr}^{+/+}, \mathrm{n}=6\right.$; $\left.\operatorname{Lepr}^{\mathrm{db3j} / \mathrm{db3j}}, \mathrm{n}=6\right)(\mathbf{I})$ Maternal and (J) Fetal blood space areas. (K) Maternal/Fetal blood space area ratio. (I-K: $\mathrm{Lepr}^{+/+}, \mathrm{n}=6$; Lepr ${ }^{\mathrm{db3j} / \mathrm{db} 3 \mathrm{j}}, \mathrm{n}=7$ ) (t-test, $\left.\wedge \mathrm{p}=0.051\right)+/+$ Lepr $^{+/+} ; \mathrm{db3j} / \mathrm{db3j}, \mathrm{Lepr}^{\mathrm{db3j} / \mathrm{db3j}}$; BS, blood space; GC, glycogen cells F, fetal; JZ, junctional zone; LZ, labyrinth zone; $\mathrm{M}$, maternal; P, placental 


\subsection{Discussion}

The microarray analysis showed that knocking the leptin receptor out in the placenta had a significant effect on gene expression. Although the microarray was not validated by qPCR, there are genes of interest that could be the focus of future investigations. The most overrepresented set of genes were solute carrier (Slc) family genes. This is important because the main function of the placenta is to transport nutrients, gas and waste between the mother and fetus, and these genes play a role in that function. All but one of the genes in this functional cluster were upregulated in the leprnull placentas.

Two Slc genes of particular interest are Slc6a4 and Slc22a3, which both transport serotonin, which has been suggested to play a role in placental development and function, as well as fetal development (Bonnin and Levitt, 2011; Viau et al., 2009). Both are important regulators of serotonin (Verhaagh et al., 2001; Viau et al., 2009). Slc6a4 was down regulated in lepr-null placentas. Similarly, it has also been found to be reduced in placentas from women with gestational diabetes (Viau et al., 2009). This serotonin transporter is expressed in migrating cells of the rat ectoplacental cone (Hansson et al., 1998) and high levels of serotonin reduce neuronal crest cell migration (Moiseiwitsch and Lauder, 1995). Preeclampsia, which occurs when placental invasion is inadequate, has also been associated with high levels of serotonin (Bottalico et al., 2004). This suggests that SLC6A4 could potentially play an important role in placenta invasion. Serotonin is 
also a vasoconstrictor, which could affect maternal-fetal blood flow, so regulation of serotonin is essential for proper placental function (Bonnin et al., 2011).

The SLC22A3 transporter also transports serotonin, but was upregulated in leprnull placentas. This transporter is co-localized with monoamine oxidase A, which degrades serotonin, in the labyrinth of the mouse placenta (Verhaagh et al., 2001). In the hippocampus of mice, SLC22A3 increases serotonin clearance (Baganz et al., 2008). This suggests that SLC22A3 plays a role in regulating serotonin levels in the placenta. Overall, serotonin may affect placental invasion and blood circulation, so its regulation is important for proper placental development and function.

The current study shows that lack of leptin signaling results in a down-regulation of Slc6a4 (transports serotonin across the placenta) and up-regulation of Slc22a3, (involved in the degradation of serotonin) which would result in a decrease in serotonin crossing the placenta. Decreased levels of serotonin are associated with increased cell migration and increased placental invasion (Hansson et al., 1998; Moiseiwitsch and Lauder, 1995), therefore lack of leptin signaling could result in increased placental invasion or act as a compensatory mechanism to offset reduced invasion caused by other altered genes (discussed below). Physiological situations involving reduced leptin signaling also means that less serotonin could be transported to the fetus, resulting in altered neuronal development causing behavioral or mental disorders, such as depression or anxiety (Bonnin and Levitt, 2011).

There were several other genes that were differentially expressed in leptin receptor null placentas on the microarray that were of interest, several of which are associated with placental invasion. One of those genes was Stmn1, which was down 
regulated in the null placentas, remaining consistent with our previous in vitro study showing that Stmn1expression was stimulated by leptin in primary mouse trophoblast cells (Schulz et al., 2009). A study in Drosophila oocyte border cells found that STMN1 was required for normal migration (Borghese et al., 2006). Stathmin 1 has been found to be overexpressed human hepatocellular carcinoma (HCC) cells and was associated with the migration and invasion of the tumor cells. When Stmn1 expression was suppressed in HCC cells using siRNAs, invasion was inhibited (Hsieh et al., 2010). A study looking at gene expression in mouse embryos lacking Stmn1 found that about half of the genes with differential expression were involved in cell adhesion and motility (Ringhoff and Cassimeris, 2009). Another study found that inhibition of stathmin in first-trimester trophoblast prevents cell migration (Yoshie et al., 2008). It is clear from these studies that STMN1 plays an important role in cell motility, migration and invasion, which are important processes for proper placental development and function. Lack of leptin signaling in the lepr-null placentas in this study may reduce placental invasion due to reduced Stmn1 expression.

Another gene that has been associated with placental invasion is Stox1, which was down regulated in leptin receptor null placentas. Insufficient trophoblast invasion results in reduced placental blood flow and leads to preeclampsia, which increases the risk for fetal growth restriction (Odegard et al., 2000). A study of families in the Netherlands with more two or more sisters who developed preeclampsia found that affected sisters had Stox1 loss of function mutations (van Dijk et al., 2005). In contrast, overexpression STOX1 mice resulted in preeclampsia-like symptoms (Doridot et al., 2013). Despite the conflicting results, this suggests that STOX1 plays a role in preeclampsia and possibly 
placental invasion. If STOX1 dysfunction leads to preeclampsia, then lepr-null placentas may have reduced placental invasion due to reduced STOX1. On the other hand, if Stox1 overexpression leads to reduced placental invasion, then reduced expression of Stox1 in lepr-null placentas, may be a compensatory mechanism. Because other altered genes may lead to reduced invasion, such as stmn1 down-regulation.

Prl3d1, placental lactogen 1 (PL-1), was down regulated in the leptin receptor null placentas, and has also been associated with placental invasion. Human placental lactogen (hPL) has been found to be increased in pregnant women with placenta previa and invasive placenta (Kawashima et al., 2014), and decreased in women with preeclampsia. (Mannik et al., 2012; Mannik et al., 2010). This shows that hPL is high when the placenta is overly invasive and low with inadequate invasion. Placental lactogens in mice have luteotropic functions that help maintain pregnancy (Galosy and Talamantes, 1995) and lactogenic functions during the second half of pregnancy (Thordarson et al., 1986). There are two placental lactogens in rodents PL-1 and PL-2. Trophoblast cells first produce PL-1, then produce PL-2 during the second half of pregnancy (Soares et al., 2007). The role murine PLs have on the placenta is unclear because of redundancies, but pregnant females lacking one copy of the receptor have reduced glucose tolerance and decreased $\beta$-islet mass growth, demonstrating the importance for PL in regulating maternal glucose homeostasis (Huang et al., 2009). Similarly, human PL was found to promote maternal $\beta$-islet growth (Brelje et al., 1993). The down-regulation of Prl3dl in lepr-null placentas may reduce invasion and possibly affect blood flow. It may also reduce maternal $\beta$-islet mass growth and glucose tolerance. High circulating leptin levels and leptin resistance is associated with pregnancies 
complicated by diabetes (Lewandowski et al., 1999). Therefore, lack of placental leptin signaling resulting in the reduction of PL may increase the risk of developing gestational diabetes.

Atg4c may also be involved in invasion, and it was down regulated in leptin receptor null placentas. This autophagy gene is involved in degrading and recycling intracellular proteins and organelles (Kusama et al., 2009). Autophagy has been shown to affect trophoblast invasion, but there are conflicting results as to whether it promotes (Nakashima et al., 2013) or inhibits (Choi et al., 2012) invasion. On the other hand, another study found no difference in invasion in JEG-3 trophoblast cells when autophagy was disrupted (Hung et al., 2013). Further studies are warrented to determine the role of autophagy in trophoblast invasion. Autophagy is stimulated when glucose and oxygen levels are low, which may protect trophoblast cells from apoptosis (Hung et al., 2013). Atg4c null mice develop normally, are fertile and have a normal lifespan; this is likely due to the many autophagic redundancies, although when under starvation conditions, these mice have a reduced autophagic response (Marino et al., 2007). Reduced invasion could result in reduced glucose and oxygen supply to the placenta and cause an increase in autophagy. However, in lepr-null placentas with reduced Atg4c expression, the autophagic response may be reduced, possibly resulting in an increase in trophoblast cell death.

Two other genes are of interest due to their involvement in placental morphological development. Hdac1 and Dnmt3l both play an important role in regulating gene expression. Hdac1, was down regulated in leptin receptor null placentas, and is a negative regulator of histone acetylation (Kidder and Palmer, 2012). In embryonic and 
trophoblast stem cells, HDAC1 is located near active genes, such as those involved in regulating self-renewal (Kidder and Palmer, 2012). However, HDAC1 has also been found to deactivate genes, such as $\mathrm{Gcm} 1$, which promotes fusion of syncyitiotrophoblast cells in the labyrinth (Chuang et al., 2006). Dnmt3l was upregulated in null placentas. The DNMT3L protein does not have DNA methylase activity, but acting as a cofactor to functioning DNA methyltransferases is necessary for maternal imprinting in the embryo and placenta (Arima et al., 2006). Mouse conceptuses lacking Dnmt3l have abnormal development of the labyrinth and spongiotrophoblast layers, and increased number of giant cells (Arima et al., 2006). Dnmt3l is overexpressed in carcinoma cells, which, in HeLa carcinoma cells, results in increased cell proliferation and anchorage-independent growth, altered morphology and changes in global gene expression (Gokul et al., 2009). HDAC1 and DNMT3L have significant involvement in the regulation of genes related to placental morphogenesis. Reduced Hdac1 in placentas lacking the leptin receptor may have a reduced population of trophoblast stem cells, due the reduced activity of genes related to self-renewal. Due to the fact that HDAC1 deactivates Gcm1 expression, downregulation of Hdac1 in lepr-null placentas may be associated with the increased expression of Gcm1 in the microarray results, although this was not validated in the qPCR results. The up-regulation of Dnmt3l in lepr-null placentas could have stimulated cell proliferation and placental growth, both of which could be mechanisms compensating for the dysregulation of others genes that reduce placental invasion and growth due to lack of leptin signaling.

Taken together, leptin signaling in the placenta likely plays an important role in trophoblast invasion, because when it is disrupted, many factors that may stimulate 
invasion are down-regulated. This is consistent with the finding that leptin stimulates mouse trophoblast invasion in vitro. However, there may be mechanisms that help compensate for this. We did not see any morphological differences that would indicate insufficient placental invasion, such as increased placental size, specifically in the labyrinth, which would be an attempt to compensate for lack of nutrients. Reduced depth of the decidua is an indicator of reduced invasion; however we did not measure this. The microarray clearly shows that gene expression in lepr-null placentas is altered and Hdac1 and Dmnt3l may be important factors affecting expression of placental genes, some of which may act as compensatory mechanisms.

Despite the considerable change in gene expression in the lepr-null placentas, there were no significant morphological alterations. Lepr-null placentas were numerically lighter than wildtype placentas, which may indicate a change that is too subtle for crude wet weight comparison to detect. We found no significant differences in total placental, junctional zone or labyrinth zone areas. Our group has previously reported a reduction in placental and junctional zone areas at day 11.5 in food restricted mice, which have decreased leptin levels (Schulz et al., 2012). Fetal to placental weight ratio, a measure of placental efficiency, was also not different.

We looked at glycogen cell size in the junctional zone and found no differences. In our previous study, we observed a possible reduction in the number of glycogen vacuoles in day 11.5 placentas from food restricted and food restricted with leptin treatment (Schulz et al., 2012), which is consistent with the current study in that leptin does not seem to affect glycogen cells. 
There were no differences found in the labyrinth blood space areas in the lepr-null placentas compared to controls. We have previously shown decreased fetal blood space areas in day 11.5 placentas from food restricted mothers versus food restricted mothers with leptin treatment (Schulz et al., 2012). Leptin has been shown to affect angiogenesis by stimulating it (Sierra-Honigmann et al., 1998) and blocking vascular endothelial growth factor (VEGF) secretions (Islami et al., 2003). VEGF expression was not found to be different in the microarray results. Four genes that may play roles in angiogenesis were upregulated in the lepr-null placentas (Meox2, Prcp, Angptl3, C1qtnf3 (Akiyama et al., 2007)), which may indicate a compensatory mechanism was activated. We previously showed that C1qtnf6, which is involved in tumor angiogenesis (Takeuchi et al., 2011), was decreased in placentas from food restricted mothers and not in food restricted with leptin treatment (Schulz et al., 2012), indicating that leptin may stimulate angiogenesis through this pathway. On the other hand, leptin may interact with other physiological factors (like insulin, or specific nutrients) such that it has a different effect in wellnourished and food restricted animals. In the current study C1qtnf3, which is also an angiogenic factor, was upregulated, not down regulated, in the lepr-null placentas which seems to contradict the results from our previous study. One study in humans showed that reduced leptin in fetal blood was associated with impaired vascularization (Huppertz et al., 2007). In contrast, a study in women with type 1 diabetes reported increased fetal leptin concentrations had little effect on placental vascularization (Nelson et al., 2009). A study in sheep also showed that leptin was not correlated with placental growth (Forhead et al., 2008). Taken together, these studies reveal the complex nature of leptin and placental angiogenesis and the need for further research. 


\subsection{Conclusion}

Even though there were no morphological alterations detected in the lepr-null placentas, there is clearly an altered gene expression profile, which indicates a possible change in placental function, possibly involving nutrient transport. Compensatory mechanisms may have been activated due to the lack of leptin receptors, which resulted in normal fetal and placental growth. Further investigation of placental function in leprnull conceptuses is needed. 


\section{CHAPER 3}

\section{HYPERLEPTINEMIA DURING PREGNANCY INCREASES OFFSPRING ACTIVITY AND PROTECTS OFFSPRING FROM WEIGHT GAIN DURING ADULTHOOD}

\subsection{Introduction}

Obesity rates have increased over the past few decades, along with associated health problems such as cardiac disease and diabetes. The CDC reported that in 20092010, 35\% of adults and 17\% of children in the U.S. were obese (Ishimori et al., 2003). The 'obesogenic' environment in which many people live promotes poor nutrition and sedentary lifestyles and is a major contributor to the obesity problem. On the other hand, some people are more likely than others to become obese regardless of lifestyle. The Developmental Origins of Health and Disease hypothesis states that the in utero environment can have lifelong effects on the fetus (Barker et al., 1989). For example, children born to mothers who are obese or have Gestational Diabetes Mellitus (GDM) have a higher risk of becoming obese (Dabelea et al., 2000a; Drake and Reynolds, 2010). Mothers suffering from obesity and/or GDM also have high levels of the hormone leptin (Kautzky-Willer et al., 2001; Matsumoto et al., 2003). This is a multifunctional peptide that is involved in energy homeostasis (Kowalski et al., 2001), immunity (Bernotiene et 
al., 2006), reproduction (Malik et al., 2001; Yang et al., 2006), and brain development (Ahima and Osei, 2004). We have previously demonstrated that high maternal leptin in combination with maternal nutrient restriction, results in greater obesity and insulin resistance in female offspring given a high fat diet (Pennington et al., 2012). As leptin is high in both obese and GDM mothers, we hypothesize that it may be involved in predisposing their offspring to obesity.

The in utero environment may lead to altered behaviors that increase offspring risk of obesity. Human studies suggest that children’s behavioral activity (Ornoy et al., 1998), motor coordination (Ornoy et al., 1998; Petersen et al., 1988), and anxiety (Rizzo et al., 1997a) are affected by maternal obesity and/or GDM. Maternal diet during pregnancy is likely to impact human offspring feeding behavior (Brion et al., 2010). Altered feeding behavior (i.e. increased preference for fatty foods) (Brion et al., 2010) and increased anxiety (Rizzo et al., 1997a) could lead to increased risk for obesity and associated diseases in adulthood. Other behavioral changes could have a negative impact on the lives of those children, such as increased hyperactivity (Ornoy et al., 1998; Rizzo et al., 1997a), and decreased fine and gross motor coordination (Ornoy et al., 1998; Petersen et al., 1988), which could last into adulthood.

The cause of these behavioral changes is still unknown. Rodent studies have shown that maternal nutrition and/or obesity during gestation affects offspring behavioral activity (Raygada et al., 1998; Vickers et al., 2003; Zhao et al., 2011), motor coordination (Zhao et al., 2011), anxiety (Bilbo and Tsang, 2010; Walker, 2010), and feeding behavior (Kirk et al., 2009; Ong and Muhlhausler, 2011; Vickers et al., 2003; Vucetic et al., 2010; Walker et al., 2008). It is difficult to compare the rodent studies and determine a cause 
for the behavioral changes, due to the wide variety of experimental designs and methods. However, altered maternal nutrition and obesity during pregnancy are associated with altered leptin levels and leptin resistance, which could play a role in programming offspring behavior.

The current study sought to determine whether hyperleptinemia during pregnancy alters offspring behavior in a way that increases their risk of weight gain. Two models of maternal hyperleptinemia were used. The first used the leptin receptor mutant mouse $\left(\mathrm{Lepr}^{\mathrm{db}}\right.$ ), which lacks the long form of the leptin receptor (McMinn, 2003). Females heterozygous for this mutation $\left(\mathrm{Lepr}^{\mathrm{db} / /}\right.$ ) have a normal phenotype until they become pregnant, and then they develop hyperleptinemia (Ishizuka et al., 1999). Under some conditions they develop gestational diabetes (Satoh et al., 2003; Yamashita et al., 2001), but that was not the case in this study. The second model used mini-osmotic pumps containing leptin implanted subcutaneously into female wildtype mice.

After weaning, behavioral tests were begun on male and female wildtype offspring from the four maternal treatment groups. They were tested at three ages: juveniles from 4 to 6 weeks, young adults from 11 to 13 weeks, and adults from 19 to 21 weeks. Five behaviors were evaluated: food consumption, food preference, locomotor activity, motor skills and anxiety-related behaviors. At 23 weeks some of the offspring were put on a high fat diet to identify potential interactions between exposure to an obesogenic environment and maternal hyperleptinemia. Three behaviors were then reevaluated at 27 to 28 weeks: food consumption, locomotor activity and anxiety-related behaviors. Our hypothesis was that maternal hyperleptinemia would alter offspring behavior in a way that would promote obesity: increase food consumption and preference 
for palatable food, decrease locomotor activity and motor coordination, and increase anxiety.

\subsection{Materials and Methods}

\subsubsection{Animals}

All animal procedures were approved by the University of Missouri-Columbia Institutional Animal Care and Use Committee and performed in accordance with the National Institutes of Health Guide for the Care and Use of Laboratory Animals. Animals were housed in a $12 / 12$ light/dark cycle at $68^{\circ} \mathrm{F}$ to $79^{\circ} \mathrm{F}$ with $30 \%$ to $70 \%$ humidity.

\subsubsection{Experimental Design}

Two mouse models of maternal hyperleptinemia, each with its own control were used in this study. Evaluation of maternal glucose, insulin and leptin was conducted at gestational day 16.5 (d16.5). Male and female wildtype offspring from the four maternal treatment groups were subject to multiple behavioral tests at three ages. At 23 weeks of age some animals were placed on a high fat diet, while the others remained on a control diet, and several behaviors were reevaluated (Figure 5). 
A

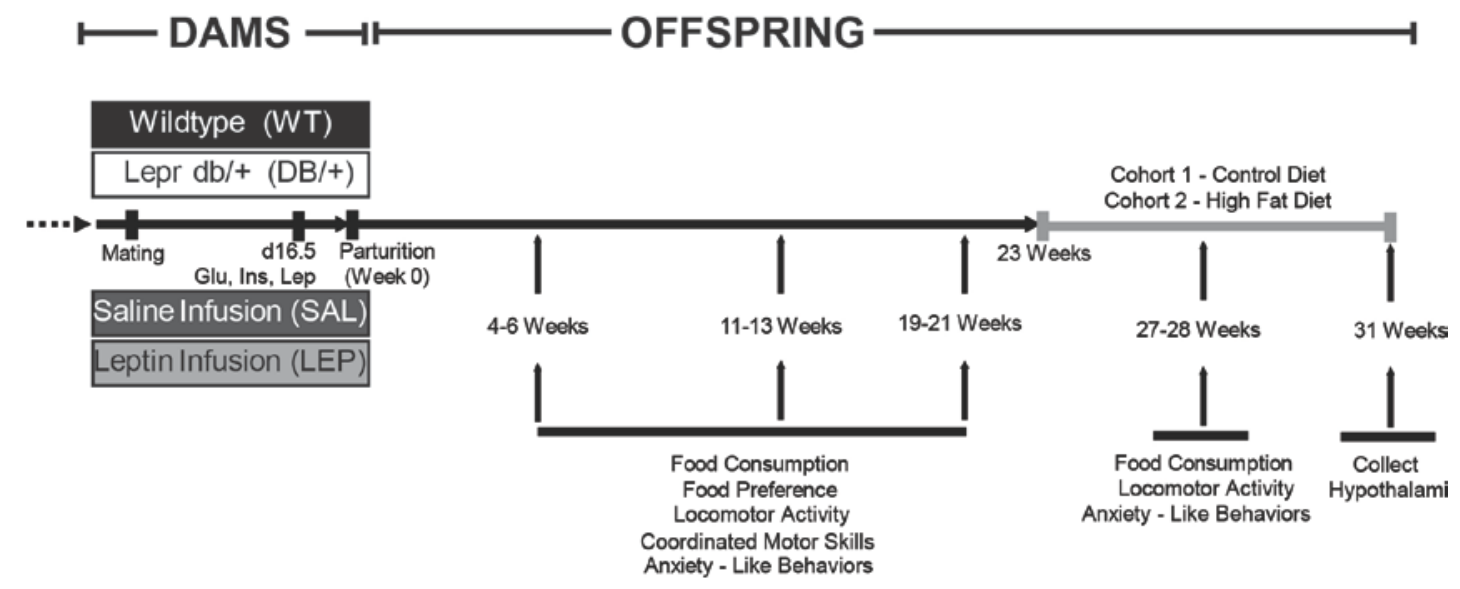

B
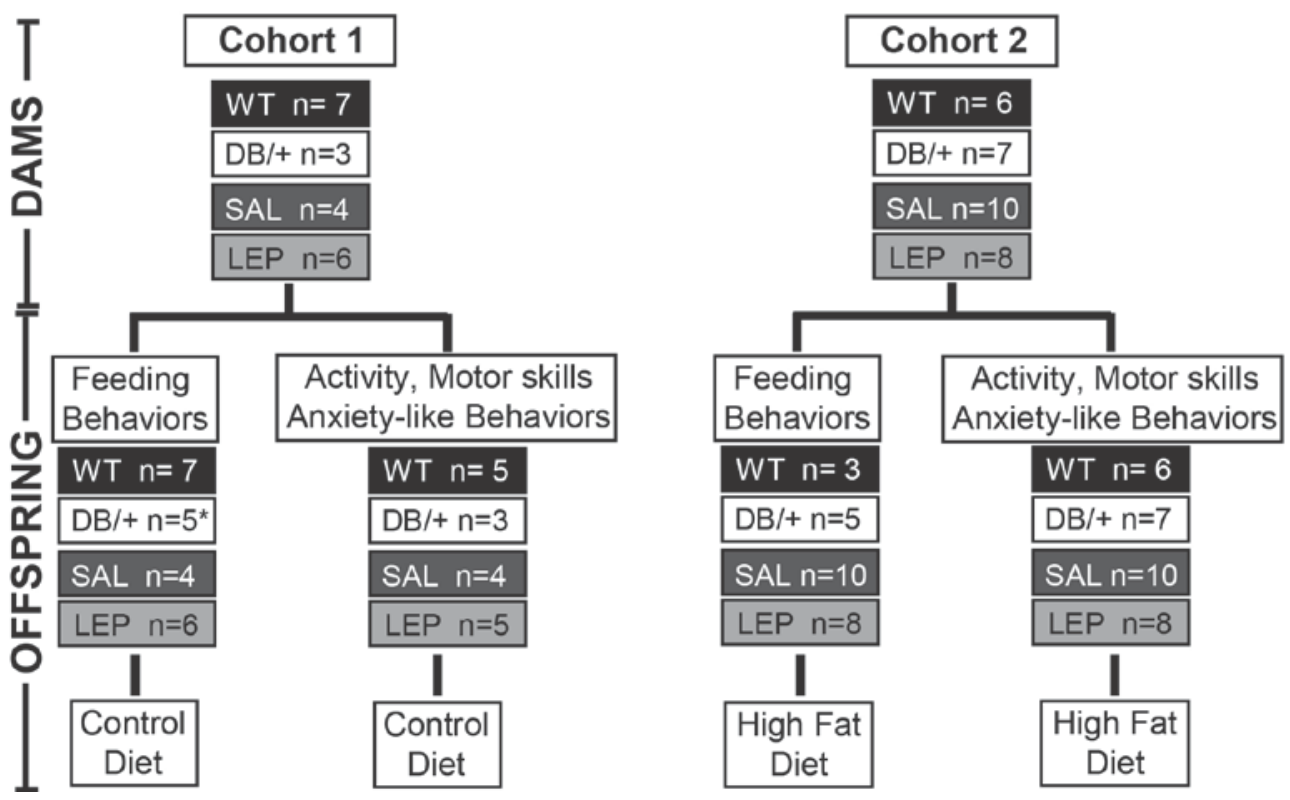

Figure 5. Maternal Hyperleptinemia Experimental Design Schematic. A: Experimental timeline: Mice were mated at the same time, 3 to 4 days after saline/leptin pump implantation. At day 16.5 postcopulation, all dams were fasted for 4 hours and blood was collected to measure glucose (Glu), insulin (Ins) and leptin (Lep). Wildtype offspring were tested for food consumption, food preference, activity, coordinated motor skills, and anxiety- like behaviors at three ages. Cohort 2 (see panel B) was place on a high fat diet, while cohort 1 remain on a control diet, food consumption, activity and anxiety-like behaviors were retested at 27 to 28 weeks of age. At 31 weeks of age hypothalami were collected. B: Experimental animal groupings and sample sizes: The experiment was conducted twice resulting in two cohorts. After offspring were weaned and genotyped, one male and one female offspring (if available) from each dam were randomly placed into a group testing feeding behaviors or in a groups testing activity, coordinated motor skills, and anxiety- like behaviors. All n's reflect the number of dams represented. *, 2 male offspring from cohort 2 were moved to cohort 1 due to small sample size. 


\subsubsection{Lepr $^{d b /+}$ Model of Pregnancy Hyperleptinemia}

Four heterozygous Lepr ${ }^{\mathrm{db} /+}$ male mice (Strain: B6.BKS(D)-Lepr ${ }^{\mathrm{db}} / \mathrm{J}$; stock number: 000697) obtained from Jackson Laboratory (Bar Harbor, Maine) were mated to eight C57Bl/6 wildtype females from our colony to establish the Lepr ${ }^{\mathrm{db}}$ colony. Tail clips were taken from weanlings ( 3 weeks old) for gDNA for genotyping according to the method published by Yamashita et al. (2001) with minor modifications. The clips, approximately $2 \mathrm{~mm}$ in length, were incubated at $55^{\circ} \mathrm{C}$ for $3-18 \mathrm{~h}$ in lysis buffer [ $50 \mathrm{mM}$ KCl, 10 mM Tris- $\mathrm{HCl}$ (pH 8.3), 2 mM MgCl2, 0.1mg/ml gelatin, 0.45\% Nonidet $\mathrm{p} 40$, $0.45 \%$ Tween 20], then incubated at $95^{\circ} \mathrm{C}$ for $10 \mathrm{~min}$. Eight hundred nanograms of gDNA was amplified by PCR as described (Yamashita et al., 2001). The PCR products were cut with AccI, then resolved on a 3.5\% agarose gel and visualized with SYBR Green (Lonza, Rockland, ME).

\subsubsection{Glucose tolerance in Pregnant Lepr $^{\mathrm{db} /+}$ Mice. A glucose tolerance test} was performed on pregnant Lepr ${ }^{\mathrm{db} /+}$ mice prior to the developmental programming study to determine whether they develop diabetes during pregnancy. Reciprocal crosses were made between wildtype C57Bl/6 control females (WT n $=7$ ) with Lepr ${ }^{\mathrm{db} /+}$ males and congenic Lepr ${ }^{\mathrm{db} /+}(\mathrm{DB} /+\mathrm{n}=9)$ females with wildtype males and they were maintained on TestDiet ${ }^{\circledR}$ (St. Louis, MO) AIN-93g (7\% fat). At day 18.5 of gestation, they were fasted for 6 hours, then given $2 \mathrm{mg} / \mathrm{g}$ body weight of glucose via intraperitoneal injection. Blood glucose levels were measured at $0,15,20,30,60$, and 120 minutes following the glucose administration. At 0 and 30 minutes an additional $100 \mu \mathrm{l}$ of blood was collected from the tail vein for measurement of serum insulin, and a terminal blood sample was collected via cardiac puncture at 120 min for measurement of serum leptin. 
3.2.2.2 Developmental Programming by Exposure to Lepr ${ }^{\mathrm{db} /+}$. In cohort 1, 13 Lepr $^{\mathrm{db} /+}$ females (DB/+) were mated with wildtype males and 13 of their wildtype sisters (WT) were mated with Lepr ${ }^{\mathrm{db} /+}$ males for 4 days, resulting in three and seven litters respectively. In cohort 2, $24 \mathrm{Lepr}^{\mathrm{db} /+}$ females were mated with wildtype males and 12 wildtype female siblings were mated with $\mathrm{Lepr}^{\mathrm{db} /+}$ males, resulting in seven and six litters respectively (Figure 5). These reciprocal crosses were performed to control for any potential littermate effects of fetal genotype. The DB/+ females had a lower pregnancy rate then WT females, and an even lower survival of pups, as some of the pups were still born or died soon after birth. (Table 5). At d 16.5, pregnant females were fasted for 4 hours, and then blood was collected from the tail vein for measurement of fasting glucose, insulin and leptin (Figure 5). Wildtype offspring of each maternal genotype were randomized to behavioral studies as detailed below. Because there were only three male offspring from $\mathrm{DB} /+$ dams in cohort one, two male offspring in the feeding behavior arm of cohort two, which had seven male offspring from the DB/+ dams, remained on a control diet instead of being placed on a high fat diet. They are represented as being part of cohort one in Figure 5.

Table 5. Pregnancy Rates

\begin{tabular}{r|cccc}
\hline \multicolumn{1}{c}{} & WT & DB/ + & SAL & LEP \\
\cline { 2 - 5 } \# of mice mated & 25 & 34 & 25 & 25 \\
\# of pluges detected & 19 & 27 & 22 & 22 \\
\# of pregnant dams & 18 & 17 & 12 & 16 \\
\# of live litters & 16 & 13 & 12 & 16 \\
Plug rate & 0.76 & 0.79 & 0.88 & 0.88 \\
Pregnacy Rate & 0.72 & 0.5 & 0.44 & 0.6 \\
Live Litter Rate & 0.64 & 0.38 & 0.44 & 0.6 \\
\hline
\end{tabular}




\subsubsection{Leptin Infusion Model of Pregnancy Hyperleptinemia}

Wildtype C57Bl/6 females obtained from our colony or received from Harlan (Indianapolis, IN) were infused with either leptin (LEP) or saline, as a control (SAL). Recombinant mouse Leptin (Sigma-Aldrich, L3772) was reconstituted in saline according to manufacturer's guidelines. Alzet Mini-Osmotic Pumps (Model 2004) (Durect Corporation, Cupertino, CA), releasing $0.25 \mu \mathrm{l} / \mathrm{hr}$ for 28 days, were filled with $1.4 \mu \mathrm{g} / \mu \mathrm{l}$ leptin solution or saline following manufacturer's instructions. The pump was then inserted subcutaneously between the scapulae and parallel to the spine, with the flow moderator positioned away from the incision. Mice were allowed to recover for 3 to 4 days before being placed with males for mating.

\subsubsection{Developmental Programming by Exposure to Leptin Infusion. Twelve} wildtype female mice with pumps containing leptin, and 11 with pumps containing saline were mated to wildtype males in cohort 1 , resulting in six and four pregnancies respectively. Thirteen wildtype female mice with pumps containing leptin, and 14 with pumps containing saline were mated to wildtype males in cohort 2, resulting in 8 and 10 pregnancies respectively. In all matings, females were placed with males until a copulatory plug was detected or four to five days had elapsed, to insure pumps would last until parturition and pups were close in age. The SAL dams had somewhat lower pregnancy rates the LEP dams (Table 6). At d 16.5, pregnant females were fasted for four hours, and then blood was collected from the tail vein for measurement of fasting glucose, insulin and leptin (Figure 5) and weights were recorded. Offspring were randomized to behavioral studies as detailed below. 


\subsubsection{Offspring Behavioral Tests}

Five behaviors (food consumption, food preference, coordinated motor skills, locomotor activity, and anxiety-related behaviors) were evaluated in the wildtype pups from the previously described matings at 4 to 6 weeks (prepubertal), 11 to 13 weeks (young postpubertal) and 19 to 21 weeks (old postpubertal) of age (Figure 5). Up to one male and one female wildtype pup from each litter were randomized to feeding behavior studies, and up to one additional male and female wildtype pup were randomized to the motor skills, locomotor activity and anxiety-related behavior studies. All offspring were weighed weekly from 4 to 31 weeks of age. Wildtype offspring were tested for food consumption, food preference, locomotor activity, coordinated motor skills, and anxietylike behaviors at 3 ages. Cohort 2 (see panel B of Figure 5) was placed on a high fat diet, while cohort 1 remained on a control diet. Food consumption, locomotor activity and anxiety-like behaviors were retested at 27 to 28 weeks of age.

Offspring in cohort 2 were placed on a high fat diet (DIO HFD D12450, Research Labs, New Brunswick, NJ) from weeks 23 to 31 while the first cohort were maintained on the regular chow diet. Food consumption, locomotor activity and anxiety- related behaviors were reassessed in both cohorts at weeks 27 to 28 (Figure 5). Offspring being evaluated for feeding behaviors were housed individually so that food consumption of individuals could be measured. Those being evaluated of all other behaviors were group housed with three to five animals per cage.

3.2.4.1 Feeding Behavior. Male and female wildtype offspring were evaluated for total amount of food intake (ages 4,11,19 weeks) and food preference (ages 5,12,20 weeks). For 7 days, consumption of a powdered standard chow diet (LabDiet 5008, 
Purina, St. Louis, MO) mixed with 50\% water was measured at 12-hour intervals by using specialized dishes that were previously constructed for this purpose (Schlitt and Schulz, 2012). Food preference was examined by introducing a high fat/high sugar chow diet (50\% LabDiet 5008 Meal, 50\% sweetened condensed milk (PD) (Schneider et al., 2010) in addition to the standard chow diet (CD) in identical dishes and measuring the nightly consumption of each. At age 28 weeks, both cohorts were assessed for food consumption over 5 days on their respective diets (cohort 1- standard chow; cohort 2 high fat).

\subsubsection{Coordinated Motor Skills. At ages 4,11, and 19 weeks, coordinated} motor skills (the ability to synchronize limb movements and maintain balance) were assessed by the University of Missouri Center for Translational Neuroscience using a rotarod apparatus (ENV-577M, Med Associates, Georgia, VT) as previously described (Sage et al., 2013). The apparatus consisted of a horizontal rod $3.2 \mathrm{~cm}$ in diameter positioned $16.5 \mathrm{~cm}$ above its base (Figure 6). Across three consecutive sessions (one session/day) mice were tested on the rotarod, which rotated at an increasing velocity for up to $5 \mathrm{~min}$, and the dependent measure was latency to fall off the rotarod.

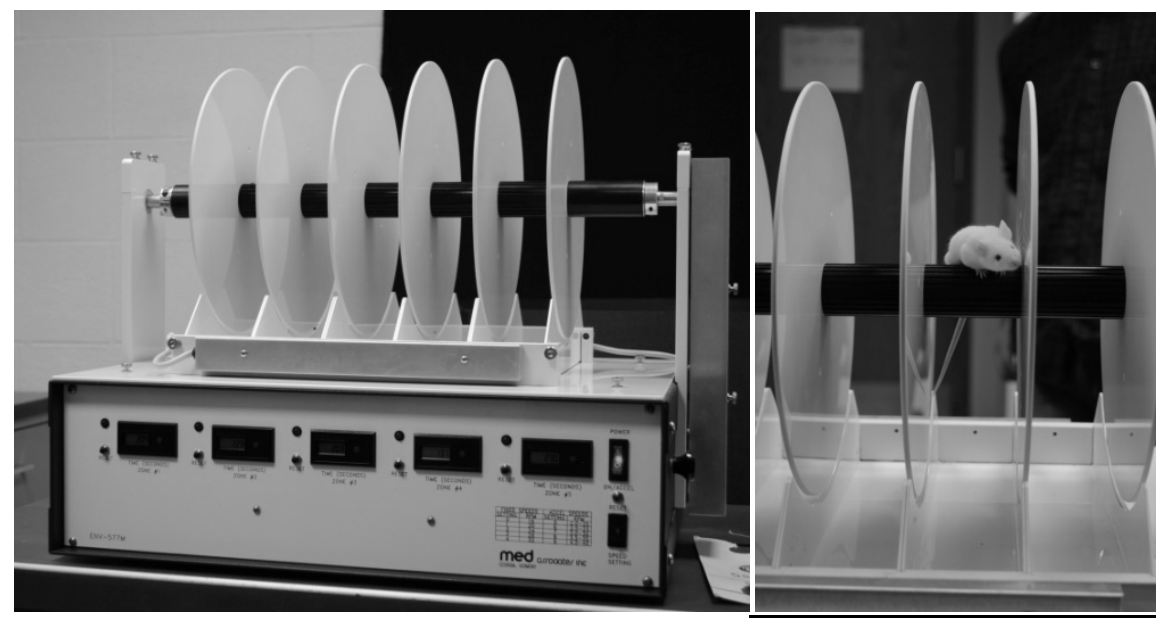

Figure 6._Rotarod Apparatus 


\subsubsection{Locomotor Activity. Locomotor activity (movement from place to place)}

was assessed in the offspring at ages 5, 12, 20 and 27 weeks using automated open- field activity monitors (Med Associates, St. Albans VT) interfaced to a computer running Med Associates Activity Monitor (ver. 4.31) software, according to procedures used previously in the Center for Translational Neuroscience (Sage et al., 2013). The apparatus consisted of a transparent box surrounded by banks of infrared sensors that were connected to the computer (Figure 7). Across 3 sessions (1 session/day) mice were placed in the center of the apparatus and allowed to move freely for 30 minutes. The dependent measures were total distance traveled and distance traveled over each 5 minute increment.

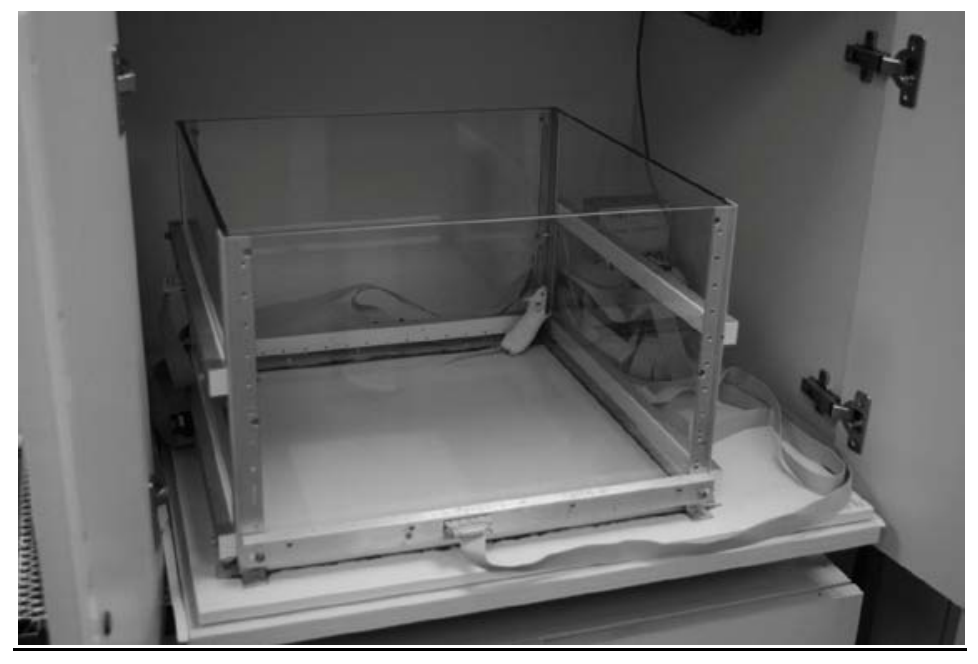

Figure 7. Open-field Activity Monitors

\subsubsection{Anxiety-related Behaviors. Anxiety-related behaviors (amount of} exploring under adverse conditions) were measured at 6, 13,21 and 28 weeks of age via the elevated-zero maze (Sage et al., 2013; Wu et al., 2003) in the University of Missouri Center for Translational Neuroscience. The zero/circular maze was divided into four quadrants of equal size; two quadrants had walls and the other two were open. It was 
made of gray acrylic and the track was $10 \mathrm{~cm}$ wide, $105 \mathrm{~cm}$ in diameter and was elevated $72 \mathrm{~cm}$ from the floor (Figure 8). Two meters above the apparatus was an incandescent lamp with no other light sources in the room. White noise was played continuously. On a single session at each age mice were placed facing out of a closed maze area and the dependent measure was the ratio of time spent in the closed versus open areas of the maze. Each 5 minute session was video recorded, then two independent observers, blinded to offspring treatment group, recorded time spent in open and closed arms, the number of times the mice entered open or closed areas and the number of times they explored (looked over) the edge in the open areas.

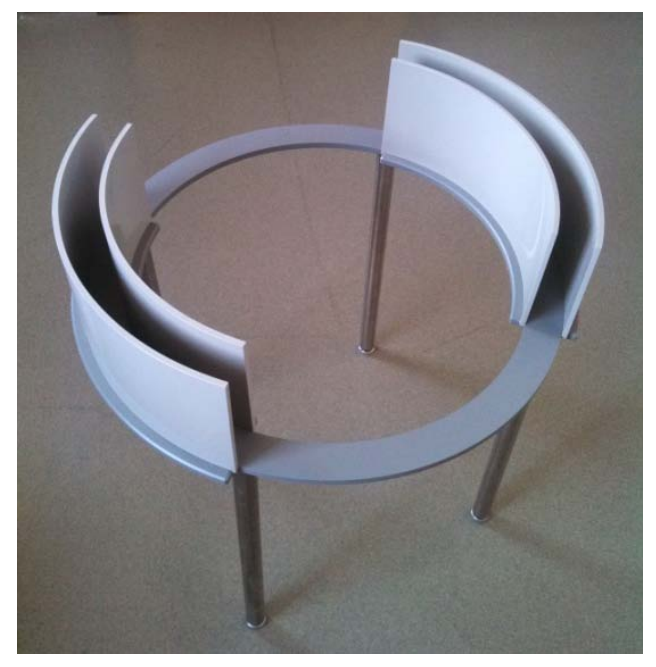

Figure 8. Elevated Zero-Maze

\subsubsection{Blood and Serum Assays}

Blood glucose concentrations were measured using a OneTouch Ultra Glucose Meter and test strips (Life Scan, Inc.).A rat/mouse insulin ELISA (Millipore, St. Charles, MO) was used to determine serum insulin concentrations. The manufacturer's assay procedure was followed, with the primary antibody incubation period extended to overnight (intrassay variation: 8.5\%). A mouse leptin ELISA kit (Millipore, St. Charles, 
MO) was used to determine leptin concentrations according to manufacturer's

instructions, with the primary antibody incubation period extended to overnight (intrassay variation d 18.5: 16.2\%; d 16.5: 14.4\%).

\subsubsection{Statistics}

Student's t-test was conducted on the maternal glucose, insulin, and leptin measurements (DB vs. WT; LEP vs. SAL; WT vs. SAL; DB vs. LEP). A repeated measures two-way analysis of variance (ANOVA) statistical test was used to analyze the maternal glucose tolerance test with fixed factors treatment group, time and treatment group x time as outlined by Littel et al. (1998). The offspring weights were also analyzed by using a repeated measures two-way ANOVA with fixed factors maternal treatment, and offspring sex, age, and diet as outlined by Littel and others (1998). Offspring anxiety data at 28 weeks was analyzed using a three-way ANOVA with maternal treatment group, sex and diet (CD or HFD) as factors. All other behavioral data were analyzed by analyses of variance split-plot in space and time with fixed factors diet, sex, age, and days within age as outlined by Steel and others (1997)

\subsection{Results}

\subsubsection{Maternal Glucose Tolerance, Insulin, Leptin and Weights}

At pregnancy d 18.5, DB/+ dams had significantly lower glucose levels during the glucose tolerance test at 15, 20, and 30 minutes after glucose administration (Figure 9A), indicating slightly better glucose tolerance than the control mothers. Maternal insulin levels at 0 and 30 min of the glucose tolerance test were not different (Figure 9B and C). Leptin levels, at 120 min, in the DB/+ dams was significantly higher than the WT dams $(\mathrm{p}=0.05)$ (Figure 9D). 
In the developmental programming studies, there was no significant difference in fasting glucose or fasting insulin concentrations among the four maternal treatment groups at pregnancy d16.5 (Figure 9E and F). Fasting serum leptin concentrations were significantly higher in DB/+ and LEP dams compared to their controls, WT and SAL, respectively (Figure 9G). The DB/+ dams also weighed significantly more than WT dams at day $16.5(\mathrm{p}<0.01)$ (Table 6). There were no differences in litter size among the groups.

Table 6. Average maternal weights and litter sizes of hyperleptinemic dams. DB/+ dams weight more than WT dams at gestational day 16.5 with no difference in litter sizes. Statistical variation represented as $\underline{+} \operatorname{SEM}(* * p<0.01)$

\begin{tabular}{c|cccc}
\hline \multicolumn{4}{c}{ Average Maternal Weights and Litter Sizes } \\
\cline { 2 - 5 } WT & $33.17 \pm 0.7$ & 17 & $6.00 \pm 0.6$ & 13 \\
$\mathrm{DB} /+$ & $37.38 \pm 0.6^{\star *}$ & 16 & $6.36 \pm 0.8$ & 13 \\
\hline $\mathrm{SAL}$ & $34.96 \pm 0.7$ & 11 & $6.45 \pm 0.5$ & 11 \\
LEP & $36.20 \pm 0.6$ & 15 & $7.27 \pm 0.5$ & 15 \\
\hline
\end{tabular}



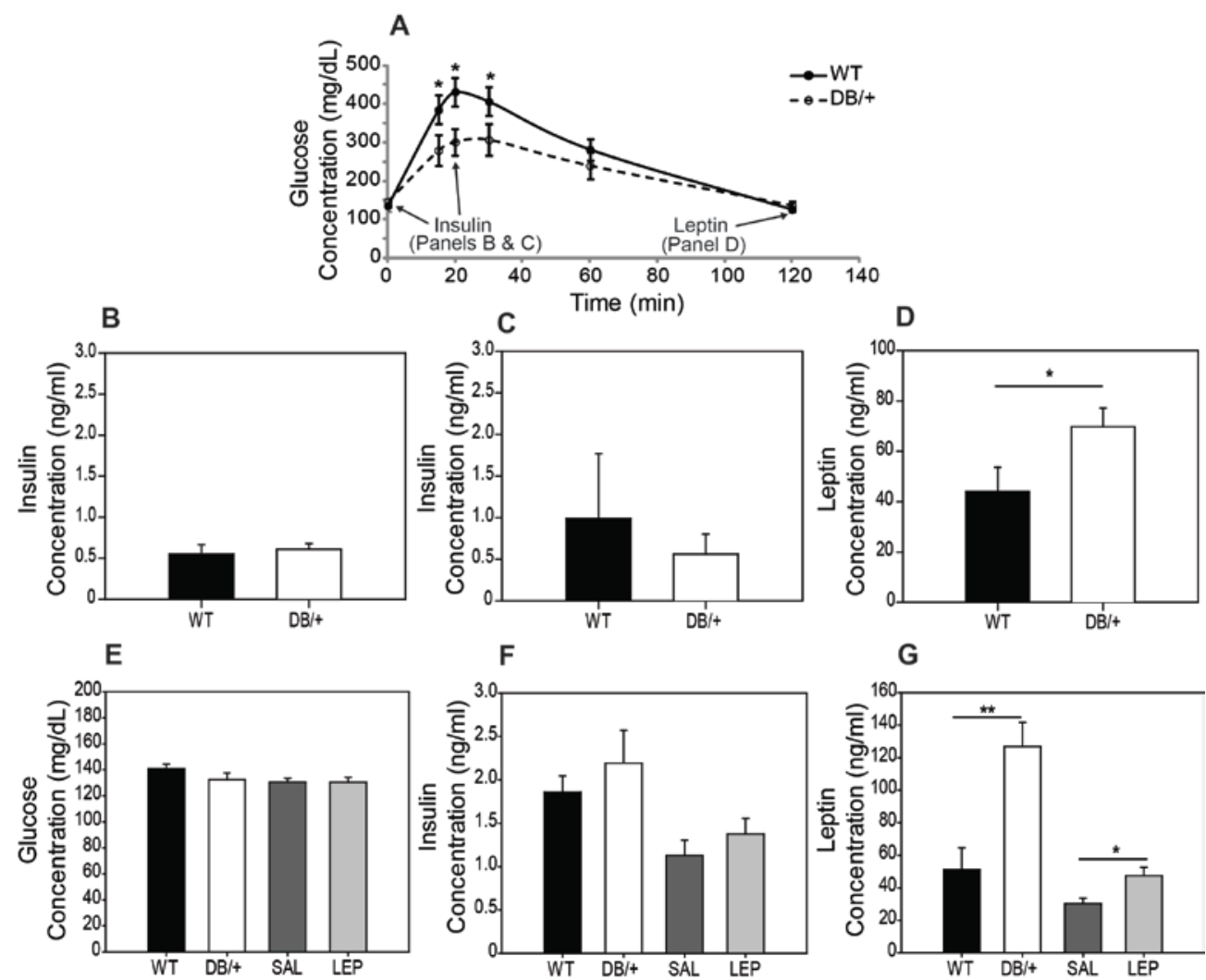

Figure 9. Hyperleptinemic Dams Glucose, Insulin and Leptin. Lacking of one copy of the leptin receptor (DB/+) results in maternal hyperleptinemia and does not cause glucose intolerance at 16.5 or 18.5 of gestation. A: A glucose tolerance test was performed after a 6 hour fast in wildtype (WT) and $\mathrm{Lepr}^{\mathrm{db} /+}(\mathrm{DB} /+)$ dams at gestational day 18.5 after giving a $2 \mathrm{~g} / \mathrm{kg}$ glucose bolus. Data are presented as averages \pm SE and were analyzed by using two-way ANOVA. Blood was collected from the tail vain to measure insulin at the 0 (Panel B) and 30 (Panel C) minute time points and leptin at the 120 (D) minute time point (n: WT=7; DB/+ = 9). The dams from the developmental programming study were fasted for 4 hours at gestational day 16.5 and blood was collected from the tail vein to measure glucose $(\mathbf{E})$, insulin $(\mathbf{F})$ and leptin $(\mathbf{G})$. Data for insulin, leptin and fasting glucose are presented as averages $\pm \mathrm{SE}$ and were analyzed by using Student's t-test (n: $\mathrm{WT}=13 ; \mathrm{DB} /+=12$; $\mathrm{SAL}=14$; $\mathrm{LEP}=14)\left({ }^{*} \mathrm{p}<0.05 ;{ }^{* *} \mathrm{p}<0.01\right)$.

\subsubsection{Offspring Weights}

As they aged, offspring of dams with pregnancy hyperleptinemia gained less weight than their respective controls. Wildtype offspring from $\mathrm{DB} /+$ dams weighed significantly less than offspring from WT dams at older ages (26, 27, 28, 30 and 31 weeks), regardless of sex or diet $(p<0.05)$ (Figure 10A and C). Weights of offspring from LEP dams diverged from those of offspring from SAL dams at 25, 26, and 29 weeks 
of age $(\mathrm{p}<0.07)$, and were significantly lower at 31 weeks $(\mathrm{p}<0.05)$ (Figure 10B and D). Male offspring weighed more than female offspring $(\mathrm{p}<0.01)$ and cohort 2 animals, which were placed on the high fat diet at 23 weeks of age, weighed more that those on the control diet $(\mathrm{p}<0.01)$, but neither sex nor diet influenced the effect of maternal hyperleptinemia. Overall, maternal hyperleptinemia reduced offspring weight gain. 

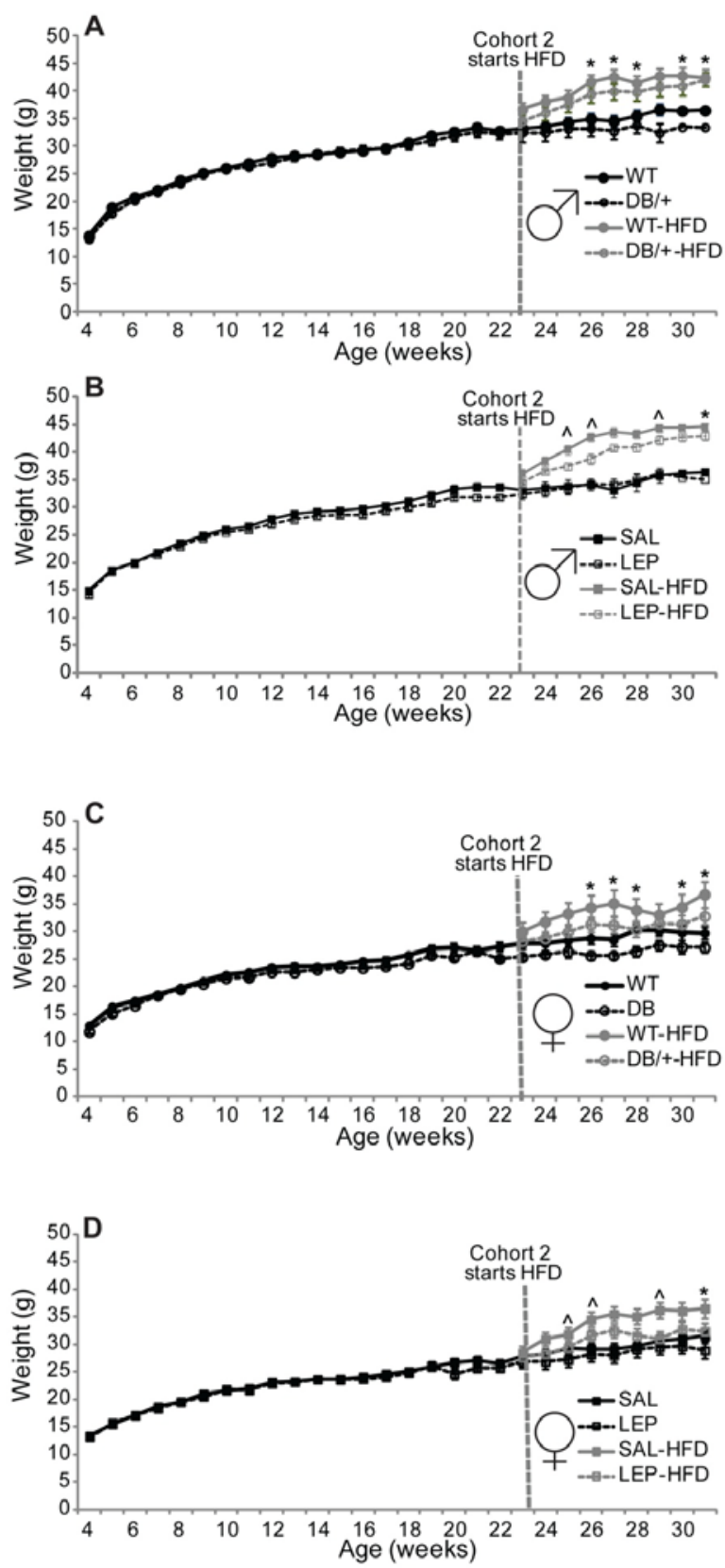

Figure 10.Weights of Offspring from Hyperleptinemic Dams. Offspring from dams with hyperleptinemia (DB/+ and LEP) weighed less than their respective controls in adulthood regardless of sex or diet. Offspring from WT (solid line, closed circles) and DB/+ (dashed line, open circles) dams (males (A); females (C)), and SAL (solid line, closed squares) and LEP (dash line, open squares) (males (B); females (D)) were weighed weekly after weaning. Male offspring (A and $\mathbf{B}$ ) weighed more than female offspring ( $\mathbf{C}$ and $\mathbf{D})(\mathrm{p}<0.01)$ and offspring on the high fat diet (HFD; grey) weighed more than those on a control diet (CD; black) Data are presented as averages $\pm \mathrm{SE}$ and were analyzed by using two-way ANOVA with offspring nested within dam. (n: Males: WT $=13$; DB/+ = 12; $\mathrm{SAL}=14 ; \mathrm{LEP}=14$; Females: $\mathrm{WT}=11 ; \mathrm{DB} /+=9 ; \mathrm{SAL}=14 ; \mathrm{LEP}=13)(\wedge \mathrm{p}<$ $\left.0.07 ;{ }^{*} \mathrm{p}<0.05\right)$ 


\subsubsection{Offspring Feeding Behavior}

3.3.3.1 Total Food Consumption. Female offspring from DB/+ dams consumed significantly more food daily at 19 weeks of age than those from WT dams $(\mathrm{p}<0.05)$, with no difference at 4 or 11 weeks $(p<0.05)$ (Figure 11C). Females from LEP dams trended toward consuming more than females from SAL dams at 11 weeks $(\mathrm{p}<0.06)$, but there were no statistically significant differences at any of the ages (Figure 11D). There were no differences in food consumption among male offspring of different maternal groups at any age (Figure 11A and B). Overall, females consumed more than males ( $\mathrm{p}$ $0.01)$.

There were no differences in food consumption among the groups at 27 weeks (Figure 11E to H). However, mice on the high fat diet consumed significantly less food than those on the control diet, regardless of maternal leptin status $(\mathrm{p}<0.01)$. 

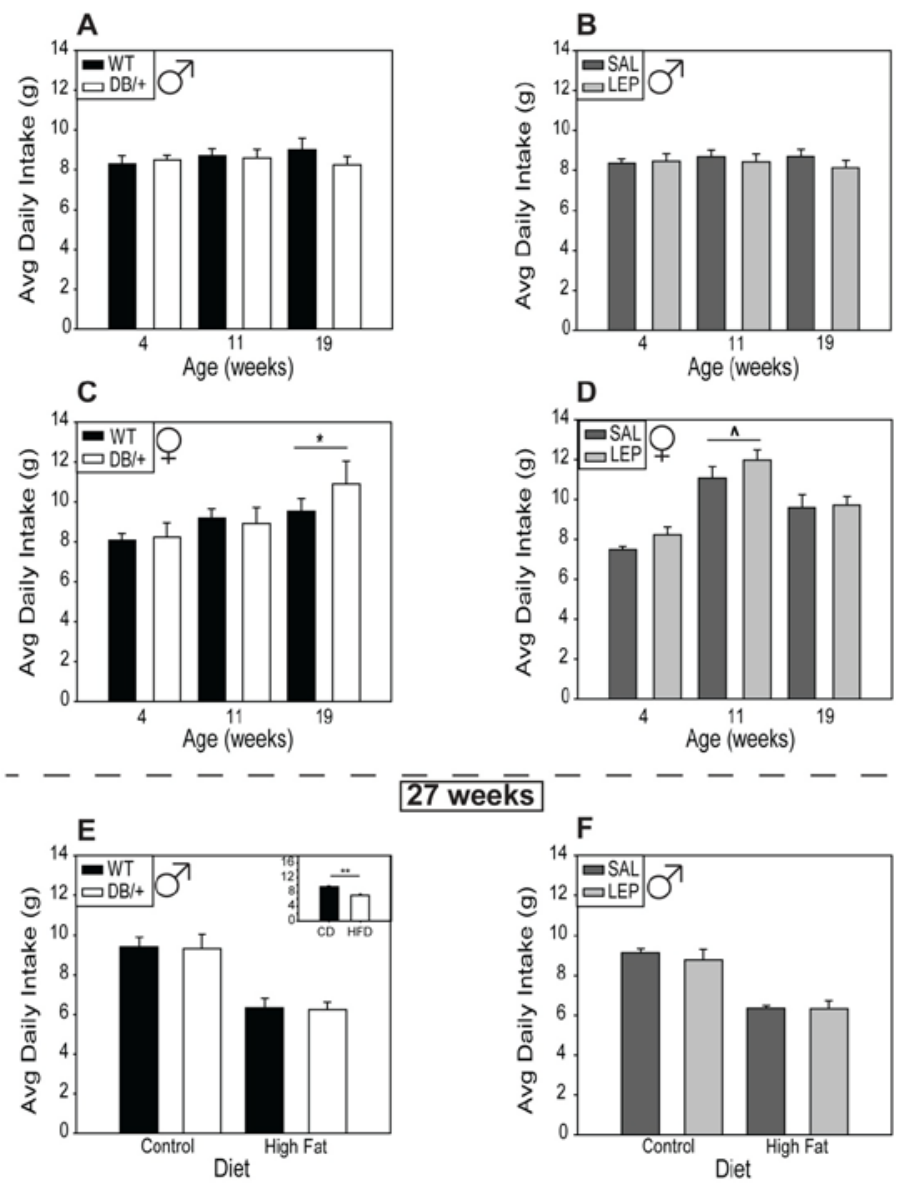

$\overline{27} \overline{\text { weeks }}$
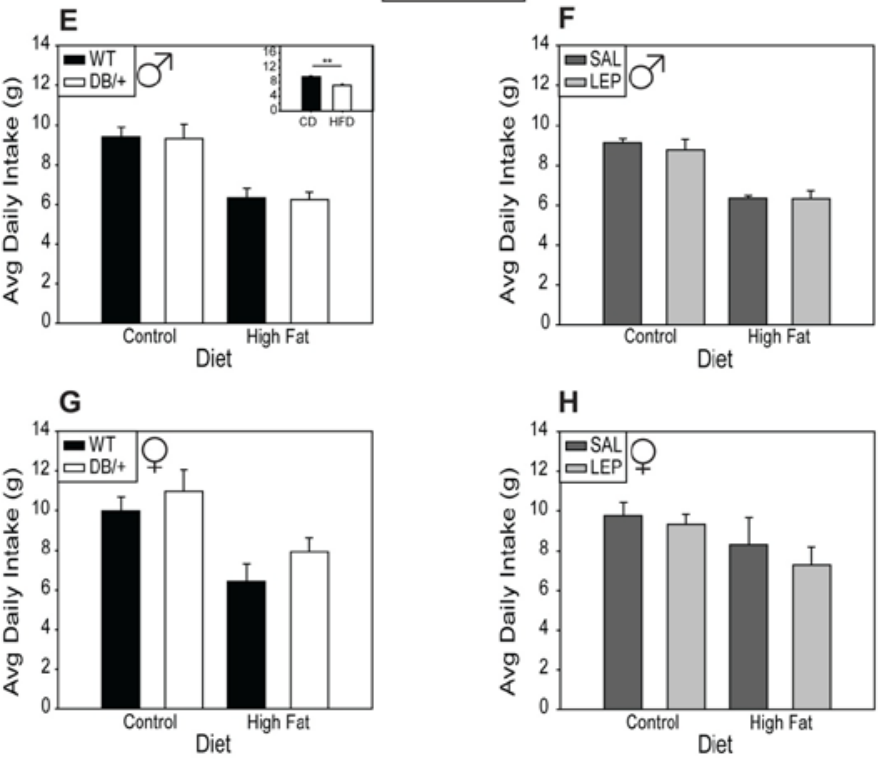

Figure 11. Food Consumption of Offspring from Hyperleptinemic Dams. Food intake was higher in female offspring from DB/+ dams in adulthood. Assessment at 5, 12 and 20 weeks of age: A: male offspring from WT (black) and DB/+ (white) dams, B: male offspring from SAL (dark gray) and LEP (light gray) dams, C: female offspring from WT and DB/+ dams, D: female offspring from SAL and LEP dams. Male (E and $\mathbf{F}$ ) and female offspring ( $\mathbf{G}$ and $\mathbf{H}$ ) food intake was reassessed at 27 weeks, some were on a high fat diet (HFD) and others on a control diet (CD). Offspring on a high fat diet consumed less regardless of maternal treatment (E inset). Data are presented as averages \pm SE and were analyzed by using analyses of variance split-plot in space and time with offspring nested within dam (n: Males: $\mathrm{WT}=10$; DB/+ = 10; SAL = 14; $\mathrm{LEP}=12$; Females: $\mathrm{WT}=9 ; \mathrm{DB} /+=6$; $\mathrm{SAL}=12 ; \mathrm{LEP}=13)\left(\wedge \mathrm{p}<0.06 ;{ }^{*} \mathrm{p}<0.05\right)$. 
3.3.3.2 Food Preference. Maternal hyperleptinemia in $\mathrm{DB} /+$ mice resulted in female offspring consuming more total food in the food preference test at some ages, but reduced their preference for a highly palatable diet. During the food preference test, female offspring from DB/+ dams consumed the same amount of the highly palatable diet (PD) as female offspring from WT dams, but consumed more of the control diet (CD), and thus more food total, at 5 and 20 weeks of age (Figure 11C). At 12 weeks, female offspring of WT and DB/+ consumed the same amount of both the PD and CD. Overall, females offspring from DB/+ dams consumed more CD then those from WT dams regardless of age $(\mathrm{p}<0.05)$. Females from LEP dams consumed more CD at 12 weeks than those from SAL dams (FIG 5D). At 5 and 20 weeks all females consumed more PD than $\mathrm{CD}$, with no difference among the groups. Overall, female offspring from LEP dams consumed more $\mathrm{CD}$ than those from SAL dams regardless of age $(\mathrm{p}<0.05)$. Males consumed more PD than $\mathrm{CD}$, but there were no differences among the groups at any age (Figure 12A and B). 

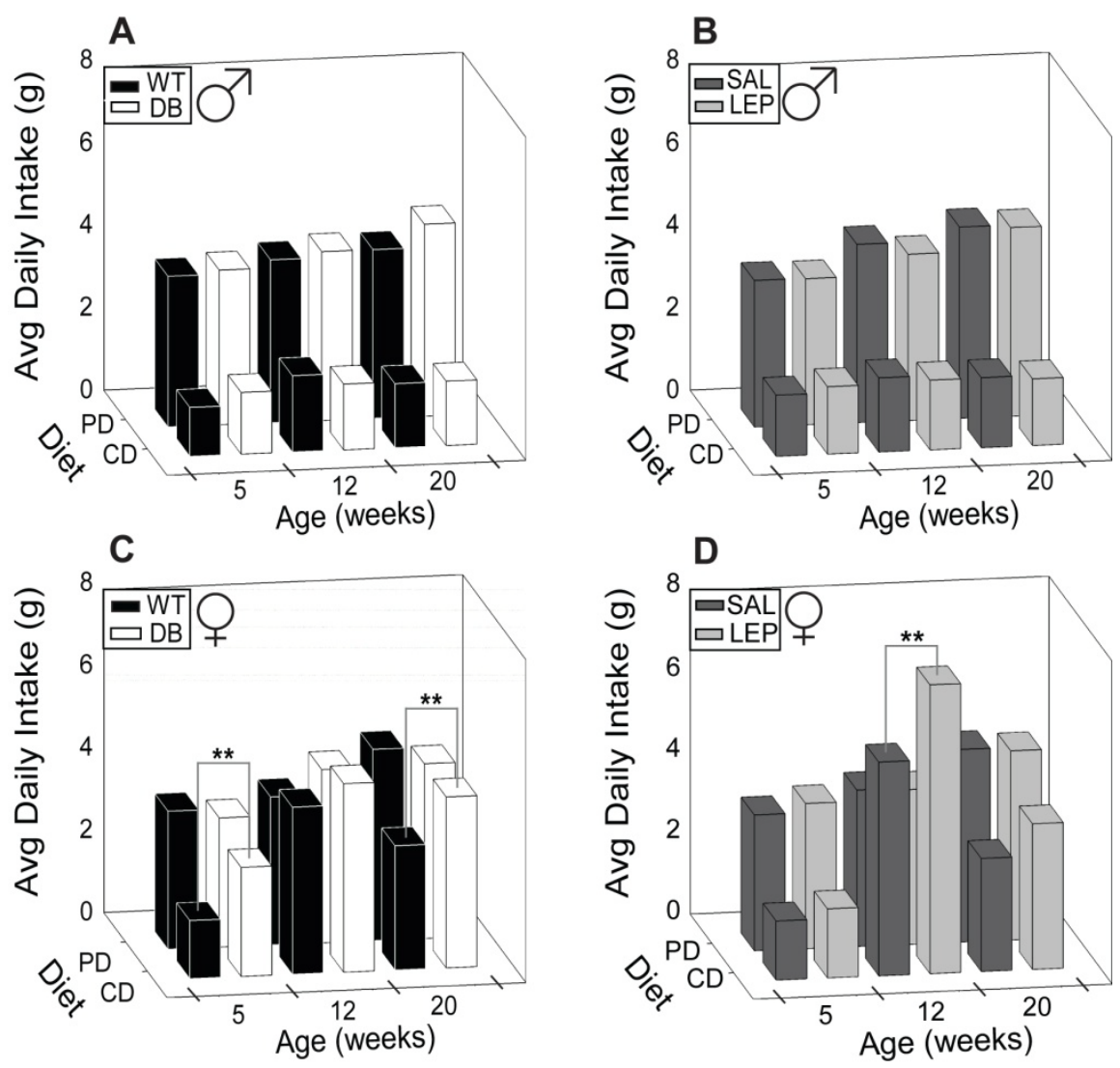

Figure 12. Food Preference of Offspring from Hyperleptinemic Dams. Female offspring from $\mathrm{DB} /+$ dams consumed more total food in the food preference test, and had a reduced preference of the palatable diet. Male $(\mathbf{A} \& \mathbf{B})$ and female $(\mathbf{C} \& \mathbf{D})$ offspring were given a control diet (CD) and a palatable diet (PD; sweetened condensed milk mixed with CD) $a b$ libitum. Data are presented as averages and were analyzed by using analyses of variance split-plot in space and time with offspring nested within dam (n: Males: $\mathrm{WT}=10 ; \mathrm{DB} /+=10 ; \mathrm{SAL}=14 ; \mathrm{LEP}=12$; Females: $\mathrm{WT}=9$; $\mathrm{DB} /+=6$; $\mathrm{SAL}=$ 12; LEP $=13)(* * \mathrm{p}<0.01)$.

\subsubsection{Offspring Locomotor Activity in Open Field}

Hyperleptinemia in DB/+ dams increased the locomotor activity level of female offspring at all ages. There was also an increase in locomotor activity male offspring of $\mathrm{db} /+$ dams, but only at 20 weeks (Figure 13A). Pairwise differences were statistically significant at 5 and 12 weeks on day 1 and 20 weeks on day 3 in the females (Figure 13C). While locomotor activity levels declined with age in the female offspring of WT 
dams, they were more consistent over time in female offspring of DB/+ dams. A significant effect on locomotor activity was not detected in female offspring from LEP dams compared to SAL, despite a numerical difference (Figure 12D) and decreasing pvalue overtime. Similarly, in males, locomotor activity declined with age in offspring of WT dams, but at 20 weeks of age male offspring from DB/+ dams were significantly more active than offspring from WT dams on days 2 and 3 (Figure 13A). There was no difference in locomotor activity level between the male offspring from LEP and SAL dams at any age (Figure 13B). There were no differences among the groups or across sexes in the time course of locomotor activity when evaluated in 5-mintue intervals across the 30-minute session (data not shown). All groups displayed higher levels of activity early in the session and lower levels later, indicating habituation to the open field. When the offspring locomotor activity was reevaluated (week 27) after cohort 2 was placed on a high fat diet, male offspring had no significant differences among groups (Figure 13E and F). The female offspring from DB/+ dams that were on the high fat diet were significantly more active than offspring from WT dams on days 1 and 2, while those on the control diet were not different (Figure 13G). There were no statistically significant differences between the female offspring from SAL and LEP dams (FIG 10H). Again, there were no differences among the groups in the slopes over the 5 minute increments of the 30 minute sessions. 

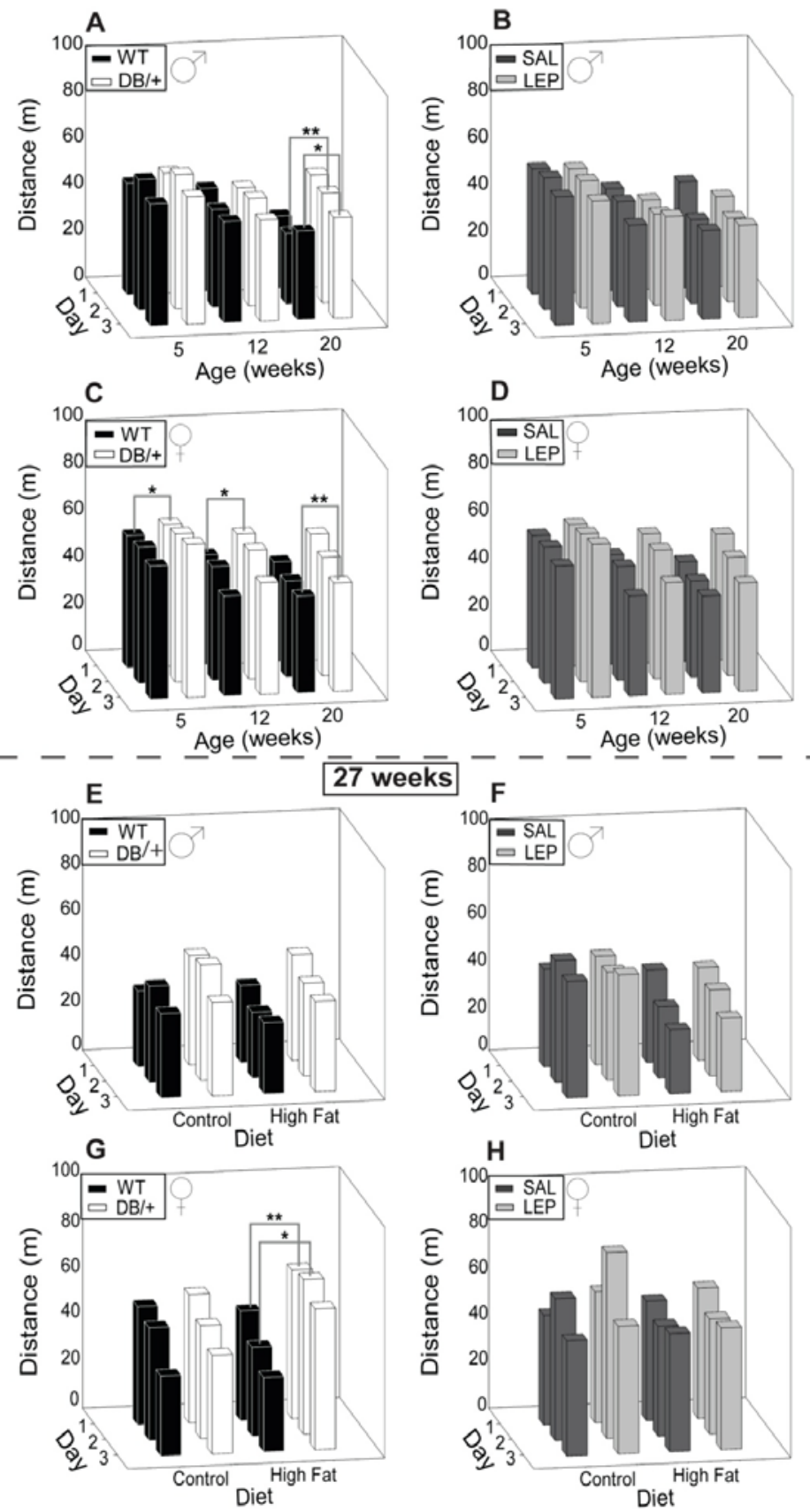

Figure 13. Locomotor Activity in an Open Field of Offspring from Hyperleptinemic Dams. Activity was increased in offspring from DB/+ dams. Assessment at 5, 12 and 20 weeks of age: A: male offspring from WT (black) and DB/+ (white) dams, B: male offspring from SAL (dark gray) and LEP (light gray) dams, C: female offspring from WT and DB/+ dams, D: female offspring from SAL and LEP dams. Male (E and $\mathbf{F}$ ) and female offspring ( $\mathbf{G}$ and $\mathbf{H}$ ) food intake was reassessed at 27 weeks, some were on a high fat diet (HFD) and others on a control diet (CD). Data are presented as averages and were analyzed by using analyses of variance split-plot in space and time with offspring nested within dam (n: Males: $\mathrm{WT}=10 ; \mathrm{DB} /+=10 ; \mathrm{SAL}=14$; $\mathrm{LEP}=13$; Females: WT = 10; DB/+ = 9; SAL = 14; LEP = 13) $\left({ }^{*} \mathrm{p}<0.05 ;{ }^{* *} \mathrm{p}<0.01\right)$. 


\subsubsection{Offspring Coordinated Motor Skills}

There were no impairments in rotarod activity that would reflect gross motor skill problems that would have affected their movement in the locomotor activity or anxietyrelated behavior analyses. There was no difference in learning over the 3 day time course at each age. There was a difference in performance in female offspring. Female offspring from $\mathrm{DB} /+$ dams remained on the rotarod significantly longer than their controls on day one at 11 weeks of age (Figure 14C). At the same age female offspring from LEP dams also had a significantly longer latency to fall than their controls (Figure 14D). There were no other differences among the females. There were no differences in coordinated motor skills among the males of any group (Figure 14A and B). 

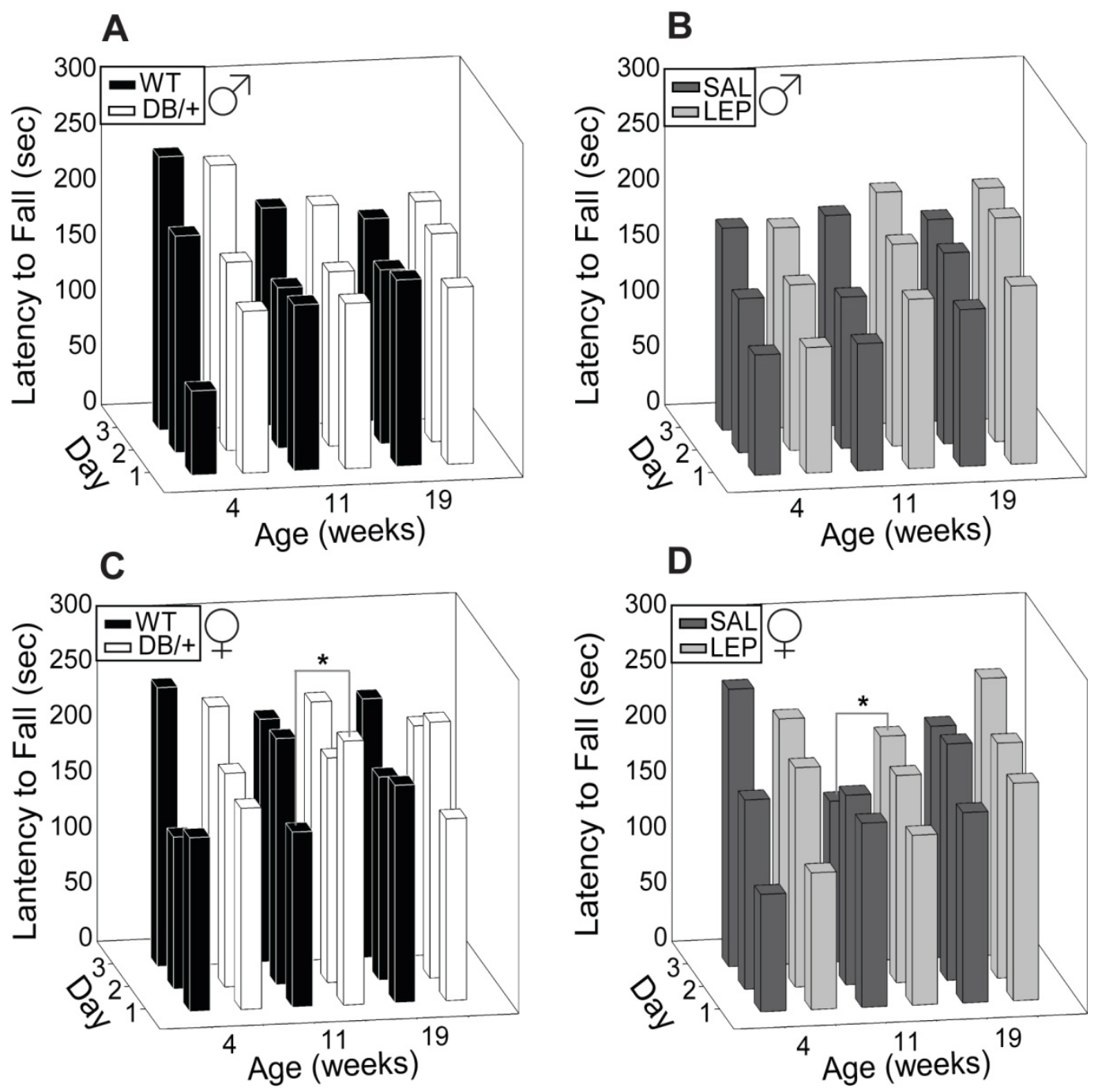

Figure 14. Coordinated Motor Skills of Offspring from Hyperleptinemic Dams. Coordinated motor skills were not impaired in any of the groups. Male (A and B) and female ( $\mathbf{C}$ and $\mathbf{D}$ ) offspring were tested on the rotarod for up to 5 minutes on 3 consecutive days at 4,11 and 19 weeks of age. Data are presented as averages and were analyzed by using analyses of variance split-plot in space and time with offspring nested within dam (n: Males: $\mathrm{WT}=10 ; \mathrm{DB} /+=10$; SAL = 14; $\mathrm{LEP}=13$; Females: $\mathrm{WT}=10$; $\mathrm{DB} /+=9 ; \mathrm{SAL}=14 ; \mathrm{LEP}=13)\left({ }^{*} \mathrm{p}<0.05\right)$

\subsubsection{Offspring Anxiety-related Behaviors}

There were no significant differences in amount of time spent in the closed sections of the zero-maze between maternal hyperleptinemic groups and their controls at any age (Figure 15). Female offspring from DB/+ dams had a higher number of entries 
into closed and open sections of the maze, compared to those from WT dams (Figure 16B). There were no other differences among treatment groups at ages 6 to 21 weeks (Figure 16). When mice were reevaluated at 28 weeks of age, after cohort 2 was placed on the high fat diet, there were no differences in the amount of time spent in the closed areas of the maze between experimental groups and their controls. However, there were significantly more exploratory behaviors (entering either open or closed areas or looking over the edge) in male offspring of $\mathrm{DB} /+$ dams than in offspring of WT dams on the control diet (Figure 16I). On the control diet, male offspring from LEP dams also took significantly more looks over the edge than male offspring of SAL dams (Figure 16K). 

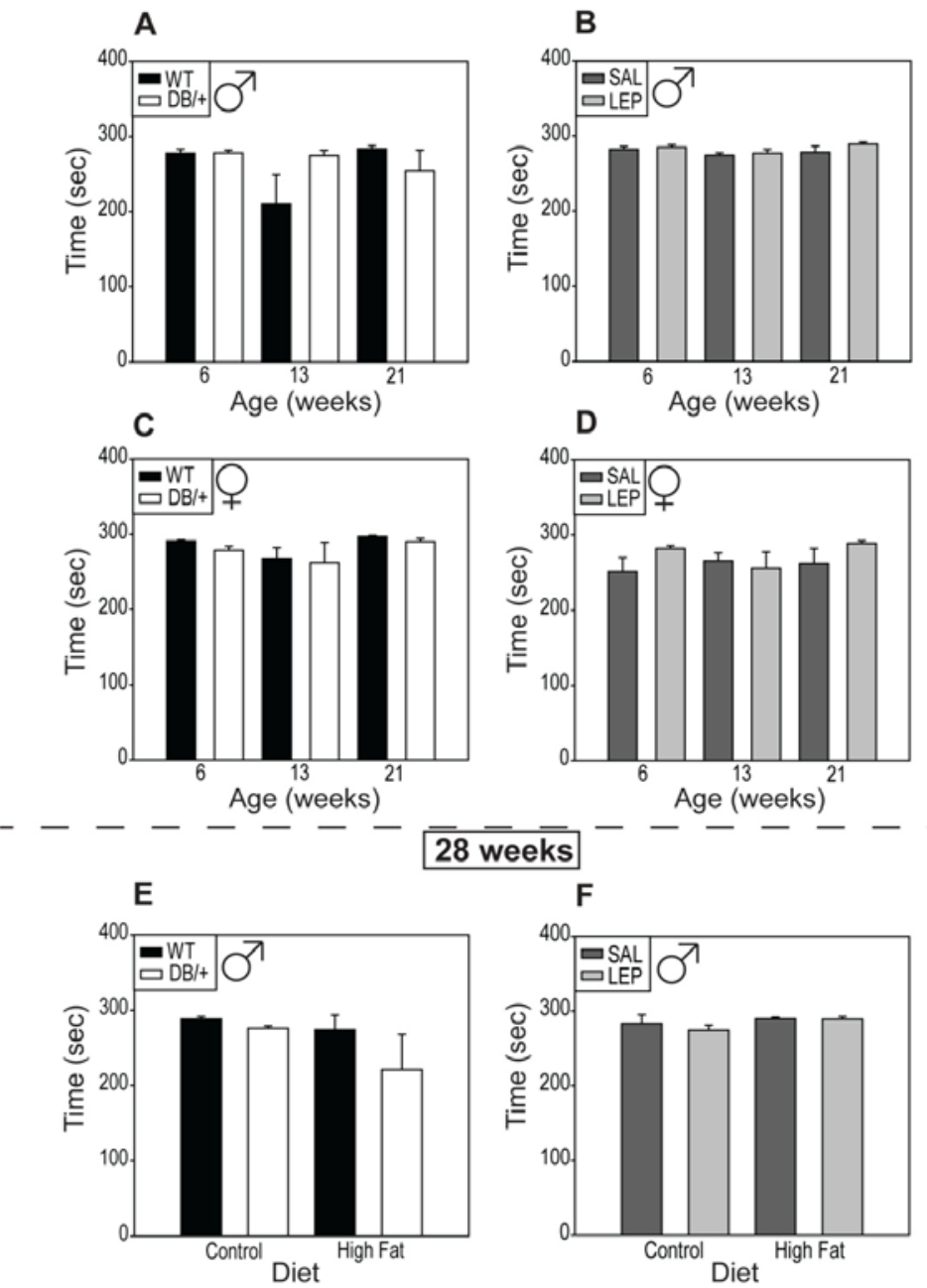

weeks
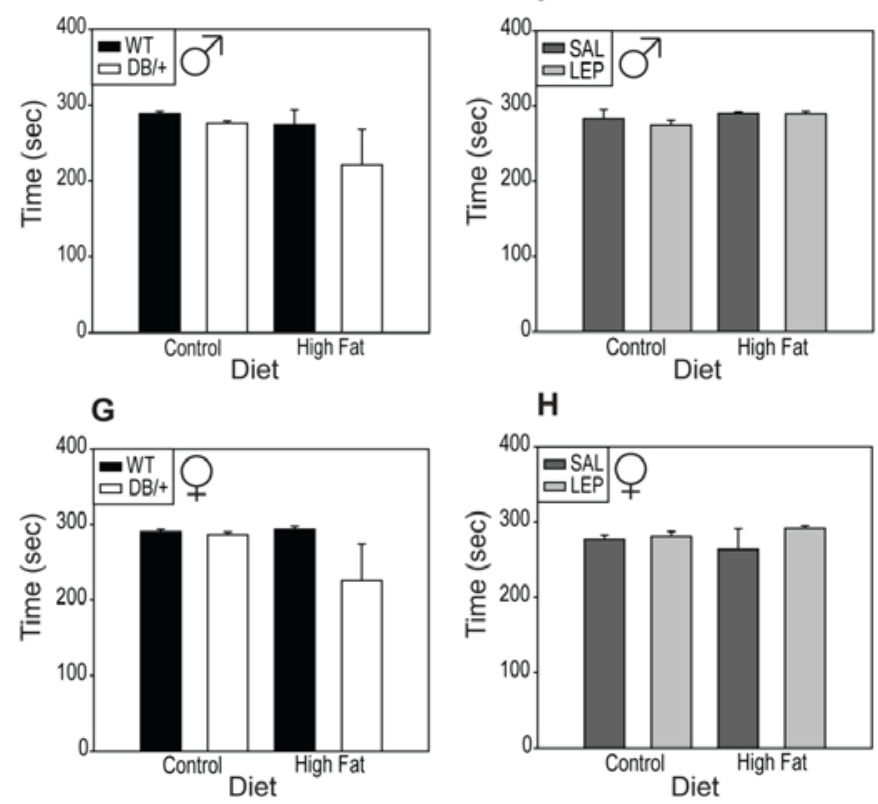

Figure 15. Anxiety-related Behaviors of Offspring from Hyperleptinemic Dams. Anxiety-like behaviors were not different among the treatment groups. The amount of time the offspring spent in closed areas of the zero-maze was assessed at weeks 5, 13 and 21 (A-D) and reassessed at 28 weeks (E-H), with some on a high fat diet (HFD) and others on a control diet (CD). Males (A,B, E,F); Females (B,C,G,H). Data are presented as averages $\pm \mathrm{SE}$ and were analyzed by using by using analyses of variance split-plot in space and time with offspring nested within dam (weeks 5-21) or three-way ANOVA (28 weeks) (n: Males: WT = 10; DB/+ = 10; SAL = 14; LEP = 13; Females: WT = 10; DB/+ = 9; $\mathrm{SAL}=14 ; \mathrm{LEP}=13$ ). 

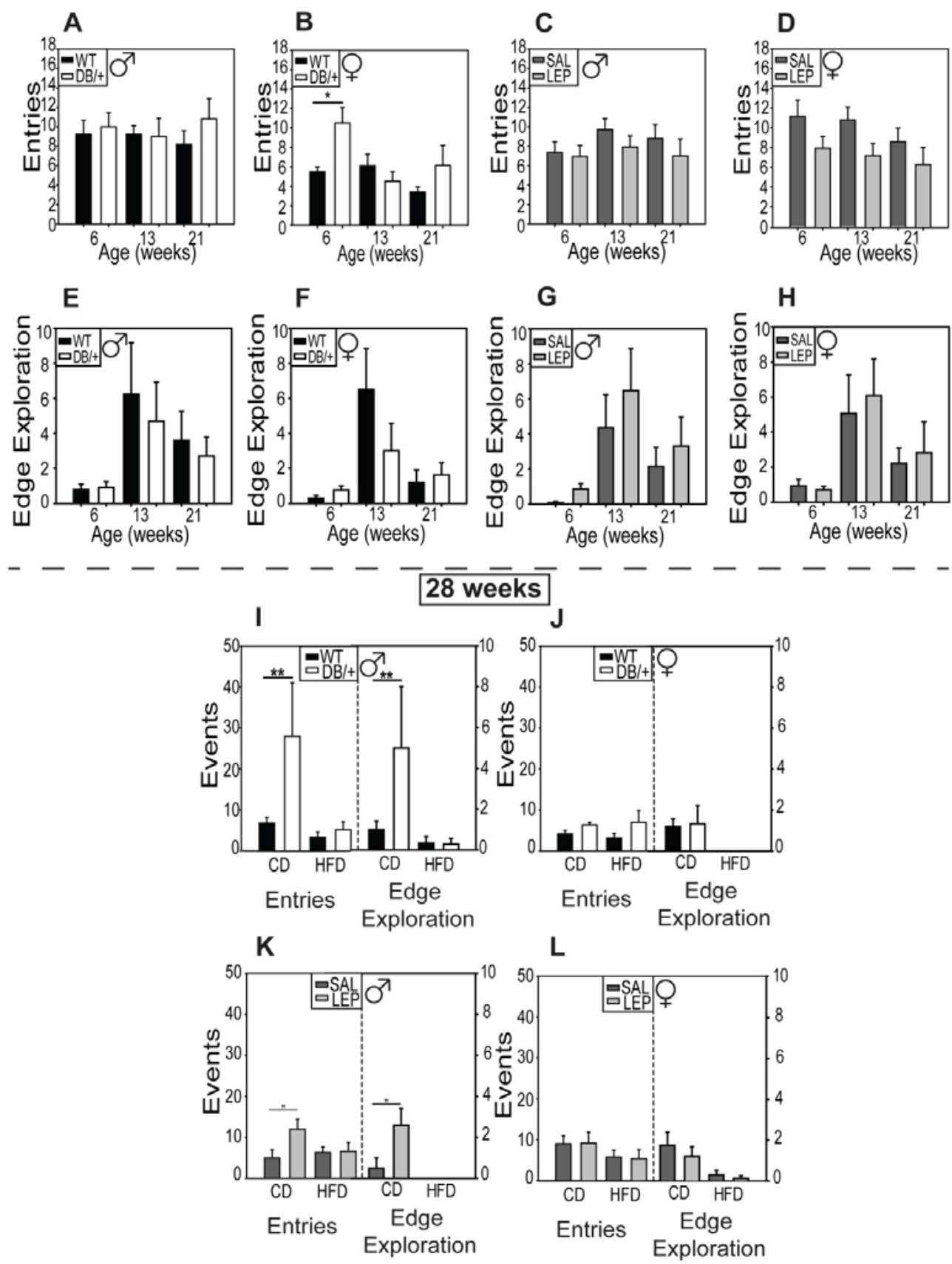

Figure 16. Exploratory Behaviors of Offspring from Hyperleptinemic Dams Exploratory behavior was increased in male offspring from $\mathrm{DB} /+$ dams. A to $\mathbf{D}$ : The number of entries into closed and open spaces on the zero maze and $\mathbf{E}$ to $\mathbf{F}$ : the number of times individual peered over the edge in open areas was assessed at 6,13 and 21 weeks. When cohort 2 was placed on a high fat diet (HFD) and cohort 1 remained on a control diet (CD) entries and edge explorations were reassessed at 28 weeks. Data are presented as averages \pm SE and were analyzed by using by using analyses of variance split-plot in space and time with offspring nested within dam (n: Males: WT $=10 ; \mathrm{DB} /+$ = 10; $\mathrm{SAL}=14 ; \mathrm{LEP}=13$; Females: $\mathrm{WT}=10 ; \mathrm{DB} /+=9$; $\mathrm{SAL}=14 ; \mathrm{LEP}=13)\left({ }^{*} \mathrm{p}<\right.$ $0.05 ; * * \mathrm{p}<0.01)$. 


\subsection{Discussion}

This study examined the role of high maternal leptin during pregnancy in developmental programming of offspring behaviors that regulate body size. Hyperleptinemia is associated with both maternal obesity and GDM (Kautzky-Willer et al., 2001; Matsumoto et al., 2003), both of which predispose offspring to obesity (Dabelea et al., 2000a; Tomita et al., 2003). We tested whether leptin was the mechanism behind this predisposition. Surprisingly, we showed that maternal hyperleptinemia, when isolated from maternal pathologies, was actually protective against excess weight gain, and that this results, at least in part, from greater spontaneous locomotor activity. However, locomotor activity was measured briefly in a novel environment in this study, which is not a highly accurate measure of long-term spontaneous physical activity or a measure of exercise. Therefore, further research is needed to understand the effect on maternal hyperleptinemia on offspring energy expenditure.

Sex differences were seen in this study and have been seen in other developmental programming studies. One study found that male rat offspring born to dams who were $20 \%$ caloric restricted during the first half of pregnancy weighed more in adulthood (Palou et al., 2010). A study in rats found 50\% food restriction during the first half of pregnancy resulted in both male and female offspring becoming obese, however it was more severe in the females (Desai et al., 2005). Male and female brains develop differently, particularly the hypothalamus, which is involved in both feeding and activity behaviors (Kotz et al., 2006; Sahu, 2004; Simerly, 2002). So, it is not unexpected that maternal hyperleptinemia affects male and female offspring behaviors differently. 
There were also differences between the two models of hyperleptinemia. The offspring from LEP dams tended to have similar patterns to the offspring from $\mathrm{DB} /+$ dams, but to a lesser degree. Although they are separate models and each have their own control, when looking at them as four groups, leptin levels in LEP dams was not significantly different from those of WT dams. This could be due to the fact that WT dams were mated to $\mathrm{DB} /+$ males, resulting in a mix of $\mathrm{WT}$ and $\mathrm{DB} /+$ conceptuses. It has been found that the offspring genotype can have an effect on maternal physiology (Petry et al., 2007).

Another possible explanation for the differences between the two models of hyperleptinemia could be that the surgery could have affected the maternal physiology, since it is a stressful event, and stress in known to affect pregnancy (Barlow et al., 1975; Parker and Douglas, 2010; Pollock et al., 1984). However, the glucocorticoids, which increase during stress, stimulate leptin production (Udden et al., 2003), which doesn't correspond with the lower leptin levels in both SAL and LEP dams.

The lower levels of leptin in LEP dams may also be due to negative feedback. Leptin negatively regulates itself (Tessier et al., 2013), so exogenous administration of leptin could cause a reduction in the production of on endogenous leptin. This would result in lower levels of leptin overall than would otherwise be achieved by administration.

\subsubsection{The Lepr ${ }^{\mathrm{db} /+}$ Model}

The Lepr ${ }^{\mathrm{db} /+}$ mouse model used in this study has been reported to develop GDM (Ishizuka et al., 1999; Satoh et al., 2003; Yamashita et al., 2001), but others have failed to find evidence of glucose intolerance in these mice (Harrod et al., 2011). There may be 
multiple factors that contribute to the onset of gestational diabetes mellitus in the heterozygous Lepr ${ }^{\mathrm{db} /+}$ mice, including the amount of fat in their diet during pregnancy, number of previous pregnancies, paternal genotype, or the presence of the misty allele in the control group (Harrod et al., 2011; Ishizuka et al., 1999; Lambin et al., 2007; Saito et al., 2003; Satoh et al., 2003; Yamashita et al., 2001; Yamashita et al., 2003b). Our findings were consistent with those of Harrod and others, (Harrod et al., 2011) who found no difference in fasting glucose or glucose tolerance at gestational day 18 between Lepr $^{\mathrm{db} /+}$ and Lepr ${ }^{+/+}$females on a 4 to $6 \%$ g/fat diet. Although it is still unclear under precisely which conditions Lepr ${ }^{\mathrm{db} /+}$ mouse can be used as a model for GDM, under current conditions it is an ideal model for hyperleptinemia in the absence of complications of obesity, diabetes or altered diet. The DB/+ dams in this study were heavier than the WT dams and the LEP dams were numerically heavier, which shows that this animals are likely leptin resistant, because high leptin levels usually decrease food consumption and in turn, weight. This indicates that the protective effect leptin had on the offspring in this study was likely not due to reduced food consumption and maternal weight gain, although we did not measure maternal food consumption.

\subsubsection{Hyperleptinemia Models}

Few studies have looked at the developmental programming effects of any period of maternal hyperleptinemia without other confounding factors. Those that have were generally consistent with our finding that maternal hyperleptinemia is protective. Leptin administration in rats from gestational day 14 through lactation protected offspring from diet induced obesity and diabetes symptoms (Stocker et al., 2004; Stocker et al., 2007). One study found that intake of a high fat diet was reduced in male offspring from leptin 
treated dams. Also, both male and female offspring from leptin treated dams had increased energy expenditure when on a high fat diet (Stocker et al., 2007). There is some evidence that mouse dams heterozygous for a mutation at the agouti locus have high leptin without other metabolic alterations at a young age, and their offspring were also resistant to obesity (Makarova et al., 2013). These offspring had decreased weight gain after weaning, were not hyperphagic, and gained less weight after fasting , though they were less responsive to exogenous leptin administration (Makarova et al., 2013). The same study found that offspring from wildtype mouse dams injected with leptin at gestational day 17 had lower body weight, and male offspring had reduced food intake and diet induced obesity(Makarova et al., 2013). In contrast, a previous study from our lab showed that female offspring from mouse dams that were food-restricted and administered leptin during the first half of pregnancy became obese when given a high fat diet (Pennington et al., 2012). High leptin in a food-restricted animal would not occur naturally and the combination during pregnancy has negative effects on the offspring. In combination with the current study, there seems to be a growing body of evidence demonstrating that leptin protects offspring from becoming obese when they are exposed during pregnancy. 


\subsubsection{Programming of Offspring Feeding Behavior and Locomotor Activity}

Table 7. Behavioral Outcome Summary

\begin{tabular}{|c|c|c|c|}
\hline \multirow[b]{2}{*}{ What was observed } & \multicolumn{2}{|c|}{$\begin{array}{l}\text { Direction of change in offspring } \\
\text { from hyperleptinemic dams }\end{array}$} & \multirow[b]{2}{*}{ What it may mean } \\
\hline & Males & Females & \\
\hline Body weight & $\downarrow$ & $\downarrow$ & maternal hyperleptinemia protects against weight gain \\
\hline Food consumption & - & $\uparrow$ & food consumption may be increased due to increased activity level \\
\hline Food preference & - & $\downarrow$ & may be due to an increase in overall food consumption \\
\hline Locomotor Activity & $\uparrow$ & $\uparrow$ & reason for reduced wieght gain \\
\hline Corridnated Motor Skills & - & $\uparrow$ & may be related to increased activity level \\
\hline Anxiety-like Behaviors & - & - & \\
\hline Exploratory Behaviors & $\uparrow$ & $\uparrow$ & may be related to increased activity level \\
\hline
\end{tabular}

The protection from weight gain associated with maternal hyperleptinemia was not explained by decreased consumption of either standard or high fat chow (Table 7). There were no differences in feeding behavior among male offspring from control and hyperleptinemic mothers, and female offspring from dams with pregnancy

hyperleptinemia actually consumed more food at some ages in both the food consumption and preference tests, despite reduced preference for the highly palatable diet (Table 7). Thus, it is possible that maternal hyperleptinemia contributes to the higher food consumption that has been observed in offspring of obese dams (Kirk et al., 2009; Walker et al., 2008), even though any effect on body weight was offset by other factors.

However, our results also demonstrate that the preference for high fat foods that has been shown in offspring of high fat-fed mothers (Ong and Muhlhausler, 2011; Vucetic et al., 2010; Walker et al., 2008) is not caused by hyperleptinemia, and may even be prevented by it. 
Adult offspring from dams with hyperleptinemia had reduced weight gain, which means that their energy intake to energy expenditure ratio may have been lower than that of offspring from control dams. A significant effect on short-term locomotor activity in an open field was detected in female offspring from $\mathrm{DB} /+$ dams, but not those from LEP dams compared to SAL, despite a numerical difference and a decreasing p-value overtime (Table 7). This indicates a possible dose effect, as LEP dams had less severe hyperleptinemia compared to their controls, than the DB/+ dams. Higher levels of locomotor activity in offspring of hyperleptinemic mothers may have contributed to the reduced weight gain and may explain the increase in food consumption, as they have higher energy demands. Other studies have also shown an increase in activity from offspring from females on high fat diets or have diabetes (Ornoy et al., 1998; Raygada et al., 1998; Rizzo et al., 1997a; Zhao et al., 2011). Raygada and others found that high intake of polyunsaturated fatty acids, which may be harmful in large amounts (Sultana et al., 2003), during pregnancy increased activity level of offspring (Raygada et al., 1998). In the rat, offspring of diabetic mothers treated with insulin had higher activity levels than either controls or diabetic mothers with poorly controlled glucose, suggesting that it is not hyperglycemia that affects offspring activity (Zhao et al., 2011); these mothers are hyperleptinemic which may explain the results. In humans, children of women with GDM display higher levels of hyperactivity associated with attention deficit disorder (Ornoy et al., 1998; Rizzo et al., 1997a). Although maternal hyperleptinemia is associated with high fat diet and diabetes it was not directly looked at in these studies, but it may explain the observed increase in offspring activity, which is clearly shown in the current study. The increase in activity may also increase energy expenditure. 
There are many ways energy is expended: reproduction, basal metabolic rate, digestion and food processing, and thermoregulation (Garland et al., 2011). Two other major categories are voluntary exercise and spontaneous physical activity (SPA). Spontaneous physical activity results in nonexercise activity thermogenesis (NEAT), which is the expenditure of energy. There is a balance between daily energy intake and daily energy expenditure and voluntary exercise and SPA can both play important roles in maintaining that balance (Garland et al., 2011). Humans in developed countries generally do not engage in much voluntary exercise, but this could potentially be offset by an increase in SPA, and therefore NEAT, if sedentary behaviors are reduced (Garland et al., 2011). Studies in both humans and rodents have shown that obese individuals are less active than individuals of normal weight and that increased spontaneous physical activity protects against obesity (Johannsen et al., 2008; Levine et al., 2005; PerezLeighton et al., 2013b; Teske et al., 2012). Two studies observed spontaneous ambulatory activity and posture in lean and obese women and found the lean women sat two or more hours less per day than obese women (Johannsen et al., 2008; Levine et al., 2005). One of the studies observed that lean women stood two hours more per day and spent twice as much time in activity than their obese counterparts (Johannsen et al., 2008). Studies in rats have found similar results (Perez-Leighton et al., 2013b; Teske et al., 2012) and have linked increased SPA with orexin receptor activation (Perez-Leighton et al., 2013a). High-activity rats were resistant to obesity and had higher NEAT, in addition to having increased expression of prepro-orexin mRNA and exhibiting more pronounced increase in activity when orexin was injected into the rostral lateral hypothalamus (Perez-Leighton et al., 2013b). Altogether, this suggests that increased SPA, and in turn NEAT, maybe 
sufficient to decrease body weight and can be programmed in offspring; however a more comprehensive study is warranted.

Hyperleptinemia resulted in more consistent increases in activity in female than male offspring of hyperleptinemic dams, despite similar protection from overweight in the two sexes (Table 7). Maternal hyperleptinemia is likely acting to prevent excessive weight gain through other mechanisms, such as increased basal metabolic rate, in male offspring.

Results of the coordinated motor skill and anxiety-related behaviors assays are also consistent with an increase in activity in female offspring of hyperleptinemic mothers. In the zero-plus maze, there was an increase in exploratory behaviors in male offspring of $\mathrm{DB} /+$ mothers, but there were no differences among treatment groups in the major measure of anxiety-related behaviors, time spent in the closed arms, suggesting that the exploratory behaviors may be more indicative of an overall increase in activity levels rather than a decrease in anxiety (Table 7). On the other hand, the increase in activity could be interpreted as an increase in exploratory behavior since they were in a novel environment. However, there was no difference in habituation over the 5 minute increments of the 30 minute sessions, indicating that exploratory behaviors were not different. Female offspring from hyperleptinemic dams stayed on the rotarod longer than their controls on 1 day at 11 weeks of age, which could indicate, rather than a difference in motor skills, a difference in physical activity. Alternatively, it could indicate altered learning or memory, as only the offspring of $\mathrm{DB} /+$ dams retained the rotarod performance gains made between days 1-3 at age 4 weeks through day 1 of testing at age 11 weeks. 
Effects of maternal hyperleptinemia on offspring learning and memory should be targeted in future investigations.

\subsubsection{Lactation Period}

One limitation of our study is that maternal hyperleptinemia may also have exerted an effect during the lactation period. In the current study, maternal leptin levels were not measured during lactation, therefore it is unknown whether the Lepr ${ }^{\mathrm{db} /+}$ dams remained hyperleptinemic after giving birth. It is reasonable to assume that the females with the leptin pumps were hyperleptinemic no more than 5 days postpartum, because the pump infusion lasts only 28 days according to the manufacturer. Lactation is a critical period of offspring development. In a study where offspring from obesity-resistant rat dams were cross fostered with obesity-prone dams, the offspring from obesity-resistant dams became obese, insulin resistant and had altered hypothalamic neuropeptides, insulin and leptin receptors (Gorski et al., 2006). Offspring raised in small litters during the lactation period, giving them access to more milk, become obese and hyperphagic (Plagemann et al., 1999). In a study where offspring were exposed to maternal junk food diet throughout gestation and lactation or just gestation, offspring exposed during both periods became more hyperphagic when on a junk food diet than those from dams on a junk food diet during gestation alone (Bayol et al., 2007).

A possible mechanism for these effects could be due to an alteration in the leptin surge that occurs in rats and mice early in the postnatal period (Alfaradhi and Ozanne, 2011). This surge is disproportionate to body fat and does not cause weight loss, which indicates that the hypothalamus is still developing (Bouret et al., 2004). Leptin has been shown to increase axon density and length in the hypothalamus of neonates in vitro, and 
is suggested to play an important role during this developmental period (Cottrell et al., 2009). When leptin is injected during early postnatal life it alters the expression of

neuropeptide Y, agouti related peptide and proopiomelanocortin, which are involved in appetite control in the hypothalamus (Proulx et al., 2002). Some studies have shown that leptin, consumed at physiological levels during lactation, protects against weight gain, leptin and insulin resistance and reduces food consumption and preference for high fat foods during adulthood in rats (Pico et al., 2007; Sanchez et al., 2008). Altogether, these studies indicate the importance of the lactation period in offspring development and that leptin may be a key player during this time. Further investigation needs to be done to separate effects of hyperleptinemia during gestation and lactation.

\subsection{Conclusion}

Maternal hyperleptinemia during pregnancy reduces offspring weight gain, even after exposure to an obesogenic diet. This is facilitated by an increase in basal activity. The increase in energy expenditure results in increased energy intake. To our knowledge, this is the first study to show that maternal hyperleptinemia alone, without the complications of obesity, diabetes or altered nutrition, programs offspring behavior in this manner. 


\section{BIBLIOGRAPHY}

Ahima R.S., Osei S.Y. (2004) Leptin signaling. Physiol. Behav. 81:223-241.

Ahima R.S., Lazar M.A. (2013) Physiology. The health risk of obesity--better metrics imperative. Science 341:856-858.

Akiyama H., Furukawa S., Wakisaka S., Maeda T. (2007) CTRP3/cartducin promotes proliferation and migration of endothelial cells. Mol. Cell. Biochem. 304:243-248.

Alfaradhi M.Z., Ozanne S.E. (2011) Developmental programming in response to maternal overnutrition. Front. Genet. 2:27.

Alfer J., Muller-Schottle F., Classen-Linke I., von Rango U., Happel L., Beier-Hellwig K., Rath W., Beier H.M. (2000) The endometrium as a novel target for leptin: differences in fertility and subfertility. Mol. Hum. Reprod. 6:595-601.

Arima T., Hata K., Tanaka S., Kusumi M., Li E., Kato K., Shiota K., Sasaki H., Wake N. (2006) Loss of the maternal imprint in Dnmt3Lmat-/- mice leads to a differentiation defect in the extraembryonic tissue. Dev. Biol. 297:361-373.

Bado A., Levasseur S., Attoub S., Kermorgant S., Laigneau J.P., Bortoluzzi M.N., Moizo L., Lehy T., Guerre-Millo M., Le Marchand-Brustel Y., Lewin M.J. (1998) The stomach is a source of leptin. Nature 394:790-793.

Baganz N.L., Horton R.E., Calderon A.S., Owens W.A., Munn J.L., Watts L.T., KoldzicZivanovic N., Jeske N.A., Koek W., Toney G.M., Daws L.C. (2008) Organic cation transporter 3: Keeping the brake on extracellular serotonin in serotonintransporter-deficient mice. Proc. Nat.l Acad. Sci. U S A 105:18976-18981.

Bahrenberg G., Behrmann I., Barthel A., Hekerman P., Heinrich P.C., Joost H.G., Becker W. (2002) Identification of the critical sequence elements in the cytoplasmic domain of leptin receptor isoforms required for Janus kinase/signal transducer and activator of transcription activation by receptor heterodimers. Mol. Endocrinol. 16:859-872.

Balthasar N., Coppari R., McMinn J., Liu S.M., Lee C.E., Tang V., Kenny C.D., McGovern R.A., Chua S.C., Jr., Elmquist J.K., Lowell B.B. (2004) Leptin 
receptor signaling in POMC neurons is required for normal body weight homeostasis. Neuron 42:983-991.

Barker D.J., Osmond C. (1986) Infant mortality, childhood nutrition, and ischaemic heart disease in England and Wales. Lancet 1:1077-1081.

Barker D.J., Winter P.D., Osmond C., Margetts B., Simmonds S.J. (1989) Weight in infancy and death from ischaemic heart disease. Lancet 2:577-580.

Barlow S.M., Morrison P.J., Sullivan F.M. (1975) Effects of acute and chronic stress on plasma corticosterone levels in the pregnant and non-pregnant mouse. J. Endocrinol. 66:90-9.

Bayol S.A., Farrington S.J., Stickland N.C. (2007) A maternal 'junk food' diet in pregnancy and lactation promotes an exacerbated taste for 'junk food' and a greater propensity for obesity in rat offspring. Br. J. Nutr. 98:843-851.

Bazer F.W., Spencer T.E., Johnson G.A., Burghardt R.C., Wu G. (2009) Comparative aspects of implantation. Reproduction 138:195-209.

Bernotiene E., Palmer G., Gabay C. (2006) The role of leptin in innate and adaptive immune responses. Arthritis Res. Ther. 8:217.

Bilbo S.D., Tsang V. (2010) Enduring consequences of maternal obesity for brain inflammation and behavior of offspring. FASEB J. 24:2104-2115.

Bjorbaek C., Elmquist J.K., El-Haschimi K., Kelly J., Ahima R.S., Hileman S., Flier J.S. (1999) Activation of SOCS-3 messenger ribonucleic acid in the hypothalamus by ciliary neurotrophic factor. Endocrinology 140:2035-2043.

Bohlen F., Kratzsch J., Mueller M., Seidel B., Friedman-Einat M., Witzigmann H., Teupser D., Koerner A., Storck M., Thiery J. (2007) Leptin inhibits cell growth of human vascular smooth muscle cells. Vascul. Pharmacol. 46:67-71.

Bolton P., Yamashita Y., Farquhar C.M. (2003) Role of fertility treatments in multiple pregnancy at National Women's Hospital from 1996 to 2001. Aust. N. Z. J. Obstet. Gynaecol. 43:364-368. 
Bonnin A., Levitt P. (2011) Fetal, maternal, and placental sources of serotonin and new implications for developmental programming of the brain. Neuroscience 197:1-7.

Bonnin A., Goeden N., Chen K., Wilson M.L., King J., Shih J.C., Blakely R.D., Deneris E.S., Levitt P. (2011) A transient placental source of serotonin for the fetal forebrain. Nature 472:347-350.

Borghese L., Fletcher G., Mathieu J., Atzberger A., Eades W.C., Cagan R.L., Rorth P. (2006) Systematic analysis of the transcriptional switch inducing migration of border cells. Dev. Cell. 10:497-508.

Bottalico B., Larsson I., Brodszki J., Hernandez-Andrade E., Casslen B., Marsal K., Hansson S.R. (2004) Norepinephrine transporter (NET), serotonin transporter (SERT), vesicular monoamine transporter (VMAT2) and organic cation transporters (OCT1, 2 and EMT) in human placenta from pre-eclamptic and normotensive pregnancies. Placenta 25:518-529.

Bouret S.G., Draper S.J., Simerly R.B. (2004) Formation of projection pathways from the arcuate nucleus of the hypothalamus to hypothalamic regions implicated in the neural control of feeding behavior in mice. J. Neurosci. 24:2797-2805.

Brelje T.C., Scharp D.W., Lacy P.E., Ogren L., Talamantes F., Robertson M., Friesen H.G., Sorenson R.L. (1993) Effect of homologous placental lactogens, prolactins, and growth hormones on islet B-cell division and insulin secretion in rat, mouse, and human islets: implication for placental lactogen regulation of islet function during pregnancy. Endocrinology 132:879-887.

Brion M.J., Ness A.R., Rogers I., Emmett P., Cribb V., Davey Smith G., Lawlor D.A. (2010) Maternal macronutrient and energy intakes in pregnancy and offspring intake at $10 \mathrm{y}$ : exploring parental comparisons and prenatal effects. Am. J. Clin. Nutr. 91:748-756.

Bult C.J., Eppig J.T., Kadin J.A., Richardson J.E., Blake J.A. (2008) The Mouse Genome Database (MGD): mouse biology and model systems., Nucleic Acids Res 36(Database issue):D724-8.

Castellucci M., De Matteis R., Meisser A., Cancello R., Monsurro V., Islami D., Sarzani R., Marzioni D., Cinti S., Bischof P. (2000) Leptin modulates extracellular matrix molecules and metalloproteinases: possible implications for trophoblast invasion. Mol. Hum. Reprod. 6:951-958. 
Cervero A., Horcajadas J.A., MartIn J., Pellicer A., Simon C. (2004) The leptin system during human endometrial receptivity and preimplantation development. J. Clin. Endocrinol. Metab. 89:2442-2451.

Cervero A., Horcajadas J.A., Dominguez F., Pellicer A., Simon C. (2005) Leptin system in embryo development and implantation: a protein in search of a function. Reprod. Biomed. Online 10:217-223.

Cervero A., Dominguez F., Horcajadas J.A., Quinonero A., Pellicer A., Simon C. (2006) The role of the leptin in reproduction. Curr. Opin. Obstet. Gynecol. 18:297-303.

Choi J.H., Lee H.J., Yang T.H., Kim G.J. (2012) Effects of hypoxia inducible factors1alpha on autophagy and invasion of trophoblasts. Clin. Exp. Reprod. Med. 39:73-80.

Chuang H.C., Chang C.W., Chang G.D., Yao T.P., Chen H. (2006) Histone deacetylase 3 binds to and regulates the GCMa transcription factor. Nucleic Acids Res. 34:1459-1469.

Clarke L., Heasman L., Juniper D.T., Symonds M.E. (1998) Maternal nutrition in earlymid gestation and placental size in sheep. Br. J. Nutr. 79:359-364.

Coleman D.L. (1973) Effects of parabiosis of obese with diabetes and normal mice. Diabetologia 9:294-298.

Cottrell E.C., Cripps R.L., Duncan J.S., Barrett P., Mercer J.G., Herwig A., Ozanne S.E. (2009) Developmental changes in hypothalamic leptin receptor: relationship with the postnatal leptin surge and energy balance neuropeptides in the postnatal rat. Am. J. Physiol. Regul. Integr. Comp. Physiol. 296:R631-639.

Cross J.C., Werb Z., Fisher S.J. (1994) Implantation and the placenta: key pieces of the development puzzle. Science 266:1508-1518.

Cumin F., Baum H.P., Levens N. (1996) Leptin is cleared from the circulation primarily by the kidney. Int. J. Obes. Relat. Metab. Disord. 20:1120-1126.

Dabelea D., Knowler W.C., Pettitt D.J. (2000a) Effect of diabetes in pregnancy on offspring: follow-up research in the Pima Indians. J. Matern. Fetal Med. 9:83-88. 
Dabelea D., Hanson R.L., Lindsay R.S., Pettitt D.J., Imperatore G., Gabir M.M., Roumain J., Bennett P.H., Knowler W.C. (2000b) Intrauterine exposure to diabetes conveys risks for type 2 diabetes and obesity: a study of discordant sibships. Diabetes 49:2208-2211.

Dahmen N., Bierbrauer J., Kasten M. (2001) Increased prevalence of obesity in narcoleptic patients and relatives. Eur. Arch. Psychiatry Clin. Neurosci. 251:8589.

Dennis G., Jr., Sherman B.T., Hosack D.A., Yang J., Gao W., Lane H.C., Lempicki R.A. (2003) DAVID: Database for Annotation, Visualization, and Integrated Discovery. Genome Biol. 4:P3.

Desai M., Gayle D., Babu J., Ross M.G. (2005) Programmed obesity in intrauterine growth-restricted newborns: modulation by newborn nutrition. Am. J. Physiol. Regul. Integr. Comp. Physiol. 288:R91-96.

Donato J., Jr., Cravo R.M., Frazao R., Elias C.F. (2011) Hypothalamic sites of leptin action linking metabolism and reproduction. Neuroendocrinology 93:9-18.

Doridot L., Passet B., Mehats C., Rigourd V., Barbaux S., Ducat A., Mondon F., Vilotte M., Castille J., Breuiller-Fouche M., Daniel N., le Provost F., Bauchet A.L., Baudrie V., Hertig A., Buffat C., Simeoni U., Germain G., Vilotte J.L., Vaiman D. (2013) Preeclampsia-like symptoms induced in mice by fetoplacental expression of STOX1 are reversed by aspirin treatment. Hypertension 61:662668.

Drake A.J., Reynolds R.M. (2010) Impact of maternal obesity on offspring obesity and cardiometabolic disease risk. Reproduction 140:387-398.

Elias C.F., Aschkenasi C., Lee C., Kelly J., Ahima R.S., Bjorbaek C., Flier J.S., Saper C.B., Elmquist J.K. (1999) Leptin differentially regulates NPY and POMC neurons projecting to the lateral hypothalamic area. Neuron 23:775-786.

Farley D.M., Choi J., Dudley D.J., Li C., Jenkins S.L., Myatt L., Nathanielsz P.W. (2010) Placental amino acid transport and placental leptin resistance in pregnancies complicated by maternal obesity. Placenta 31:718-724.

Ford E.S., Li C., Zhao G. (2010) Prevalence and correlates of metabolic syndrome based on a harmonious definition among adults in the US. J. Diabetes 2:180-193. 
Forhead A.J., Lamb C.A., Franko K.L., O'Connor D.M., Wooding F.B., Cripps R.L., Ozanne S., Blache D., Shen Q.W., Du M., Fowden A.L. (2008) Role of leptin in the regulation of growth and carbohydrate metabolism in the ovine fetus during late gestation. J. Physiol. 586:2393-2403.

Frederich R.C., Hamann A., Anderson S., Lollmann B., Lowell B.B., Flier J.S. (1995) Leptin levels reflect body lipid content in mice: evidence for diet-induced resistance to leptin action. Nat. Med. 1:1311-1314.

Galosy S.S., Talamantes F. (1995) Luteotropic actions of placental lactogens at midpregnancy in the mouse. Endocrinology 136:3993-4003.

Garland T., Jr., Schutz H., Chappell M.A., Keeney B.K., Meek T.H., Copes L.E., Acosta W., Drenowatz C., Maciel R.C., van Dijk G., Kotz C.M., Eisenmann J.C. (2011) The biological control of voluntary exercise, spontaneous physical activity and daily energy expenditure in relation to obesity: human and rodent perspectives. J. Exp. Biol. 214:206-229.

Gilmartin A.B., Ural S.H., Repke J.T. (2008) Gestational diabetes mellitus. Rev. Obstet. Gynecol. 1:129-134.

Gokul G., Ramakrishna G., Khosla S. (2009) Reprogramming of HeLa cells upon DNMT3L overexpression mimics carcinogenesis. Epigenetics 4:322-329.

Gorski J.N., Dunn-Meynell A.A., Hartman T.G., Levin B.E. (2006) Postnatal environment overrides genetic and prenatal factors influencing offspring obesity and insulin resistance. Am. J. Physiol. Regul. Integr. Comp. Physiol. 291:R768778.

Green E.D., Maffei M., Braden V.V., Proenca R., DeSilva U., Zhang Y., Chua S.C., Jr., Leibel R.L., Weissenbach J., Friedman J.M. (1995) The human obese (OB) gene: RNA expression pattern and mapping on the physical, cytogenetic, and genetic maps of chromosome 7. Genome Res. 5:5-12.

Guelinckx I., Devlieger R., Beckers K., Vansant G. (2008) Maternal obesity: pregnancy complications, gestational weight gain and nutrition. Obes. Rev. 9:140-150.

Halaas J.L., Gajiwala K.S., Maffei M., Cohen S.L., Chait B.T., Rabinowitz D., Lallone R.L., Burley S.K., Friedman J.M. (1995) Weight-reducing effects of the plasma protein encoded by the obese gene. Science 269:543-546. 
Hansson S.R., Mezey E., Hoffman B.J. (1998) Serotonin transporter messenger RNA in the developing rat brain: early expression in serotonergic neurons and transient expression in non-serotonergic neurons. Neuroscience 83:1185-1201.

Hara J., Beuckmann C.T., Nambu T., Willie J.T., Chemelli R.M., Sinton C.M., Sugiyama F., Yagami K., Goto K., Yanagisawa M., Sakurai T. (2001) Genetic ablation of orexin neurons in mice results in narcolepsy, hypophagia, and obesity. Neuron 30:345-354.

Harrod J.S., Rada C.C., Pierce S.L., England S.K., Lamping K.G. (2011) Altered contribution of RhoA/Rho kinase signaling in contractile activity of myometrium in leptin receptor-deficient mice. Am. J. Physiol. Endocrinol. Metab. 301:E362369.

Hervey G.R. (1959) The effects of lesions in the hypothalamus in parabiotic rats. J. Physiol. 145:336-352.

Hickey M.S., Israel R.G., Gardiner S.N., Considine R.V., McCammon M.R., Tyndall G.L., Houmard J.A., Marks R.H., Caro J.F. (1996) Gender differences in serum leptin levels in humans. Biochem. Mol. Med. 59:1-6.

Hillier T.A., Pedula K.L., Schmidt M.M., Mullen J.A., Charles M.A., Pettitt D.J. (2007) Childhood obesity and metabolic imprinting: the ongoing effects of maternal hyperglycemia. Diabetes Care 30:2287-2292.

Hoegh A.M., Borup R., Nielsen F.C., Sorensen S., Hviid T.V. (2010) Gene expression profiling of placentas affected by pre-eclampsia. J. Biomed. Biotechnol. 2010:787545.

Hoggard N., Hunter L., Duncan J.S., Williams L.M., Trayhurn P., Mercer J.G. (1997) Leptin and leptin receptor mRNA and protein expression in the murine fetus and placenta. Proc. Natl. Acad. Sci. U. S. A. 94:11073-11078.

Hsieh S.Y., Huang S.F., Yu M.C., Yeh T.S., Chen T.C., Lin Y.J., Chang C.J., Sung C.M., Lee Y.L., Hsu C.Y. (2010) Stathmin1 overexpression associated with polyploidy, tumor-cell invasion, early recurrence, and poor prognosis in human hepatoma. Mol. Carcinog. 49:476-487. 
Huang C., Snider F., Cross J.C. (2009) Prolactin receptor is required for normal glucose homeostasis and modulation of beta-cell mass during pregnancy. Endocrinology 150:1618-1626.

Hung T.H., Hsieh T.T., Chen S.F., Li M.J., Yeh Y.L. (2013) Autophagy in the human placenta throughout gestation. PLoS One 8:e83475.

Huppertz B., Abe E., Murthi P., Nagamatsu T., Szukiewicz D., Salafia C. (2007) Placental angiogenesis, maternal and fetal vessels--a workshop report. Placenta 28 Suppl A:S94-96.

Ishimori T., Nakano S., Kagawa M., Yokoe K., Togami T., Asakura H., Kusuhara T., Ohkawa M., Nagao S., Yamashita Y., Sugiura S. (2003) Virtual endoscopic images by 3D FASE cisternography for neurovascular compression. Magn. Reson. Med. Sci. 2:145-149.

Ishizuka T., Klepcyk P., Liu S., Panko L., Gibbs E.M., Friedman J.E. (1999) Effects of overexpression of human GLUT4 gene on maternal diabetes and fetal growth in spontaneous gestational diabetic C57BLKS/J Lepr(db/+) mice. Diabetes 48:10611069.

Islami D., Bischof P., Chardonnens D. (2003) Modulation of placental vascular endothelial growth factor by leptin and hCG. Mol. Hum. Reprod. 9:395-398.

Jansson N., Greenwood S.L., Johansson B.R., Powell T.L., Jansson T. (2003) Leptin stimulates the activity of the system A amino acid transporter in human placental villous fragments. J. Clin. Endocrinol. Metab. 88:1205-1211.

Jansson T., Ekstrand Y., Bjorn C., Wennergren M., Powell T.L. (2002) Alterations in the activity of placental amino acid transporters in pregnancies complicated by diabetes. Diabetes 51:2214-2219.

Johannsen D.L., Welk G.J., Sharp R.L., Flakoll P.J. (2008) Differences in daily energy expenditure in lean and obese women: the role of posture allocation. Obesity (Silver Spring) 16:34-39.

Kamran P., Sereti K.I., Zhao P., Ali S.R., Weissman I.L., Ardehali R. (2013) Parabiosis in mice: a detailed protocol. J. Vis. Exp. 
Kautzky-Willer A., Pacini G., Tura A., Bieglmayer C., Schneider B., Ludvik B., Prager R., Waldhausl W. (2001) Increased plasma leptin in gestational diabetes. Diabetologia 44:164-172.

Kawashima A., Sekizawa A., Ventura W., Koide K., Hori K., Okai T., Masashi Y., Furuya K., Mizumoto Y. (2014) Increased levels of cell-free human placental lactogen mRNA at 28-32 gestational weeks in plasma of pregnant women with placenta previa and invasive placenta. Reprod. Sci. 21:215-220.

Kidder B.L., Palmer S. (2012) HDAC1 regulates pluripotency and lineage specific transcriptional networks in embryonic and trophoblast stem cells. Nucleic Acids Res. 40:2925-2939.

Kirk S.L., Samuelsson A.M., Argenton M., Dhonye H., Kalamatianos T., Poston L., Taylor P.D., Coen C.W. (2009) Maternal obesity induced by diet in rats permanently influences central processes regulating food intake in offspring. PLoS One 4:e5870.

Kitahara S., Yamashita M., Ikemoto Y. (2003) Effects of pentobarbital on purinergic P2X receptors of rat dorsal root ganglion neurons. Can. J. Physiol. Pharmacol. 81:1085-1091.

Kitawaki J., Koshiba H., Ishihara H., Kusuki I., Tsukamoto K., Honjo H. (2000) Expression of leptin receptor in human endometrium and fluctuation during the menstrual cycle. J. Clin. Endocrinol. Metab. 85:1946-1950.

Kotagal S., Krahn L.E., Slocumb N. (2004) A putative link between childhood narcolepsy and obesity. Sleep Med. 5:147-150.

Kotz C.M. (2008) Rewired to be thin? When exercise hits the brain. Am. J. Physiol. Regul. Integr. Comp. Physiol. 294:R288-289.

Kotz C.M., Wang C., Teske J.A., Thorpe A.J., Novak C.M., Kiwaki K., Levine J.A. (2006) Orexin A mediation of time spent moving in rats: neural mechanisms. Neuroscience 142:29-36.

Kowalski T.J., Liu S.M., Leibel R.L., Chua S.C., Jr. (2001) Transgenic complementation of leptin-receptor deficiency. I. Rescue of the obesity/diabetes phenotype of LEPR-null mice expressing a LEPR-B transgene. Diabetes 50:425-435. 
Kusama Y., Sato K., Kimura N., Mitamura J., Ohdaira H., Yoshida K. (2009) Comprehensive analysis of expression pattern and promoter regulation of human autophagy-related genes. Apoptosis 14:1165-1175.

Lambin S., van Bree R., Caluwaerts S., Vercruysse L., Vergote I., Verhaeghe J. (2007) Adipose tissue in offspring of Lepr(db/+) mice: early-life environment vs. genotype. Am. J. Physiol. Endocrinol. Metab. 292:E262-271.

Lawlor D.A., Fraser A., Lindsay R.S., Ness A., Dabelea D., Catalano P., Davey Smith G., Sattar N., Nelson S.M. (2010) Association of existing diabetes, gestational diabetes and glycosuria in pregnancy with macrosomia and offspring body mass index, waist and fat mass in later childhood: findings from a prospective pregnancy cohort. Diabetologia 53:89-97.

Lee G., Li C., Montez J., Halaas J., Darvishzadeh J., Friedman J.M. (1997) Leptin receptor mutations in $129 \mathrm{db} 3 \mathrm{~J} / \mathrm{db} 3 \mathrm{~J}$ mice and $\mathrm{NIH}$ facp/facp rats. Mamm. Genome. 8:445-447.

Levine J.A., Lanningham-Foster L.M., McCrady S.K., Krizan A.C., Olson L.R., Kane P.H., Jensen M.D., Clark M.M. (2005) Interindividual variation in posture allocation: possible role in human obesity. Science 307:584-586.

Lewandowski K., Horn R., O'Callaghan C.J., Dunlop D., Medley G.F., O'Hare P., Brabant G. (1999) Free leptin, bound leptin, and soluble leptin receptor in normal and diabetic pregnancies. J. Clin. Endocrinol. Metab. 84:300-306.

Littell R.C., Henry P.R., Ammerman C.B. (1998) Statistical analysis of repeated measures data using SAS procedures. J. Anim. Sci. 76:1216-1231.

Maamra M., Bidlingmaier M., Postel-Vinay M.C., Wu Z., Strasburger C.J., Ross R.J. (2001) Generation of human soluble leptin receptor by proteolytic cleavage of membrane-anchored receptors. Endocrinology 142:4389-4393.

Magarinos M.P., Sanchez-Margalet V., Kotler M., Calvo J.C., Varone C.L. (2007) Leptin promotes cell proliferation and survival of trophoblastic cells. Biol. Reprod. 76:203-210.

Makarova E.N., Chepeleva E.V., Panchenko P.E., Bazhan N.M. (2013) The influence of abnormally high leptin levels during pregnancy on the metabolic phenotypes in progeny mice. Am. J. Physiol. Regul. Integr. Comp. Physiol. 
Malassine A., Frendo J.L., Evain-Brion D. (2003) A comparison of placental development and endocrine functions between the human and mouse model. Hum. Reprod. Update 9:531-539.

Malik N.M., Carter N.D., Murray J.F., Scaramuzzi R.J., Wilson C.A., Stock M.J. (2001) Leptin requirement for conception, implantation, and gestation in the mouse. Endocrinology 142:5198-5202.

Mannik J., Vaas P., Rull K., Teesalu P., Laan M. (2012) Differential placental expression profile of human Growth Hormone/Chorionic Somatomammotropin genes in pregnancies with pre-eclampsia and gestational diabetes mellitus. Mol. Cell Endocrinol. 355:180-187.

Mannik J., Vaas P., Rull K., Teesalu P., Rebane T., Laan M. (2010) Differential expression profile of growth hormone/chorionic somatomammotropin genes in placenta of small- and large-for-gestational-age newborns. J. Clin. Endocrinol. Metab. 95:2433-2442.

Marino G., Salvador-Montoliu N., Fueyo A., Knecht E., Mizushima N., Lopez-Otin C. (2007) Tissue-specific autophagy alterations and increased tumorigenesis in mice deficient in Atg4C/autophagin-3. J. Biol. Chem. 282:18573-18583.

Masuzaki H., Ogawa Y., Sagawa N., Hosoda K., Matsumoto T., Mise H., Nishimura H., Yoshimasa Y., Tanaka I., Mori T., Nakao K. (1997) Nonadipose tissue production of leptin: leptin as a novel placenta-derived hormone in humans. Nat. Med. 3:1029-1033.

Matsumoto M., Yamashita H., Kitagawa K., Kohriyama T. (2003) [Molecular mechanism of brain infarction]. Rinsho Shinkeigaku 43:891-893.

McMinn J.E. (2003) Lesson from Models of Monogenic and Polygenic Obesity in Rodents, in: M. Tschoep (Ed.), Obesity.

Mesman I., Roseboom T.J., Bonsel G.J., Gemke R.J., van der Wal M.F., Vrijkotte T.G. (2009) Maternal pre-pregnancy body mass index explains infant's weight and BMI at 14 months: results from a multi-ethnic birth cohort study. Arch. Dis. Child. 94:587-595.

Miehle K., Stepan H., Fasshauer M. (2012) Leptin, adiponectin and other adipokines in gestational diabetes mellitus and pre-eclampsia. Clin. Endocrinol. (Oxf) 76:2-11. 
Moiseiwitsch J.R., Lauder J.M. (1995) Serotonin regulates mouse cranial neural crest migration. Proc. Natl. Acad. Sci. U. S. A. 92:7182-7186.

Morash B., Li A., Murphy P.R., Wilkinson M., Ur E. (1999) Leptin gene expression in the brain and pituitary gland. Endocrinology 140:5995-5998.

Mustonen A.-M. (2003) Seasonality, photoperiod and nutritional status in the control of endocrinological weight-regulation, Biology, University of Joensuu, Joensuu. pp. 120.

Myers M.G., Jr., Leibel R.L., Seeley R.J., Schwartz M.W. (2010) Obesity and leptin resistance: distinguishing cause from effect. Trends Endocrinol. Metab. 21:643651.

Nakashima A., Yamanaka-Tatematsu M., Fujita N., Koizumi K., Shima T., Yoshida T., Nikaido T., Okamoto A., Yoshimori T., Saito S. (2013) Impaired autophagy by soluble endoglin, under physiological hypoxia in early pregnant period, is involved in poor placentation in preeclampsia. Autophagy 9:303-316.

Nelson S.M., Coan P.M., Burton G.J., Lindsay R.S. (2009) Placental structure in type 1 diabetes: relation to fetal insulin, leptin, and IGF-I. Diabetes 58:2634-2641.

Odegard R.A., Vatten L.J., Nilsen S.T., Salvesen K.A., Austgulen R. (2000) Preeclampsia and fetal growth. Obstet. Gynecol. 96:950-955.

Ogden C.L., Carroll M.D., Kit B.K., Flegal K.M. (2013) Prevalence of obesity among adults: United States, 2011-2012. NCHS Data Brief:1-8.

Ogier V., Ziegler O., Mejean L., Nicolas J.P., Stricker-Krongrad A. (2002) Obesity is associated with decreasing levels of the circulating soluble leptin receptor in humans. Int. J. Obes. Relat. Metab. Disord. 26:496-503.

Ong Z.Y., Muhlhausler B.S. (2011) Maternal "junk-food" feeding of rat dams alters food choices and development of the mesolimbic reward pathway in the offspring. FASEB J. 25:2167-2179.

Ono T., Guthold R., Strong K. (2005) WHO Global Comparable Estimates. 
Ornoy A., Ratzon N., Greenbaum C., Peretz E., Soriano D., Dulitzky M. (1998) Neurobehaviour of school age children born to diabetic mothers. Arch. Dis. Child Fetal Neonatal Ed. 79:F94-99.

Palou M., Priego T., Sanchez J., Palou A., Pico C. (2010) Sexual dimorphism in the lasting effects of moderate caloric restriction during gestation on energy homeostasis in rats is related with fetal programming of insulin and leptin resistance. Nutr. Metab. (Lond) 7:69.

Paneth N., Susser M. (1995) Early origin of coronary heart disease (the "Barker hypothesis"). BMJ 310:411-412.

Parker V.J., Douglas A.J. (2010) Stress in early pregnancy: maternal neuro-endocrineimmune responses and effects. J. Reprod. Immunol. 85:86-92.

Pattyn F., Robbrecht P., De Paepe A., Speleman F., Vandesompele J. (2006) RTPrimerDB: the real-time PCR primer and probe database, major update 2006. Nucleic Acids Res. 34:D684-688.

Pelleymounter M.A., Cullen M.J., Baker M.B., Hecht R., Winters D., Boone T., Collins F. (1995) Effects of the obese gene product on body weight regulation in ob/ob mice. Science 269:540-543.

Pennington K.A., Harper J.L., Sigafoos A.N., Beffa L.M., Carleton S.M., Phillips C.L., Schulz L.C. (2012) Effect of food restriction and leptin supplementation on fetal programming in mice. Endocrinology 153:4556-4567.

Perez-Leighton C.E., Butterick-Peterson T.A., Billington C.J., Kotz C.M. (2013a) Role of orexin receptors in obesity: from cellular to behavioral evidence. Int. J. Obes. (Lond) 37:167-174.

Perez-Leighton C.E., Boland K., Billington C.J., Kotz C.M. (2013b) High and low activity rats: elevated intrinsic physical activity drives resistance to diet-induced obesity in non-bred rats. Obesity (Silver Spring) 21:353-360.

Perez-Perez A., Gambino Y., Maymo J., Goberna R., Fabiani F., Varone C., SanchezMargalet V. (2010) MAPK and PI3K activities are required for leptin stimulation of protein synthesis in human trophoblastic cells. Biochem. Biophys. Res Commun. 396:956-960. 
Petersen M.B., Pedersen S.A., Greisen G., Pedersen J.F., Molsted-Pedersen L. (1988)

Early growth delay in diabetic pregnancy: relation to psychomotor development at age 4. Br. Med. J. (Clin Res Ed) 296:598-600.

Petry C.J., Ong K.K., Dunger D.B. (2007) Does the fetal genotype affect maternal physiology during pregnancy? Trends Mol. Med. 13:414-421.

Pico C., Oliver P., Sanchez J., Miralles O., Caimari A., Priego T., Palou A. (2007) The intake of physiological doses of leptin during lactation in rats prevents obesity in later life. Int. J. Obes. (Lond) 31:1199-1209.

Plagemann A., Harder T., Rake A., Voits M., Fink H., Rohde W., Dorner G. (1999) Perinatal elevation of hypothalamic insulin, acquired malformation of hypothalamic galaninergic neurons, and syndrome $\mathrm{x}$-like alterations in adulthood of neonatally overfed rats. Brain Res. 836:146-155.

Pollock R.E., Babcock G.F., Romsdahl M.M., Nishioka K. (1984) Surgical stressmediated suppression of murine natural killer cell cytotoxicity. Cancer Res. 44:3888-3891.

Proulx K., Richard D., Walker C.D. (2002) Leptin regulates appetite-related neuropeptides in the hypothalamus of developing rats without affecting food intake. Endocrinology 143:4683-4692.

Ramos M.P., Rueda B.R., Leavis P.C., Gonzalez R.R. (2005) Leptin serves as an upstream activator of an obligatory signaling cascade in the embryo-implantation process. Endocrinology 146:694-701.

Raygada M., Cho E., Hilakivi-Clarke L. (1998) High maternal intake of polyunsaturated fatty acids during pregnancy in mice alters offsprings' aggressive behavior, immobility in the swim test, locomotor activity and brain protein kinase $\mathrm{C}$ activity. J. Nutr. 128:2505-2511.

Rentsch J., Chiesi M. (1996) Regulation of ob gene mRNA levels in cultured adipocytes. FEBS Lett. 379:55-59.

Rinaudo P., Wang E. (2011) Fetal Programming and Metabolic Syndrome. Annu. Rev. Physiol.:107-130. 
Ringhoff D.N., Cassimeris L. (2009) Gene expression profiles in mouse embryo fibroblasts lacking stathmin, a microtubule regulatory protein, reveal changes in the expression of genes contributing to cell motility. BMC Genomics 10:343.

Rizzo T.A., Metzger B.E., Dooley S.L., Cho N.H. (1997a) Early malnutrition and child neurobehavioral development: insights from the study of children of diabetic mothers. Child Dev. 68:26-38.

Rizzo T.A., Silverman B.L., Metzger B.E., Cho N.H. (1997b) Behavioral adjustment in children of diabetic mothers. Acta. Paediatr. 86:969-974.

Roseboom T., de Rooij S., Painter R. (2006) The Dutch famine and its long-term consequences for adult health. Early Hum. Dev. 82:485-491.

Sage A.S., Vannest S.C., Fan K.H., Will M.J., Lever S.Z., Lever J.R., Miller D.K. (2013) N-Phenylpropyl-N'-(3-methoxyphenethyl)piperazine (YZ-185) Attenuates the Conditioned-Rewarding Properties of Cocaine in Mice. ISRN Pharmacol. 2013:546314.

Sahu A. (2004) Minireview: A hypothalamic role in energy balance with special emphasis on leptin. Endocrinology 145:2613-2620.

Saito H., Yamashita T., Inagaki K., Habu N., Araki K., Ozawa H., Mizutari K. (2003) [Nocturnal pulse oximetry diagnosis for screening pediatric obstructive sleep apnea syndrome]. Nihon Jibiinkoka Gakkai Kaiho 106:1127-1134.

Sakurai T., Amemiya A., Ishii M., Matsuzaki I., Chemelli R.M., Tanaka H., Williams S.C., Richardson J.A., Kozlowski G.P., Wilson S., Arch J.R., Buckingham R.E., Haynes A.C., Carr S.A., Annan R.S., McNulty D.E., Liu W.S., Terrett J.A., Elshourbagy N.A., Bergsma D.J., Yanagisawa M. (1998) Orexins and orexin receptors: a family of hypothalamic neuropeptides and $\mathrm{G}$ protein-coupled receptors that regulate feeding behavior. Cell 92:573-585.

Saladin R., De Vos P., Guerre-Millo M., Leturque A., Girard J., Staels B., Auwerx J. (1995) Transient increase in obese gene expression after food intake or insulin administration. Nature 377:527-529.

Sanchez J., Priego T., Palou M., Tobaruela A., Palou A., Pico C. (2008) Oral supplementation with physiological doses of leptin during lactation in rats 
improves insulin sensitivity and affects food preferences later in life. Endocrinology 149:733-740.

Satoh H., Ishikawa H., Kamma H., Yamashita Y.T., Sekizawa K. (2003) HnRNP A2/B1 proteins in nontumorous alveolar cells. Lung 181:219-225.

Schaiff W.T., Knapp F.F., Jr., Barak Y., Biron-Shental T., Nelson D.M., Sadovsky Y. (2007) Ligand-activated peroxisome proliferator activated receptor gamma alters placental morphology and placental fatty acid uptake in mice. Endocrinology 148:3625-3634.

Schlitt J.M., Schulz L.C. (2011) The source of leptin, but not leptin depletion in response to food restriction, changes during early pregnancy in mice. Endocrine 41:227235.

Schlitt J.M., Schulz L.C. (2012) The source of leptin, but not leptin depletion in response to food restriction, changes during early pregnancy in mice. Endocrine 41:227235.

Schneider M., Heise V., Spanagel R. (2010) Differential involvement of the opioid receptor antagonist naloxone in motivational and hedonic aspects of reward. Behav. Brain. Res. 208:466-472.

Schulz L.C. (2010) The Dutch Hunger Winter and the developmental origins of health and disease. Proc. Natl. Acad. Sci. U. S. A. 107:16757-16758.

Schulz L.C., Widmaier E.P. (2004) The effect of leptin on mouse trophoblast cell invasion. Biol. Reprod. 71:1963-1967.

Schulz L.C., Widmaier E.P., Qiu J., Roberts R.M. (2009) Effect of leptin on mouse trophoblast giant cells. Biol. Reprod. 80:415-424.

Schulz L.C., Schlitt J.M., Caesar G., Pennington K.A. (2012) Leptin and the placental response to maternal food restriction during early pregnancy in mice. Biol. Reprod. 87:120.

Shichida Y., Yamashita T. (2003) Diversity of visual pigments from the viewpoint of G protein activation--comparison with other $\mathrm{G}$ protein-coupled receptors.

Photochem. Photobiol. Sci. 2:1237-1246. 
Sierra-Honigmann M.R., Nath A.K., Murakami C., Garcia-Cardena G., Papapetropoulos A., Sessa W.C., Madge L.A., Schechner J.S., Schwabb M.B., Polverini P.J., Flores-Riveros J.R. (1998) Biological action of leptin as an angiogenic factor. Science 281:1683-1686.

Simerly R.B. (2002) Wired for reproduction: organization and development of sexually dimorphic circuits in the mammalian forebrain. Annu. Rev. Neurosci. 25:507-536.

Soares M.J., Konno T., Alam S.M. (2007) The prolactin family: effectors of pregnancydependent adaptations. Trends Endocrinol. Metab. 18:114-121.

Steel R., Torrie J., Dickey D. (1997) Principles and Procedures of Statistics: A Biometrical Approach. 3rd ed. McGraw-Hill.

Stocker C., O'Dowd J., Morton N.M., Wargent E., Sennitt M.V., Hislop D., Glund S., Seckl J.R., Arch J.R., Cawthorne M.A. (2004) Modulation of susceptibility to weight gain and insulin resistance in low birthweight rats by treatment of their mothers with leptin during pregnancy and lactation. Int. J. Obes. Relat. Metab. Disord. 28:129-136.

Stocker C.J., Wargent E., O'Dowd J., Cornick C., Speakman J.R., Arch J.R., Cawthorne M.A. (2007) Prevention of diet-induced obesity and impaired glucose tolerance in rats following administration of leptin to their mothers. Am. J. Physiol. Regul. Integr. Comp. Physiol. 292:R1810-1818.

Strine T.W., Mokdad A.H., Dube S.R., Balluz L.S., Gonzalez O., Berry J.T., Manderscheid R., Kroenke K. (2008) The association of depression and anxiety with obesity and unhealthy behaviors among community-dwelling US adults. Gen. Hosp. Psychiatry. 30:127-137.

Sultana S., Morishita S., Awai K., Kawanaka K., Ohyama Y., Nakayama Y., Imuta M., Arakawa A., Yamashita Y. (2003) Evaluation of hypervascular hepatocellular carcinoma in cirrhotic liver by means of helical CT: comparison of different contrast medium concentrations within the same patient. Radiat. Med. 21:239245.

Takahashi T., Hatao K., Yamashita Y., Tanizawa Y. (2003) Ectopic ACTH syndrome due to thymic atypical carcinoid treated with combination chemotherapy of cisplatin and etoposide. Intern. Med. 42:1197-1201. 
Takeuchi T., Adachi Y., Nagayama T. (2011) Expression of a secretory protein C1qTNF6, a C1qTNF family member, in hepatocellular carcinoma. Anal. Cell Pathol. (Amst) 34:113-121.

Teske J.A., Billington C.J., Kuskowski M.A., Kotz C.M. (2012) Spontaneous physical activity protects against fat mass gain. Int. J. Obes. (Lond) 36:603-613.

Teske J.A., Levine A.S., Kuskowski M., Levine J.A., Kotz C.M. (2006) Elevated hypothalamic orexin signaling, sensitivity to orexin A, and spontaneous physical activity in obesity-resistant rats. Am. J. Physiol. Regul. Integr. Comp. Physiol. 291:R889-899.

Tessier D.R., Ferraro Z.M., Gruslin A. (2013) Role of leptin in pregnancy: consequences of maternal obesity. Placenta 34:205-211.

Thompson D.B., Ravussin E., Bennett P.H., Bogardus C. (1997) Structure and sequence variation at the human leptin receptor gene in lean and obese Pima Indians. Hum. Mol. Genet. 6:675-679.

Thordarson G., Villalobos R., Colosi P., Southard J., Ogren L., Talamantes F. (1986) Lactogenic response of cultured mouse mammary epithelial cells to mouse placental lactogen. J. Endocrinol 109:263-274.

Tomimatsu T., Yamaguchi M., Murakami T., Ogura K., Sakata M., Mitsuda N., Kanzaki T., Kurachi H., Irahara M., Miyake A., Shima K., Aono T., Murata Y. (1997) Increase of mouse leptin production by adipose tissue after midpregnancy: gestational profile of serum leptin concentration. Biochem. Biophys. Res Commun. 240:213-215.

Tomita H., Sugano E., Abe T., Yamashita A., Tamai M. (2003) Comparative study of cathepsin D and S in rat IPE and RPE cells. Adv. Exp. Med. Biol. 533:343-346.

Udden J., Bjorntorp P., Arner P., Barkeling B., Meurling L., Rossner S. (2003) Effects of glucocorticoids on leptin levels and eating behaviour in women. J. Intern. Med. 253:225-231.

van Dijk M., Mulders J., Poutsma A., Konst A.A., Lachmeijer A.M., Dekker G.A., Blankenstein M.A., Oudejans C.B. (2005) Maternal segregation of the Dutch preeclampsia locus at 10q22 with a new member of the winged helix gene family. Nat. Genet. 37:514-519. 
Verhaagh S., Barlow D.P., Zwart R. (2001) The extraneuronal monoamine transporter Slc22a3/Orct3 co-localizes with the Maoa metabolizing enzyme in mouse placenta. Mech. Dev. 100:127-130.

Viau M., Lafond J., Vaillancourt C. (2009) Expression of placental serotonin transporter and 5-HT 2A receptor in normal and gestational diabetes mellitus pregnancies. Reprod. Biomed. Online 19:207-215.

Vickers M.H., Breier B.H., McCarthy D., Gluckman P.D. (2003) Sedentary behavior during postnatal life is determined by the prenatal environment and exacerbated by postnatal hypercaloric nutrition. Am. J. Physiol. Regul. Integr. Comp. Physiol. 285:R271-273.

Vickers M.H., Breier B.H., Cutfield W.S., Hofman P.L., Gluckman P.D. (2000) Fetal origins of hyperphagia, obesity, and hypertension and postnatal amplification by hypercaloric nutrition. Am. J. Physiol. Endocrinol. Metab. 279:E83-87.

Vucetic Z., Kimmel J., Totoki K., Hollenbeck E., Reyes T.M. (2010) Maternal high-fat diet alters methylation and gene expression of dopamine and opioid-related genes. Endocrinology 151:4756-4764.

Walker C.D. (2010) Maternal touch and feed as critical regulators of behavioral and stress responses in the offspring. Dev. Psychobiol. 52:638-650.

Walker C.D., Naef L., d'Asti E., Long H., Xu Z., Moreau A., Azeddine B. (2008) Perinatal maternal fat intake affects metabolism and hippocampal function in the offspring: a potential role for leptin. Ann. N. Y. Acad. Sci. 1144:189-202.

Wang J., Liu R., Hawkins M., Barzilai N., Rossetti L. (1998) A nutrient-sensing pathway regulates leptin gene expression in muscle and fat. Nature 393:684-688.

Whitaker R.C. (2004) Predicting preschooler obesity at birth: the role of maternal obesity in early pregnancy. Pediatrics 114:e29-36.

Wu X., Yamashita F., Hashida M., Chen X., Hu Z. (2003) Determination of matrine in rat plasma by high-performance liquid chromatography and its application to pharmacokinetic studies. Talanta 59:965-971. 
Yamashita H., Shao J., Qiao L., Pagliassotti M., Friedman J.E. (2003a) Effect of spontaneous gestational diabetes on fetal and postnatal hepatic insulin resistance in Lepr(db/+) mice. Pediatr. Res. 53:411-418.

Yamashita H., Shao J., Ishizuka T., Klepcyk P.J., Muhlenkamp P., Qiao L., Hoggard N., Friedman J.E. (2001) Leptin administration prevents spontaneous gestational diabetes in heterozygous Lepr(db/+) mice: effects on placental leptin and fetal growth. Endocrinology 142:2888-2897.

Yamashita S., Nomoto T., Ohta T., Ohki M., Sugimura T., Ushijima T. (2003b) Differential expression of genes related to levels of mucosal cell proliferation among multiple rat strains by using oligonucleotide microarrays. Mamm. Genome. 14:845-852.

Yang Y.J., Cao Y.J., Bo S.M., Peng S., Liu W.M., Duan E.K. (2006) Leptin-directed embryo implantation: leptin regulates adhesion and outgrowth of mouse blastocysts and receptivity of endometrial epithelial cells. Anim. Reprod. Sci. 92:155-167.

Yoon S.J., Cha K.Y., Lee K.A. (2005) Leptin receptors are down-regulated in uterine implantation sites compared to interimplantation sites. Mol. Cell Endocrinol. 232:27-35.

Yoshie M., Kashima H., Bessho T., Takeichi M., Isaka K., Tamura K. (2008) Expression of stathmin, a microtubule regulatory protein, is associated with the migration and differentiation of cultured early trophoblasts. Hum. Reprod. 23:2766-2774.

Zhang F., Basinski M.B., Beals J.M., Briggs S.L., Churgay L.M., Clawson D.K., DiMarchi R.D., Furman T.C., Hale J.E., Hsiung H.M., Schoner B.E., Smith D.P., Zhang X.Y., Wery J.P., Schevitz R.W. (1997) Crystal structure of the obese protein leptin-E100. Nature 387:206-209.

Zhang Y., Proenca R., Maffei M., Barone M., Leopold L., Friedman J.M. (1994) Positional cloning of the mouse obese gene and its human homologue. Nature 372:425-432.

Zhao J., Del Bigio M.R., Weiler H.A. (2009) Maternal arachidonic acid supplementation improves neurodevelopment of offspring from healthy and diabetic rats. Prostaglandins Leukot. Essent. Fatty Acids 81:349-356. 
Zhao J., Del Bigio M.R., Weiler H.A. (2011) Maternal arachidonic acid supplementation improves neurodevelopment in young adult offspring from rat dams with and without diabetes. Prostaglandins Leukot. Essent. Fatty Acids 84:63-70. 
VITA

Kelly Pollock was born in Columbia, Missouri on October $18^{\text {th }}$, 1985 . After completing her degree at Rock Bridge Senior High School in Columbia in 2004, she attended Moberly Area Community College and earned an Associate of Arts degree in general studies with a biology emphasis in 2006. She earned her Bachelor's degree in 2008 from Southeast Missouri State University, in Cape Girardeau, Missouri, majoring in wildlife biology and conservation. While attending Southeast Missouri State she worked at Dogwood Veterinary Hospital. In 2009 she entered the Graduate school of the University of Missouri studying animal science and majoring in reproductive physiology in the laboratory of Dr. Laura Schulz. 